\title{
FILIAL THERAPY WITH NON-OFFENDING PARENTS OF CHILDREN WHO HAVE BEEN SEXUALLY ABUSED
}

\section{DISSERTATION}

\author{
Presented to the Graduate Council of the \\ University of North Texas in Partial \\ Fulfillment of the Requirements
}

For the Degree of

DOCTOR OF PHILOSOPHY

By

Mary Bassett Costas, B.S., M.Ed.

Denton, Texas

August, 1998 
Costas, Mary Bassett, Filial therapy with non-offending parents of children who have been sexually abused. Doctor of Philosophy (Counseling and Student Services), August, 1998, 173 pp., 37 tables, references, 130 titles.

This study was designed to determine the effectiveness of filial therapy as a method of intervention for non-offending parents and their children who have experienced sexual abuse. Filial therapy is a didactic/dynamic approach used by play therapists to train parents to be therapeutic agents with their children. Parents are taught basic child-centered play therapy skills and the utilization of these skills in weekly play sessions with their children. Parents learn to create a special environment which enhances and strengthens the parent-child relationship, thus assisting in personal growth and change for both the parent and child. The purpose of this study was to determine if filial therapy is effective in: (a) increasing the acceptance of non-offending parents of their sexually abused children; (b) reducing the stress level of non-offending parents; (c) improving empathic behaviors of non-offending parents toward their sexually abused child; (d) decreasing the anxiety of sexually abused children; (e) enhancing the self-concept of sexually abused children; (f) decreasing behavior problems of sexually abused children as reported by their non-offending parents; and (g) enhancing the emotional adjustment of sexually abused children.

The experimental group parents $(n=14)$ received 10 weekly 2 -hour filial therapy training sessions and participated in weekly 30-minute play sessions with 
their children. The control group $(n=12)$ received no treatment during the ten weeks. Parent participants completed three instruments: The Porter Parental Acceptance Scale, the Parenting Stress Index, and the Child Behavior Checklist. Child participants completed three instruments: the Joseph Pre-School and Primary Self-Concept Screening Test, Child Anxiety Scale, and the Draw A Person: Screening Procedure for Emotional Disturbance. Parent and child participants were videotaped playing together before and after the training to measure empathic behavior in parent-child interactions.

Analyses of Covariance revealed that the non-offending parents in the experimental group significantly increased their level of empathy in their interactions with their children; significantly increased their attitude of acceptance toward their children; and significantly reduced their level of parental stress. Measures of children's behavior, anxiety, emotional adjustment, and self-concept indicated positive trends. This study supports filial therapy as an effective intervention for non-offending parents and their children who have experienced sexual abuse. 


\title{
FILIAL THERAPY WITH NON-OFFENDING PARENTS OF CHILDREN WHO HAVE BEEN SEXUALLY ABUSED
}

\section{DISSERTATION}

\author{
Presented to the Graduate Council of the \\ University of North Texas in Partial \\ Fulfillment of the Requirements
}

For the Degree of

DOCTOR OF PHILOSOPHY

By

Mary Bassett Costas, B.S., M.Ed.

Denton, Texas

August, 1998 


\section{Copyright by}

\section{Mary Bassett Costas}

1998 


\section{ACKNOWLEDGMENTS}

I gratefully acknowledge Karen Rodriguez of the Texas Department of Protective and Regulatory Services for her generous support and enthusiasm of my study. I further acknowledge Joan Phillips, who as my minor professor, traveled from the University of Oklahoma to facilitate the completion of my study. 


\section{TABLE OF CONTENTS}

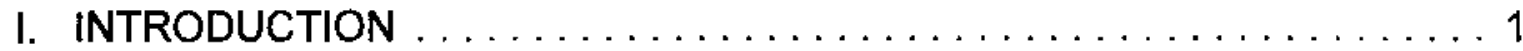

Statement of the Problem $\ldots \ldots \ldots \ldots \ldots \ldots \ldots \ldots \ldots \ldots \ldots$

Synthesis of Related Literature $\ldots \ldots \ldots \ldots \ldots \ldots \ldots \ldots \ldots \ldots$

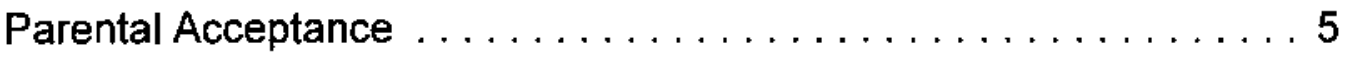

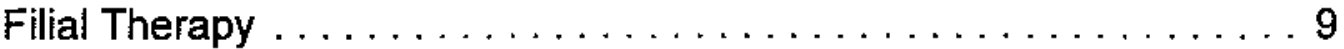

Impact of Sexual Abuse on Children and Parents .......... 23

Summary ............................. 33

II. METHODS AND PROCEDURES $\ldots \ldots \ldots \ldots \ldots \ldots \ldots \ldots \ldots \ldots$

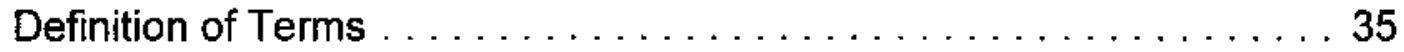

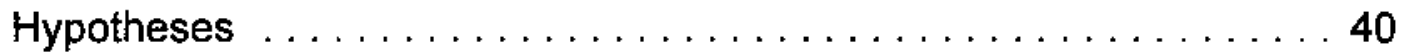

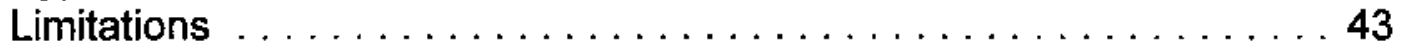

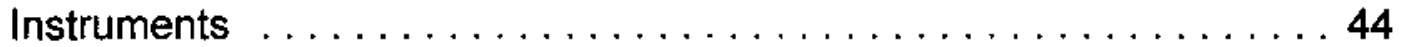

Porter Parental Acceptance Scale . . . . . . . . . . . . . . 44

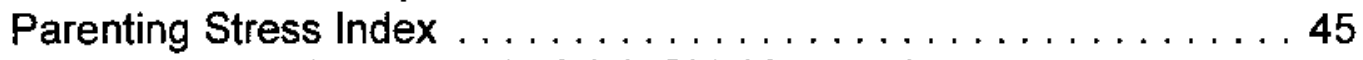

Measurement of Empathy in Adult-Child Interaction . . . . . . 46

Child Behavior Checklist-Parent Report Form ............ 49

Child Anxiety Scale . . . . . . . . . . . . . . . . . . . . 50

Joseph Preschool and Primary Self-Concept Screening Test .... 51

Draw A Person: Screening Procedure for Emotional Disturbance . . 52

Selection of Subjects $\ldots \ldots \ldots \ldots \ldots \ldots \ldots \ldots \ldots \ldots \ldots \ldots$

Collection of Data . . . . . . . . . . . . . . . . . . . 58

Treatment: Ten-Week Filial Therapy Training Model . . . . . . . . . . . 59

Facilitator ...........................6.64

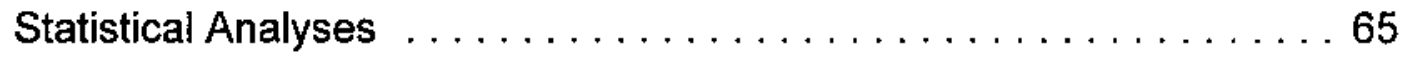

III. RESULTS AND DISCUSSION $\ldots \ldots \ldots \ldots \ldots \ldots \ldots \ldots \ldots \ldots 6$

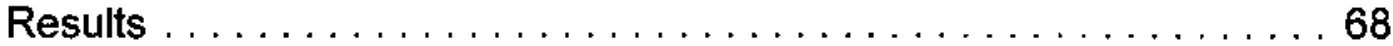

Discussion ............................. 93

Parental Acceptance ...................... 93

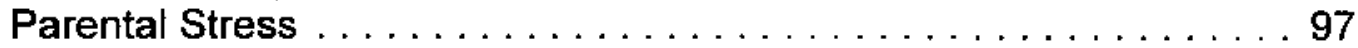

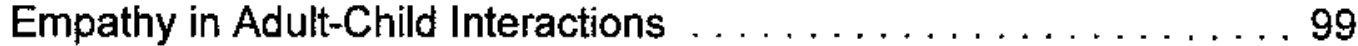

Problematic Behaviors of Children . . . . . . . . . . . . . . 101

Children's Anxiety . . . . . . . . . . . . . . . . . . 103 
Children's Self-Concept . . . . . . . . . . . . . . . . . . . . 103

Emotional Disturbance . . . . . . . . . . . . . . . . . . . . . . . 104

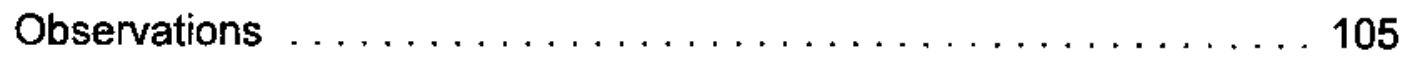

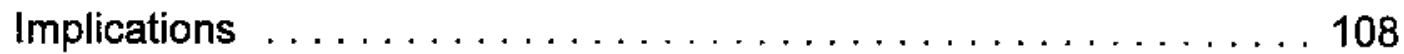

Recommendations . . . . . . . . . . . . . . . . . 109

Conclusion $\ldots \ldots \ldots \ldots \ldots \ldots \ldots \ldots \ldots \ldots \ldots \ldots \ldots \ldots \ldots \ldots \ldots$

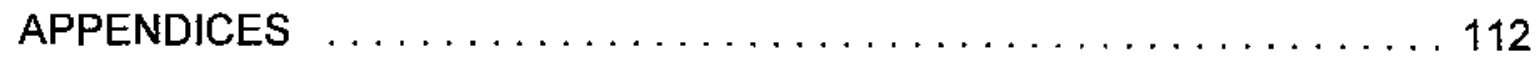

A Letter of Agreement

From Child Protective Services . . . . . . . . . . . . . 112

B Marketing Samples ...................... 114

C Parenting Class Information and Consent Forms . . . . . . . . 121

D Demographics Data Form ...................... 125

E Letter of Permission to Use The Porter Parental

Acceptance Scale . . . . . . . . . . . . . . . . . . . . . 127

F Porter Parental Acceptance Scale . . . . . . . . . . . . . 129

G Measure of Empathy in Adult-child Interaction

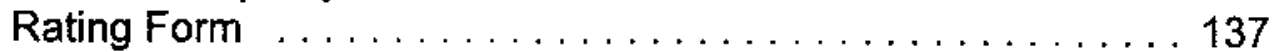

H Filial Therapy Training Session

Outline And Handouts . . . . . . . . . . . . . . . 139

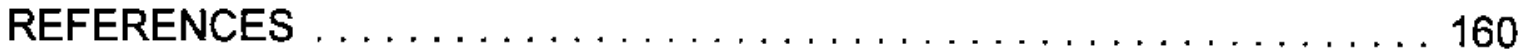




\section{LIST OF TABLES}

Table

Page

1. Interrater Reliability Coefficients of Concordance for Coding of the Measurement Of Empathy in Adult-Child Interactions Scales

2. Mean Total Scores for the Porter Parental Acceptance Scale (PPAS) . . 69

3. Analysis of Covariance Data for the Mean Total Scores for the PPAS .. 69

4. Mean Scores for the PPAS Subscale: Respect for the Child's Feelings and Right to Express Them ....................... 70

5. Analysis of Covariance Data for the Mean Scores on the PPAS Subscale: Respect for the Child's Feelings and Right to Express Them . . . . . . 70

6. Mean Scores for the PPAS Subscale: Appreciation of the Child's Unique Makeup .............................. 71

7. Analysis of Covariance Data for the Mean Scores on the PPAS Subscale:

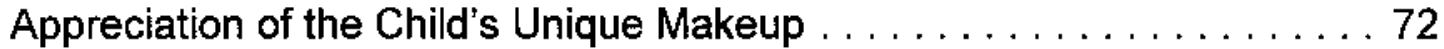

8. Mean Scores for the PPAS Subscale: Recognition of the Child's Need for Autonomy and Independence $\ldots \ldots \ldots \ldots \ldots \ldots \ldots \ldots \ldots$

9. Analysis of Covariance Data for the Mean Scores on the PPAS Subscale: Recognition of the Child's Need for Autonomy and Independence . . . . . 73

10. Mean Scores for the PPAS Subscale: Unconditional Love . . . . . . . . 74

11. Analysis of Covariance Data for the Mean Scores on the PPAS Subscale: Unconditional Love ............................. 74

12. Mean Scores for the Parenting Stress Index (PSI) $\ldots \ldots \ldots \ldots \ldots$

13. Analysis of Covariance Data for the Mean Scores for the PSI . . . . . 76

14. Mean Scores for the PSI Subscale: Parent Domain $\ldots \ldots \ldots \ldots \ldots 77$ 
Table

Page

15. Analysis of Covariance Data for the Mean Scores for the PSI Subscale: Parent Domain . . . . . . . . . . . . . . . . . . . 77

16. Mean Scores for the PSI Subscale: Child Domain $\ldots \ldots \ldots \ldots \ldots \ldots 78$

17. Analysis of Covariance Data for the Mean Scores for the PSI Subscale: Child Domain

18. Mean Total Scores for the Measurement of Empathy in Adult-child Interaction Rating Form (MEACl) $\ldots \ldots \ldots \ldots \ldots \ldots \ldots \ldots$

19. Analysis of Covariance Data for the Mean Total Scores on the MEACl . 80

20. Mean Total Scores for the MEACI Subscale: Communication Of Acceptance

21. Analysis of Covariance Data for the Mean Total Scores on the MEACl Subscale: Communication of Acceptance

22. Mean Total Scores for the MEACl

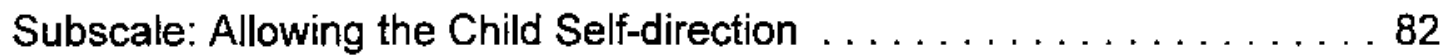

23. Analysis of Covariance Data for the Mean Total Scores on the MEACI Subscale: Allowing the Child Self-direction . . . . . . . . . . . 83

24. Mean Total Scores for the MEACI Subscale: Involvement . . . . . . 84

25. Analysis of Covariance Data for the Mean Total Scores on the MEACI Subscale: Involvement

26. Total Mean T-scores for Total Behavior Problems on the Parent Form of the Child Behavior Checklist (CBC)

27. Analysis of Covariance Data for the Mean T-scores for Total Behavior Problems on the Parent Form of the CBC . . . . . . . . . . . . 86

28. Mean T-scores for Externalizing Behavior Problems on the Parent Report Form of the CBC

29. Analysis of Covariance Data for the Mean T-scores on Externalizing Behavior Problems on the Parent Report Form of the CBC 
Table

Page

30. Mean T-scores for Internalizing Behavior Problems on the Parent Report Form of the $\mathrm{CBC} \ldots \ldots \ldots \ldots \ldots \ldots \ldots \ldots \ldots \ldots \ldots$

31. Analysis of Covariance Data for the Mean T-scores for Internalizing Behavior Problems on the Parent Form of the CBC

32. Mean Total Sten Scores for the Child Anxiety Scale (CAS) $\ldots . \ldots .90$

33. Analysis of Covariance Data for the Mean Total Sten Scores on the CAS 90

34. Mean Total Scores for the Joseph Pre-school and Primary Self-concept Screening Test (JPPCST) . . . . . . . . . . . . . . . 91

35. Analysis of Covariance Data for the Mean Total Scores on the JPPCST . 91

36. Mean Total T-scores for the Draw a Person: Screening Procedure for

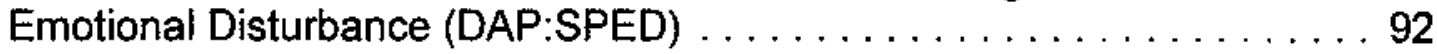

37. Analysis of Covariance Data for the Mean Total T-scores on the DAP:SPED . . . . . . . . . . . . . . . . 93 


\section{CHAPTER I}

\section{INTRODUCTION}

Beginning in the 1970s, when adult survivors first spoke out about their childhood experiences, sexual abuse has steadily gained attention as a national social problem (Hooper, 1992). Throughout the 1980s, studies were conducted to gain knowledge of the prevalence of child sexual abuse, the short- and longterm effects on and the psychopathology of the victims, and the characteristics of the offenders (Green, 1993). In 1993 researchers for the National Committee for Prevention of Child Abuse estimated that 2,989,000 children were reported to child protective services as alleged victims of abuse or neglect, and of these, $15 \%$, or approximately 450,000 , were cases of child sexual abuse (Kinnear, 1996).

The impact of childhood sexual abuse can be seen on a continuum ranging from neutral to very negative. According to Gil (1991), children are unable to understand or explain fully the impact of abuse. Often symptomatic behaviors are the first clue that something is very wrong. Finkelhor (1986) listed the most common short-term effects that sexually abused children regularly exhibit: fear/anxiety, depression, difficulties in school, anger/hostility, inappropriate sexualized behavior, and running away or delinquency. In addition to the abuse, there are other contributing factors that make it difficult to 
determine fully the origin of the symptoms. What has been substantiated throughout the literature is that sexual abuse of a child constitutes a major factor for later adult psychopathology (Ligezinska, Firestone, Manion, Mclntyre, Ensom, \& Wells, 1996).

There is no accepted formula for treating children of sexual abuse. According to James (1989), professionals should carefully consider each child's experiences, strengths, vulnerabililities, and resources when planning treatment. Because the factors vary greatly, many kinds of psychotherapy and/or medication may be appropriate. A multimodal approach that includes individual, group, and family therapy has gained wide acceptance (Sgroi, 1982).

Interpersonal relationships, both before and after the abuse, are a source of much interest. A review of the literature reveals that much has been written about the importance of the relationship between the mother and child (Duncan, 1985; Esparza, 1993; Everson, Hunter, Runyon, Edelsohn, \& Coulter, 1989; Howard, 1993; Lovett, 1995; Newberger, Gremy, Waternaux, \& Newberger, 1993); yet, in cases in which the whole family is intact following the abuse, both parents play an important role in the mental health of the child (Davies, 1995; Regehr, 1990).

One reported factor often associated with sexually abused children is the absence of the victim's mother. Finkethor (1986) stated that this absence can take many forms, from psychological and emotional indifference to physical absence due to an illness or job. However, the mother is an important factor in the child's recovery and has been cited in the literature as a vital element 
(Esparza, 1993). Many professionals believe that treatment is not complete before the relationship between mother and daughter is addressed. Hildebrand and Forbes (1987) suggested that a mother-daughter dyad be included in treatment so that the two can communicate and the daughter can experience the support of the mother. Helping mothers and fathers, who often lack positive childhood family experiences of their own, to acquire skills of acceptance and empathy is instrumental in strengthening the parent-child relationship.

Bringing the parent and child together for treatment can often be a challenge. The parent may need assistance in understanding how he or she can be supportive and relate differently to the child. Therapists can help parents by teaching them new parenting skills and encouraging parents to view themselves as instrumental in their children's development and mental health. B. G. Guerney (1964) developed filial therapy as an alternative method for treating young children with behavioral and emotional problems. In this approach, the parent becomes the therapeutic agent. Utilizing a small-group format, parents receive training through didactic instruction, videotape viewing, and role-playing. The major therapeutic strategy is to train parents to become the therapeutic agent in their children's lives by teaching them to conduct special play sessions modeled after play therapy as practiced by Axline (1969), Ginott (1965), and Moustakas (1959). Untike more behaviorally oriented therapies, this model of therapy is not directed toward specific problems, but rather focuses on strengthening the parent-child relationship. According to B. G. Guerney (1964), the filial play sessions have three main objectives:( a) to allow the child to 
understand more clearly the parents' feelings, attitudes, or behaviors toward the child; (b) to facilitate the child's communication of thoughts, needs, and feelings to the parents; and (c) to enhance the child's self-respect, self-worth, and confidence.

Both the B. G. Guerney, Guerney, and Andronico (1966) model, extending from 6 to 18 months, and a shorter 10-week model developed by Landreth (1991) have been proven to be effective with a number of different populations. Filial therapy has been effectively used with parents of emotionally disturbed children (Sywulak, 1977/1978), parents of children with learning difficulties (L. F. Guerney, 1979; Kale, 1997), parents of children with stuttering problems (Andronico \& Blake, 1971), parents of chronically ill children (Glazer-Waldman, Zimmerman, Landreth, \& Norton, 1992; Tew, 1997), children of divorced parents (Glazer-Waldman, 1991), single parents (Bratton, 1993/1994), incarcerated fathers and their children (Lobaugh, 1991/1992), incarcerated mothers and their children (Harris, 1995), Chinese parents and children (Chau, 1996; Yuen, 1997), and Native American parents and children (Glover, 1996).

Filial therapy has been found to promote a more positive and secure relationship between parents and children (B. G. Guerney, 1964), to be effective in increasing the self-esteem level of parents (Glass, 1987), to increase the acceptance level of parents toward their children (Bratton, 1993/1994; Glass, 1987; Kale, 1997/1998; Lebovitz, 1982/1983; Lobaugh, 1991/1992; Sensue, 1981; Sywulak, 1977/1978), to reduce parenting stress (Bratton,1993/1994; Chau, 1996; Harris, 1995; Kale, 1997; Lobaugh, 1991/1992; Tew,1997; Yuen, 
1997), and to reduce children's problematic behavior (Lebovitz, 1983; Lobaugh, 1991/1992; Tew,1997). Whether or not filial therapy is effective with the families of children who have been sexually abused has not been determined.

\section{Statement of the Problem}

The problem with which this investigation was concerned is that of determining the effectiveness of filial therapy in increasing parents' levels of acceptance of their children, facilitating parent's empathic responsiveness, and reducing parental stress in a group of non-offending parents of sexually abused children. In addition, this study was designed to determine the effectiveness of filial therapy in decreasing children's anxiety, enhancing the self-esteem of children, decreasing the behavior problems of children, and enhancing the emotional adjustment of sexually abused children whose parents participate in filial therapy.

\section{Synthesis of Related Literature}

The following review is a synthesis of theoretical constructs and research related to three major areas: (a) the variable of parental acceptance as it relates to the parent-child relationship and to the development of self-esteem in the child; (b) the use of filial therapy and its significance as an area of study; and (c) the impact of sexual abuse on children and their parents.

\section{Parental Acceptance}

Axline (1969) defined acceptance as a feeling that is within the experiencing individual. She asserted that acceptance grows out of a genuine and sincere interest in the other person. Acceptance is a sensitivity to the rights 
and capacities of the other person to be an individual and to be able to assume responsibility for himself or herself (Axline, 1971). Parental acceptance can be extended to mean the feelings and behaviors of parents that convey unconditional love for their children. Porter (1954) identified parental acceptance as one of the essential elements underlying the whole structure of the parent-child relationship. For the purpose of measuring this elusive construct, Porter developed the first operational definition of parental acceptance: Parental acceptance may be defined as feelings and behavior on the part of the parents which are characterized by unconditional love for the child, a recognition of the child as a person with feelings who has a right and a need to express those feelings, a value for the unique make-up of the child, and a recognition of the child's need to differentiate and separate himself from his parents in order that he may become an autonomous individual. (p. 177) According to Coopersmith (1967), parental acceptance embodies a parent's love and approval of his or her child regardless of the child's appearance, abilities, and performance. This unconditional acceptance is communicated through an awareness of the child's needs and desires, a concern for the child's interests, and the expression of affection and approval. This expressed parental acceptance helps children to learn that they can depend on significant others for support and help in life. With the freedom from anxiety that accompanies an accepting relationship with parents, children gain a certainty of their own worth and are able to express affection for others and work 
toward growth and maturity. Their interactions with others confirm and reinforce their conception of their own value, thereby providing them with a firm feeling of security (Perkins, 1974).

According to Coopersmith (1967), the most important contribution to the development of self-esteem is the amount of respectful, accepting, and empathic treatment received from significant others. Eisman (1981) and Cox (1970) found that the self-concept of the child was highly correlated to parental acceptance or rejection. C. Rogers (1951) believed that, in contrast to positive or negative evaluation, acceptance reduces the need for defensiveness and thus allows the child to explore a sense of self. One of the major conditions needed to develop children's self-esteem is parental acceptance (Cooper, Holman, \& Braithwaite, 1983; Coopersmith, 1967).

E. C. Rohner, Chaille, and Rohner (1980) studied the relationship between locus of control and perceived parental acceptance. They found that children's belief that they had control over events and actions in their life increased significantly with children's perceptions of increased parental acceptance. In a study by Baumrind (1967), self-controlled, self-reliant, explorative, and content preschool children were found to have parents who manifested positive behavior and who were more consistent, more loving, and more secure in child-rearing methods than the parents of less well-adjusted children. These parents were also more likely to have given a reason with a directive, to have communicated more closely with their children, to have enforced directives, and not to have been over-protective or over-restrictive with 
their children.

Research has shown that a correlation exists between parental acceptance and adjustment in children. Kagen and Moss (1962) reported parental rejection to be related to aggressive behavior in children. Medennus (1965) linked parental rejection to manifested signs of maladjustment in children. Hurley (1967) reported parental rejection to be related to children's lower scores on intelligence tests. Ausbel, Balthazar, Rosenthal, Blackman, Schpoont, \& Welkowitz, (1954) found that children who perceive their parents as rejecting were less independent and less able to postpone immediate gratification. Burchinal, Hawkes, and Gardner (1957) found that children who had fathers who were accepting scored lower on social maladjustment scales and that children whose mothers were accepting scored lower on a personal inferiority measure.

According to R. P. Rohner (1980), parental acceptance of children affects behavioral and personality traits in many facets of children's lives. Rejected or emotionally abused children tend more than accepted children to be hostile and aggressive or to have problems with the management of hostility and aggression. Depending on the degree of rejection, children are inclined to be dependent or defensively independent, to be emotionally unstable or unresponsive, and to have a negative world view. E. C. Rohner (1980) found that personality and behavioral traits of children varied directly with children's perception of parental acceptance-rejection and that this relationship was not affected significantly by children's age or gender. 


\section{Filial Therapy}

In the past, society has offered minimal commitment toward the training of parents depending primarily on preparation for parenting which evolves from one's childhood experiences, thus leaving many parents ill-equipped to carry out this primary task of life (Bratton, 1993/1994; Giveans, 1988; Lobaugh, 1991/1992; Wolfe, Edwards, Manion, \& Koverola, 1989). Filial therapy, which trains parents to be sensitive to and accepting of children's feelings during special play sessions, is one way to teach new patterns of relating while enhancing existing skills (Lobaugh, 1991/1992).

Programs to train parents to be more effective in parent-child relationships have been helpful, yet training based on the child's natural tendency to play is an innovative concept that places the focus on the child. Bettelheim (1987) considered play to be the child's natural medium of communication. Landreth (1991) suggested that parents form a new perceptual awareness of their children and their potential as they observe their children's play because thoughts and feelings are expressed by young children primarily through play. The benefits of self-directed play provide the child with opportunities to practice and master new skills, in addition to giving the child the time and freedom for introspection and development of an inner life (Lobaugh, 1991/1992).

The literature reveals that training parents to be therapeutic agents in their children's lives can be traced to the early part of the 20th century, when Freud (1959) effectively incorporated the father of a phobic 5-year-old into the treatment of the child by instructing the father in how to respond to the child's 
play. Freud asserted that the father's special knowledge of the child, by which he was able to interpret the son's remarks, was indispensable. Additionally, Freud believed that only the father could have persuaded the child to make the changes he made. Baruch (1949) and Jacobs (1949) promoted home play sessions for the purpose of fostering more effective parent-child relationships. Fuchs (1957), on the advice and encouragement of her father, Carl Rogers, employed regularly scheduled play times with her child. Fuchs described pivotal outcomes in helping her daughter overcome emotional reactions related to a toilet-training problem. Not only was the problem resolved, but Fuchs also reported positive changes in herself. Moustakas (1959) also advocated that parents use play therapy sessions at home with their children.

In the early 1960 s, Bernard Guerney was the first to use the term filial therapy to describe an intervention aimed at helping parents utilize aspects of child-centered play therapy in the enhancement of their relationships with their own children. Parents are trained by therapists in the skills and strategies of child-centered play therapy as practiced by Axline (1969), Ginott (1965), and Moustakas (1959). Filial therapy enhances the relationship that already exists between a parent and child by facilitating the development of empathy, genuineness, and acceptance on the part of the parent in weekly 30-minute play sessions. These conditions allow the child to develop a new perception of the parent as an ally.

Initially, filial therapy was developed as an alternative therapeutic intervention for children who were experiencing behavioral and emotional 
difficulties. Landreth (1991) extended the concept of relationship enhancement to all parents and children, stating that even children and parents who were not experiencing difficulties could benefit from learning more effective ways of relating. He contended that extending therapeutic skills from the professional into the hands of parents could significantly improve the mental health of future generations.

Filial therapy has been utilized and assessed for effectiveness in a number of studies with different populations. Stover and Guerney (1967) analyzed the results of training mothers in filial therapy techniques and found a significant increase in the use of reflective statements by the mothers and a decrease in directive statements, as measured by direct observation. Selfreports by the mothers evidenced a positive influence on the parent-child relationship and the child's general emotional adjustment at the end of treatment.

Because the Stover and Guerney (1967) study did not utilize a control group, Oxman (1972) matched the parents in that study with volunteer parents on the following variables: age of parents and children, size of family, geographical location, and social economic status. Results showed that the experimental group reported a significantly greater improvement in their children's behavior than did the matched control group.

B. G. Guerney and Stover (1971) supported their earlier 1967 results with a group study of 51 mothers and their children. Both studies substantiated that mothers could learn to reflect feelings, allow their children self-direction, and demonstrate involvement in the emotional behaviors and expressions of their 
children. Assessments completed by clinicians and parents indicated improvement of psychosocial adjustment and symptomatology in all 51 children. Twenty-eight of the children were rated as very much improved. No child remained the same or became worse. As a result of the play sessions, the children showed increased interaction with mothers in activities, found appropriate outlets for their feelings of aggression, engaged in more realistic methods of sharing and conversing with their mothers, and decreased their dependence while increasing their leadership abilities.

A longitudinal investigation of the B. G. Guerney and Stover (1971) study was conducted by L. Guerney (1975). The original participants were surveyed 1 to 3 years later. The responses to the questionnaire indicated that only 1 of the 42 respondents needed to seek further treatment for the child. Thirty-two of the respondents stated that their children had continued to improve, with $64 \%$ of the parents stating that the children's continued improvement was related to their improved ability to relate to the children. The parents' overall evaluation of the filial therapy training was positive. This follow-up study suggests that the positive results of the filial training may still be in effect as long as 3 years later.

In an attempt to control for possible differences between parents who seek treatment and those who do not, Sywulak (1977/1978) utilized a design in which the participants acted as their own control group. The study presented process data as well as pre- and postdata. The participants, 13 mother/father pairs and 6 single mothers, were asked to complete assessment instruments 4 months prior to training, at a 2-month midpoint during training, and finally after 4 
months of training. The results of the study showed significant improvement in child adjustment as well as in parental acceptance. The improvements were evident at the 2-month midpoint and were maintained after 4 months of training. Other findings demonstrated that withdrawn children evidenced faster changes than aggressive children, that fathers detected change in adjustment later than did mothers, and that parents exhibited the capacity and the willingness to employ filial skills.

Sensue (1981) conducted a 3-year follow-up of the Sywulak (1977/1978) study and found even higher scores at the end of 6 months of treatment, with no significant losses 2 to 3 years later. At the time of follow-up, children who had formerly been diagnosed as maladjusted were found to be as well adjusted as a control group of children who had never been diagnosed. Furthermore, both parents and children maintained that the filial training had resulted in positive change within the family.

Wall (1979) examined three variations of play therapy, including therapy conducted by graduate therapist trainees, by nontrained parents, or by parents directed and observed by therapist trainees. Parents who received instruction and feedback from therapist trainees improved their skills in empathic communication with their children. The children's expressions of negative feelings and their increased ability to accurately perceive negative attitudes in their families were evidence of their improved adjustment. Wall (1979) concluded that the parent's acceptance of negative feelings might have a more potent effect on children than acceptance of the same feelings by a therapist. 
In a similar investigation, Lebovitz (1983) compared the effectiveness of a filial therapy group, a group conducting supervised play sessions, and a control group. Mothers' filial therapy skills were appraised, and change was assessed by parents, teachers, and independent observers. Children in both the filial therapy and play session groups demonstrated proportionately fewer problem behaviors than did the control group. The filial therapy group displayed a greater decrease in problem behaviors than did the play session group. The filial therapy group mothers communicated more acceptance of their children's feelings, allowed their children more self-direction, and exhibited more involvement with their children than did mothers in the play session group. Children in the filial therapy group evidenced a greater decrease in dependence than did the children in the play session group. Parents in both the filial therapy group and the play session group reported that they had become more accepting of their children. This was not found in the control group.

Payton (1980) conducted a study comparing the effectiveness of parents who received filial therapy training, paraprofessionals who received filial therapy training, and a control group. Parents trained in filial therapy showed significantly higher scores on parenting attitude than did either the paraprofessional or the control group. Parents trained in filial therapy also reported significant improvement in their children's behaviors as compared to the paraprofessional and the control group. The investigator concluded that parents trained in filial therapy were more effective than paraprofessionals in affecting their children's personality adjustment. 
Children who received play therapy sessions with their parents in addition to sessions with a therapist were the focus of a study by Kezur (1980). The components of mother-child communication and the effects of these communication patterns on the relationship were examined. The mothers in the study received parent training while their children were seen in individual play therapy by a trained therapist. The mother and child met jointly in videotaped play sessions, and received feedback on the sessions from the therapist. The following results were obtained: (a) mothers developed effective communication skills, based on therapeutic principles; (b) the children who expressed anger towards their mothers in the therapist-facilitated play sessions became more open and communicative with their mothers in the parent play sessions; (c Imothers developed new awareness in communication; (d) mothers who grew in self-awareness changed in positive directions with their children; (e) mothers were better able to meet the needs of their children when they learned to honor their own needs; (f) mothers who accepted joint responsibility for the problems with their children developed new communication skills; (g) mothers who opened themselves to a relationship with the researcher made greater gains in communication skills; (h) positive changes developed in the mother-child relationship as both gained in self-esteem; (I) mothers gained more from feedback when they were open to viewing and commenting on themselves in videotape review; (j) closeness and effective communication increased as mothers and children became more involved in the joint sessions; and (k) in the mother-child pairs, where the most change occurred, the mothers tended to 
report improvement in other relationships.

Dematatis (1981) correlated traditional filial therapy training with an integrated filial therapy training program, which included affect simulation and videotape recall modeled after Kagan's Interpersonal Process Recall (IPR) training. The results showed significant gains in parental acceptance, affect sensitivity, allowance of self-direction, and involvement for both groups.

Glass (1987) compared the effectiveness of filial therapy training with a control group of parents who received no training. The parents in the filial therapy group reported significant results in increased feelings of unconditional love for their children, increased understanding of their children's play, and decreased perception of expressed conflict in their family. Additional results, although not statistically significant, demonstrated change in (a) increased parental acceptance, (b) respect for children's feelings and their right to express themselves, (c) recognition of children's need for autonomy and independence, (d) an increase in self-esteem of both parent and child; and (e) increased closeness between parent and child while maintaining the family role structure.

Packer (1990) discovered that parents who received filial training perceived themselves as possessing skills that could effect positive changes in the behavior of their children. The study determined that the children, as a result of filial therapy, better managed their negative emotions. Fathers were more readily accepted as authority figures in the presence of the mothers as a result of the filial therapy.

Filial therapy has been used with unique populations and in a multiplicity 
of settings. Hornsby and Applebaum (1978) examined a series of 60 clinical cases and reported that filial therapy had been effective with children with a variety of diagnoses. The effectiveness of filial therapy, evident in this study, included cases involving a borderline psychotic child, a child in active conflict with a parent, and a handicapped child. Evidence of improvement in parent-child relationships and the children's problem behaviors was highlighted by the fact that filial therapy allowed parents to be active in the psychotherapeutic process. Additionally, when filial therapy was applied in the school setting, it was demonstrated that involving parents in their children's treatment enhanced the parents' blaming of the school for their child's problems because they no longer felt helpless. Parents involved in filial therapy were also discovered to be more motivated to undertake and stay with their children's treatment (Andronico \& Guerney, 1967; Ellinwood, 1989; B. Guerney \& Flumen, 1970).

Andronico and Blake (1971) explored the effects of filial therapy on young children with stuttering problems and reported that parents became more involved in their children's treatment, developed positive parent-child interactions, and effectively changed the home environment. Results indicated that, as parents developed more awareness of the child, they learned to inhibit their tendency to cut off or pressure the child who was stuttering, improving the parents' day-to-day interactions with the child.

Boll (1972) studied the effects of filial therapy with mothers of mentally retarded children. The study compared a traditionally trained filial therapy group of mothers, a group trained in filial therapy and given additional instruction on 
specific reinforcement and extinction techniques, and a control group. Results indicated that both groups trained in filial therapy perceived improvement in the socially adaptive behavior displayed by their children, with the highest improvement being noted in the traditionally trained group. Boll suggested that this difference might be accounted for by the fact that parents in the traditionally trained group seemed to form a closer relationship and attended training more consistently than did the parents in the group in which there was an expert who taught information on reinforcement and extinction techniques.

Examining the effectiveness of filial therapy as a treatment for emotionally disturbed children, B. G. Guerney (1976) found that the children showed significant improvement on the measures of social adjustment and reduction in conflicts with parents, teachers, and peers. The number of the children's symptoms decreased significantly, as did the mothers' dissatisfaction with their children. The variables of socioeconomic background, degree or kind of child maladjustment, maternal attitude, or personality were not determinants.

The effectiveness of filial therapy in a community mental health center was researched by Ginsberg (1976), using foster parents, single-parent families, and families with different socioeconomic status. Positive results were found across all groups. Parent reports, school progress, and sibling and peer interaction indicated significant changes for mothers living in a low socioeconomic community. Filial therapy was found to reduce stress and enhance the ability of foster or adopted children and parents to build a mutually satisfactory relationship. L. Guerney and Gavigan's (1981) study supported 
these results, finding that foster parents were more accepting of their foster children after filial therapy training.

Glazer-Waldman (1991) studied the effectiveness of the Landreth (1991)10-week filial therapy model with the parents of chronically ill children and found that there was not a statistically significant difference between pretest and posttest measures of acceptance and anxiety for parents of chronically ill children. However, the five parents in the study did report positive change in themselves and positive change in their children. A comparison of the scores on the measures of anxiety found that the parents' perceptions of their children's anxiety was more closely matched to the children's actual anxiety scores on the posttest.

Lobaugh (1991/1992) investigated the significance of the Landreth (1991) 10-week filial therapy model with incarcerated fathers. When compared to the control group, the fathers in the filial group significantly increased their acceptance of their children and significantly reduced their level of parental stress. In addition to the enhanced parent-child relationship, the children in the experimental group benefited from an increase in self-esteem and a decrease, as perceived by the parent, in problematic behaviors.

Lahti (1993), utilizing ethnographic methodology, found that the basis of the Landreth (1991) 10-week filial therapy training process is focused, along with teaching parenting skills, on balancing a didactic component with a group counseling format in order to provide an atmosphere conducive to personal exploration and support. The results determined that parental stress was 
reduced as the parents learned and applied new parenting skills. Parents reported gaining objectivity through review of videotaped sessions and encouragement from the process of receiving and giving feedback within the group. Parents reported empowerment in a greater awareness of self and in the ability to view realistically the parent-child relationship. Increased and enhanced communication, more realistic expectations, and less friction were reported as contributing to closer parent-child and marital relationships. Changes were noted in children's increased and enhanced communication, increased responsibility for actions, decreased withdrawn and aggressive behavior, and increased feelings of happiness.

Bavin-Hoffman (1994) conducted a 3-year follow-up study using 20 married couples who had participated in the Landreth (1991) 10-week filial therapy model. Utilizing a phenomenological approach to collect the data, she found recurring themes of improved communication and behavior. Parents reported increased unity with their spouses, elevated understanding of their children's play, heightened parental confidence, and increased acceptance of their children.

Utilizing an experimental-control group design, Bratton (1993/1994) found that the Landreth (1991) 10-week filial therapy model equipped single parents with healthier parenting skills and provided them with the emotional support they needed. In the experimental group, single parents reported that they had more empathy, acceptance, and involvement with their children as a result of filial therapy. The parents demonstrated the ability to be more empathic with their 
children as observed in play sessions. They increased significantly in respect for their children's feelings, their children's unique make-up, their children's need for autonomy, and their children's need for unconditional love. Overall, parental stress, as well as perceived problems of child behavior, decreased significantly. Harris (1995) studied the effectiveness of the Landreth (1991) filial therapy model with incarcerated mothers who received 2-hour filial therapy training sessions biweekly for 5 weeks and conducted biweekly 30-minute play sessions with one of their children. The results were compared to those with mothers in a control group. The mothers in the experimental group significantly increased their empathic interaction with their children and their attitude of acceptance toward their children and experienced a decrease in the number of reported problems with their children's behavior.

Three recent studies investigated the effectiveness of the Landreth (1991) filial therapy model with culturally different populations. Chau (1996) investigated the use of filial therapy with Chinese parents. The Chinese parents who received training demonstrated significant changes compared to the Chinese parents in the control group, who did not receive training. The experimental group evidenced a significant increase in their level of empathic interactions with their children, a significant increase in their attitude of acceptance toward their children, and a significant reduction in their level of stress related to parenting. Glover (1996) utilized filial therapy training as an intervention for Native American parents and their children residing on the Flathead Reservation in Montana. Children in the experimental group significantly increased their level of 
desirable play behaviors with their parents. Although the measures of parental acceptance, parental stress, and children's self-concepts did not show significant change, positive trends were shown on all measures. This study gives rise to questions regarding the suitability of current self-concept measurement instruments for Native American children and possible cultural differences in the concepts of parental stress and parental acceptance.

Yuen (1997) examined the effectiveness of the Landreth (1991) 10-week filial therapy training model with immigrant Chinese parents in Canada. The experimental group parents reported a significant increase in their level of empathic interaction with their children, a significant increase in their acceptance level toward their children, a significant decrease in their level of stress related to parenting, and a significant decrease in the number of problem behaviors they perceived in their children.

Utilizing an experimental-control group design, Tew (1997) found that the Landreth (1991) 10-week filial therapy model helped parents with chronically ill children to adopt a therapeutic role during special play times and in turn reported a decrease in stress related to parenting. Parents also reported an increase of accepting attitudes toward their children and a reduction in their children's behavior problems including anxious/depressed behaviors.

Kale (1997) investigated the significance of the Landreth (1991) 10-week filial therapy model with parents of children experiencing learning difficulties. When compared to the control group, the parents in the filial group significantly increased their acceptance of their children and significantly reduced their level 
of parental stress. The parents also reported benefiting from the group format whereby they experienced other parents with similar struggles in raising children with learning difficulties.

Impact of Sexual Abuse on Children and Parents

In today's society, childhood sexual abuse is a complex, multifaceted issue that is further complicated by varying legal definitions and interpretations from state to state. Most professionals agree, however, that the key basic elements of exploitation of the child are use of coercion, gentle though it may be, and some level of gratification gained by the adult (Chinaware, 1996). According to Browne and Finkelhor (1986), childhood sexual abuse consists of two interwoven but discernible types of interactions involving forced or coerced sexual behavior with a child or sexual activity between a child and a much older person, whether or not obvious coercion is involved. (A common definition of "much older" is 5 or more years.) Common to most childhood sexual abuse occurrences are the child's feelings of helplessness, powerlessness, confusion, and guilt. The abuse can run the gamut of sexual inappropriateness, from an event as seemingly as innocent as the subtle touching of body parts to the inappropriate display of sexually explicit material to oral, anal, or vaginal stimulation and to intercourse (Sgroi, 1988).

Initially, childhood sexual abuse was thought to be a product of atypical family environments, but the field now recognizes that childhood sexual abuse can exist in all socioeconomic and family settings. Statistically, girls are at much greater risk than boys, but it is believed that boys are abused far more than is 
reported. Approximately one in three girls is sexually abused before age 18 and one in four by age 14; whereas for boys, the estimate is that one in six boys is sexually abused before age 16 (Hopper, 1997). Some professionals believe that the average age of onset varies from ages 8 to 12 (Finkelhor, 1984). Statistics have shown, however, that $60 \%$ of reported childhood cases involve children 12 years of age and older (National Center on Child Abuse and Neglect, 1981). For girls, statistics show that those at greatest risk have poor relationships with their mothers, live in a home in which a great deal of parental conflict exists or in which parents show little affection toward each other, or live with a stepfather in the home (Finkelhor, 1986; Kinnear, 1996). In general, historical factors that evidence the strongest linkage to childhood sexual abuse have been those involving parent and family relationships.

Peters (1988) found in her analysis that not being close to the mother was the variable that was most predictive of sexual abuse. In female cases in which the perpetrator is the victim's father or stepfather, the loyalty toward the perpetrator is a particularly delicate area. Despite initial appearances, incest victims do have a great deal of loyalty toward the offender, and there are seemingly good reasons for this. During the family's development, the father is usually the primary relational resource for the daughter. The mother often appears distant, unavailable, and depleted. The father, on the other hand, is relationally pursuant, and although he sexually abuses his daughter, whatever attention and affection she receives usually originates with him. Also, she is tacitly taught by the family to take care of her father in many ways, and this 
sense of responsibility usually adds to her loyalty toward him (Sgroi, 1988).

Numerous factors influence the impact of childhood sexual abuse. These factors include, but are not limited to, the age of the child at onset of the abuse, the length of time the abusive situation lasts, the relationship of the abuser, the child's developmental status, the use of force, the family's emotional climate, the degree of shame or guilt of the victim, and/or the reaction of parent, professional, or others (Everstine \& Everstine, 1989; Gil, 1991). An analysis of the studies that have examined the relationship between abuse-specific variables and outcome suggests that several factors are consistently associated with greater trauma in the victim. These factors include abuse involving penetration, abuse involving force or violence, and abuse involving a close relationship to the offender (Beitchman, Zucker, Hood, daCosta, \& Akman, 1991). Studies are not clear, however, as to when the effects of the trauma are realized in relation to abuse occurrence. Studies do show that perception of the victim's self to the world is distorted (Kinnear, 1996). Such a wide range of determinant factors (i.e., severity of abuse, sex, relationship, age) makes comparisons difficult, and the lack of correlation between the behavioral status of the children and characteristics of either the abuse or the perpetrators points to the conclusion that no single factor determines the prognosis of child sexual abuse (Browne \& Finkelhor, 1986; Dubowitz, Black, Harrington, \& Verschoore, 1993; Ligezinska et al., 1996). Initial effects are reactions that occur within 2 years of the termination of abuse. A landmark study conducted by researchers associated with theTufts New England Medical Center, Division of Child Psychiatry (1984) gathered data in four areas: 
(a) overt behavior; (b) somaticized reactions; (c) internalized emotional states; and (d) self-esteem. The greatest incidence of psychopathology was found in the 7-to 13 -year-old group, with $40 \%$ scoring in the seriously disturbed range. Friedrich, Urquiza, and Beilke (1986) noted that younger children (up to age 5) exhibited a tendency to score high on the Internalizing scale (Child Behavior Checklist), whereas older children (ages 6 to 12) were more apt to have higher scores on the Externalizing scale.

D. S. Everstine and Everstine (1989) provided a generally accepted list of symptoms summarized from the literature. These symptoms typify the effects of childhood sexual abuse on children: fear, inability to trust, anger and hostility, inappropriate sexual behavior, depression, guilt or shame, problems in school, somatic complaints, sleep disturbance, eating disorders, phobic or avoidant behavior, regressive behavior, self-destructive behavior or accident-proneness, and runaway behavior. Childhood sexual abuse also is noted as having an effect on self-esteem, but this effect has not been correlated through empirical studies (Finkelhor, 1986). Sgroi (1982) listed 10 factors that affect childhood sexual abuse victims and become treatment issues as the damaged goods syndrome: guilt, fear, depression, low self-esteem and poor social skills, repressed anger and hostility, impaired ability to trust, blurred role boundaries and role confusion, pseudomaturity coupled with failure to accomplish developmental tasks, and selfmastery and control. Studies clearly indicate that children who are sexually abused are more likely to develop depressive or schizoid symptoms compared to children who are physically abused. However, sex differences existed with 
regard to type of abuse and behavioral symptoms in that boys are more often victims of physical abuse and are also more likely to exhibit conduct disorder (Beitchman et al., 1991).

Psychotherapeutic models have been developed to prescribe treatment of sexual abuse. Among the models proposed to define the trauma of sexual abuse, the one most often mentioned is the Post-Traumatic Stress Disorder (PTSD) model (Beitchman et al., 1991; Finkelhor, 1988). An alternative to the PTSD approach is a model Finkelhor and Browne (1985) called the Traumagenic Model of Child Sexual Abuse (TMCSA.) It is an eclectic, but all-encompassing model that suggests numerous and different dynamics to account for the variety of different types of symptoms. The TMCSA incorporates some elements of the PTSD model, but is also broad enough to explain sexual abuse of the non-PTSD variety. The model proposes four traumagenic dynamics to explain the impact of sexual abuse: traumatic sexualization, betrayal, stigmatization, and powerlessness.

There is no one correct way to treat victims of childhood sexual abuse. Providing a sensitive, secure environment in which the individual feels a degree of control is the first step in the process (Sgroi, 1988). Also critical is helping the child learn to comfort herself or himself by assisting the child in identifying activities that make the child feel good, that reduce anxiety, or that channel aggression. Some examples of these activities include seeking out people with whom the child can talk, listening to music, writing, learning relaxation exercises, or finding appropriate, active outlets for aggressive play. The therapist should 
consult with the parent, as well as work with the child, in identifying and using these activities (Strand, 1991). The most important aspect is the child's willingness to acknowledge and talk about what has happened. This means not pressing the child for details but conveying a clear message of receptiveness to hearing about the child's experience and feelings (Hollin \& Howells, 1991). Giarretto (1989) delineated the four goals of therapy for childhood sexual abuse victims as catharsis, confrontation, self-identification, and self-management (Bagley \& King, 1989).

Both coaching one parent in serving as a trustworthy role model and providing suitable role boundaries when a child has been sexually abused have been found to be helpful (Bagley \& King, 1989). Whatever transpires in sessions between the child and the therapist is still confidential and has not been tested in the real world. However, James (1989) pointed out the importance of the child's caregivers' (but not the offending parent) being involved with the treatment team. This involvement greatly assists the child in overcoming the negative dynamics of something secret having happened and can substantially facilitate the development of healthy relationships (Bagley \& King, 1989). Hyde, Bentovim, and Monck (1995) submitted in their study that mothers and caregivers benefit from group and individual interventions. Numerous existing programs that treat victims of sexual abuse. Two of the programs, The Christopher Street Program in Minneapolis and the Child Sexual Abuse Treatment Program, utilize parent group and mother/daughter counseling, among other treatment interventions (Vargo, Stavrakaki, Ellis, \& Williams, 1988). 
According to a study by Lovett (1993), family violence is intergenerational. Stopping childhood sexual abuse requires strong, forceful interventions that go beyond the treatment for the victims. Conceptualizing the family as a system helps therapists to comprehend the crucial role the family plays in the nurturing and healing of one of its members following sexual abuse. Childhood sexual abuse affects the entire family, and the family's response, in turn, has a major effect on the person who was abused (Dubowitz et al., 1993; MacDonald, Lambie, \& Simmonds, 1995). Because children, especially younger children, are emotionally and physically dependent upon parents and other family members for care and support, they often reflect the family's feelings about the events that happen in their lives. For this reason, it is essential that therapists involve both the parents and siblings in the therapy process from the onset. Although the therapeutic format may vary, depending upon the needs of the specific case, what is fundamentally important is to fuse the family members into the treatment plan in a meaningful way and not to treat the child as an isolated individual (Everstine \& Everstine, 1989). The significance of distorted parental beliefs must also be acknowledged. Madonna, van Scoyk, and Jones (1991) compared the parental thinking of sexually abused children with the non-abused psychiatric population and found in the former group a pattern of rigid beliefs, emotional unavailability, and a failure to develop appropriate autonomy. The victims of childhood sexual abuse are more likely to come from disturbed families that have a historical incidence of marital separation/divorce, parental substance abuse, and psychiatric disturbance (Beitchman et al., 1991). 
Lovett (1993) found a significant correlation between a sexual abuse victim's level of competence and a warm, accepting relationship with the mother. This correlation clearly supports clinical intervention on behalf of the motherdaughter relationship. Lovett's research indicated that mothers of sexual abuse victims may play a pivotal role in the healing process. Examining the motherchild relationship from the mother's perspective, as well as from the victim's perspective, could also prove valuable to the therapeutic process. This examination could analyze the extent to which the two similarly perceive the relationship (Lovett, 1993). Before attention is turned to the sexually abusive relationship between fathers and their children, it is important to consider the basic care of the child. Thus, as Furniss (1983) has described, the primary focus needs to be on improving mother-child relationships. This includes improving communication, increasing trust, and restoring relationships (Hollin \& Howells, 1991).

One research study has indicated that mothers appear to be blamed for the sexual abuse itself or for their response following the abuse (Newberger et al., 1993). Unfortunately, such biases have affected child welfare workers in their contacts with mothers of sexual abuse victims. Child welfare workers hold numerous biased assumptions about the non-offending mother based on the "collusive mother" theory (Johnson, 1992). Therapeutic intervention is often necessary in that the psychological needs of the mother are an integral component of treating child sexual abuse (Newberger et al., 1993). Problems 
commonly identified by professionals with regard to the non-offending mother include low self-esteem, a sense of powerlessness, learned helplessness, unmet family-of-origin needs, passivity, dependency, difficulty in separating emotional needs, denial, depression, and poor self image (DeYoung, 1994; Hilderbrand \& Forbes, 1987; Newberger et al., 1993; Sgroi \& Dana, 1982). These nonoffending mothers are not the lone cause of their dysfunctional families, but rather an essential element in the family's recovery (Haenes, 1996).

Significantly, studies have shown a high incidence of sexual abuse in mothers of sexually abused children (Beitchman et al., 1991) in childhood sexual abuse cases, Hildebrand and Forbes (1987) noted that, it was rare for a mother to have had a close relationship with her own mother, leading to speculation that it would be difficult to establish such intimacy with her own daughters.

Additionally, the mother may react with feelings of guilt, believing that she failed to protect the child, or of anxiety from her own unmet needs (Everstine \& Everstine, 1989). The mother may interfere often, making treatment in sexual abuse cases difficult.

In the therapeutic process, emphasis on the strengths and, thus, the empowerment of the non-offending mother can result in a both a physically and mentally stronger woman who can mother her daughter, serve as a role model, and be an effective agent for her children (Walker, 1988). Mothers are the essential element in the healing process of families marred by abusive fathers. The therapeutic needs of the mother in therapy are often similar to those of the abused child. She also is prone to suffer from impaired self-esteem, distorted 
motivations and loyalties, inadequate limit-setting skills, built-up anger, and impaired communication patterns. It is imperative to the healing process that provision for emotional support, guidance, and coping skills be part of the support provided to help the mother with the many new-life tasks she finds herself facing. It is important to remember that the mother is suddenly confronted with many new challenges and responsibilities, which she may or may not be equipped to handle. These new challenges and responsibilities include financially supporting her children and maintaining her household, applying for public assistance, seeking legal advice, parenting her children, and facing life as a single person (Bagley \& King, 1989). Studies indicate that a mother's support is a highly significant, if not the most significant, factor affecting the child's healing (Everson et al., 1989) and that a lack of support from the mother can have significantly detrimental effects (Hooper, 1992). Successful group work with mothers can be a major tool in circumventing the cyclical nature of child sexual abuse and in reducing the likelihood of further abuse within these families (Hildebrand \& Forbes, 1987).

It is common for childhood sexual abuse victims to experience feelings of anger at and betrayal by their mothers for not having protected them from the abuse. Daughters who are sexually abused by their fathers frequently are angrier with their mothers than with their abusers. Such feelings are in part the result of children's fantasies that their mothers are all-knowing and powerful, feelings that are derived from their early experiences of total dependence on their mother. To a degree, maternal failure is inevitable against such unrealistic expectations 
(Hooper, 1992). In line with earlier cited studies, Finkelhor(1984) found in his sample of college students that the women at higher risk were the ones identified as not being close to their mothers or having received little affection from their mothers or fathers.

\section{Summary}

In recent years, childhood sexual abuse has become an area of interest for professionals as the welfare of children has moved to the forefront of public concern. Initially, childhood sexual abuse was thought to be a product of atypical family environments, but presently the field recognizes that childhood sexual abuse can exist in all socioeconomic and family settings (Finkelhor, 1984). The impact of childhood sexual abuse is unique to each individual. Thus, the professional working with victims of this type of abuse is charged with understanding both the individual and the current literature. Research indicates that parents and victims of sexual abuse need a multimodal approach to treatment (Sgroi, 1982). Families of children who have been sexually abused are overwhelmed, and the consequences are complex; many factors mediate the cause and outcome of childhood sexual abuse (Everstine \& Everstine, 1989; Gil, 1991).

The major treatment strategy in filial therapy is to train parents to become the therapeutic agents in their children's lives as they extend an atmosphere of empathy, genuineness, and acceptance in special weekly play sessions (B. G. Guerney, 1964). In filial therapy, children gain confidence and self-direction as they develop a new perception of the parent as an ally. Parental acceptance has 
been found to be an important element in children's emotional adjustment (R. P. Rohner, 1980), locus-of-control (E. C. Rohner et al., 1980), and self-esteem (Coopersmith, 1967). Child victims of sexual abuse suffer with low self-esteem, anxiety, inability to trust, somatic complaints, anger and hostility, powerlessness, and problems in school (Everstine \& Everstine, 1989). Filial therapy has been shown to be effective in increasing the self-esteem of both parents and children (Glass, 1987; Lobaugh, 1991/1992). It empowers parents by relying on them as the change agents in their children's lives (Payton, 1980). Training the parents of children who have been sexually abused to become therapeutic agents in their children's lives appears to be an efficient and effective way to facilitate healing and significantly improve the future mental health of these children and their families. 


\section{CHAPTER ॥}

\section{METHODS AND PROCEDURES}

The purpose of this study was to determine whether or not filial therapy is effective in (a) increasing the acceptance level of non-abusing parents of their sexually abused children; (b) reducing the stress level of non-abusing parents; (c) improving empathic behaviors of non-offending parents toward their sexually abused child; (d) decreasing the anxiety of sexually abused children; (e) enhancing the self-concept of sexually abused children; (f) decreasing behavior problems of sexually abused children as reported by their non-offending parents; and (g) enhancing the emotional adjustment of sexually abused children. This chapter provides definitions of terms, hypotheses, instrumentation, selection of subjects, data-collection method, the 10-week training model, the facilitator's qualifications, and statistical analysis.

\section{Definition of Terms}

Allowing the child self-direction is the behavioral willingness on the part of the parent the follow the child's lead rather than attempt to control the child's behavior. For the purpose of this study, allowing the child self-direction was operationally defined as the parents' scores on this subscale of the MEACI (Stover, Guerney, \& O'Connell, 1971).

Anxiety in children is often expressed in fearfulness, withdrawal, somatic 
complaints, changes in sleep patterns, nightmares, attentional problems, interpersonal problems, and temper tantrums. For the purposes of this study, anxiety was operationally defined as the child's scores on the Child Anxiety Scale (CAS) (Gillis, 1980).

Appreciation for the child's unique make-up means that a parent values and shows pleasure in the child's uniqueness. For the purpose of this study, appreciation of the child's unique make-up was operationally defined as the parents' scores on this subscale of the PPAS (Porter, 1954).

Child was defined in this study as a child between the ages of 4 years and 10 years who had experienced sexual abuse and the abuse was documented by an investigating agency.

Communication of Acceptance as understood in this study involves the parent's verbal expression of acceptance-rejection of the child. For the purpose of this study, communication of acceptance was operationally defined as the parents' scores on this subscale of the MEACl (Stover et al., 1971).

Emotional adjustment is the intrapersonal and interpersonal conflicts that a child subjectively experiences. Emotional adjustment refers to the affect a child feels in relation to the self and the ideal self and the child's perceptions of significant others. For the purpose of this study, emotional adjustment was operationally defined as the total score on the Draw a Person: Screening Procedure for Emotional Disturbance (DAP:SPED) (Naglieri, McNeish, \& Bardos, 1991).

Empathy refers to parents' sensitivity to their children's current feelings 
and parents' ability to verbally communicate this understanding to the child. For the purpose of this study, empathy was operationally defined as the parents' total scores on the Measurement of Empathy in Adult-Child Interaction (MEACl) (Stover et al., 1971).

Externalizing behavior problems refers to aggressive behavior such as excessive arguing, sudden changes in mood and feelings, and temper tantrums. Externalizing behavior problems also refers to delinquent behavior such as not displaying guilt after misbehavior, thinking of sex too much, and lying or cheating (Achenbach, 1991). For the purpose of this study, externalizing behavior problems was operationally defined as the score on the Externalizing subscale of the Parent Form of the Child Behavior Checklist (CBCL) (Achenbach, 1991).

Filial therapy was defined in this study as

a unique approach used by professionals trained in Play Therapy to train parents to be therapeutic agents with their own children through a format of didactic instruction, demonstration play sessions, required at-home laboratory play sessions, and supervision. Parents are taught basic childcentered play therapy skills, including responsive listening, recognizing children's emotional needs, therapeutic limit setting, building children's self-esteem, and structuring required weekly play sessions with their children using a special kit of selected toys. Parents learn how to create a nonjudgmental, understanding, and accepting environment which enhances the parent-child relationship, thus facilitating personal growth and change for child and parent. (G.L. Landreth, personal communication, 
June 27, 1995)

Internalizing behavior problems refers to withdrawn behavior such as preferring to be alone, refusing to talk, and being secretive. Internalizing behavior problems also refers to anxious/depressed behaviors such as complaining of loneliness, excessive crying, and perfectionism. Somatic complaints such as being overly tired and physical problems without any known medical cause, such as headaches and nausea, are also included in internalizing behavior problems (Achenbach, 1991). For the purpose of this study, internalizing behavior problems was operationally defined as the score on the Internalizing subscale of the Parent Form of the CBCL.

Involvement is described in this study as a measure of the parents' attention to and participation on the child's activities. For the purpose of this study, involvement was operationally defined as the parents' score on this subscale of the MEACl (Stover et al., 1971).

Non-offending parent includes any significant caregiver, not necessarily biological or adoptive parent, who was not involved in the abuse of the child.

Parental acceptance includes the feelings and behaviors on the part of the parents that are characterized by unconditional love for the child, a recognition of the child as a person with feelings who has a right and a need to express those feelings, a value for the unique make-up of the child, and a recognition of the child's need to differentiate and separate from the parents in order to become an autonomous individual (Porter, 1954). For the purpose of this study, parental acceptance was operationally defined as the parents' scores 
on the Porter Parental Acceptance Scale (PPAS)(Porter, 1954).

Parental stress describes the degree of stress in the parent-child system as perceived by the parent. For the purpose of this study, parental stress was operationally defined as the parents' scores on the Parenting Stress Index (PSI) (Abidin, 1983).

Play therapy has been defined by Landreth (1991) as

a dynamic interpersonal relationship between a child and a therapist trained in play therapy procedures who provides selected play materials and facilitates the development of a safe relationship for the child to fully express and explore self (feelings, thoughts, experiences, and behaviors) through the child's natural medium of communication, play. (p. 14) Recognition for the child's need of autonomy and independence denotes the parents' understanding of children's need to differentiate and separate from their parents in order to mature in a healthy manner. For the purpose of this study, recognition of the child's need for autonomy and independence was operationally defined as the parents' scores on this subscale of the PPAS (Porter, 1954).

Respect for the child's feelings and right to express them denotes the parents' willingness to allow the child to express feelings and still show positive regard for the child. For the purpose of this study, respect for the child's feelings and right to express them was operationally defined as the parents' scores on this subscale of the PPAS (Porter, 1954).

Self-esteem is the internal measures of a child's worth. The child forms a 
sense of self based on outside experiences and inside perceptions. For the purpose of this study, self-esteem was operationally defined as the child's total scores on the Joseph Pre-school and Primary Self-Concept Screening Test (JPPSST) (Joseph, 1979).

Sexual abuse, for the purpose of this study, was defined as an occurrence in which a child, between the ages of 4 and 10 is tricked, coerced, forced, or threatened to have any kind of sexual contact (such as genital exposure, masturbation, fellatio, cunnilingus, digital penetration of vagina or anus opening, penile penetration of vagina or anus opening, or dry intercourse) with any adult or child at least 5 years older, including the explicit showing of pornographic films or pictures or the taking of pornographic films or pictures (Gil,1991). This includes sexual abuse by family members, generally called incest; by trusted nonfamily members; and by strangers, sometimes called sexual assault.

Unconditional love is the love a parent shows toward a child without placing conditions or minimum standards on his or her behavior in order for the child to receive that love. For the purpose of this study, unconditional love was operationally defined as the parents' scores on this subscale of the PPAS (Porter, 1954).

\section{Hypotheses}

To carry out the purposes of this study, the following hypotheses were formulated:

1. The experimental group parents will attain a significantly higher mean total score on the Porter Parental Acceptance Scale (PPAS) posttest than 
will the control group parents.

(a) The experimental group parents will attain a significantly higher mean score on the Respect for the Child's Feelings and Right to Express Them subscale of the PPAS posttest than will the control group parents.

(b) The experimental group parents will attain a significantly higher mean score on the Appreciation of the Child's Unique Makeup subscale of the PPAS posttest than will the control group parents. (c) The experimental group parents will attain a significantly higher mean score on the Recognition of the Child's Need for Autonomy and Independence subscale of the PPAS posttest than will the control group parents.

(d) The experimental group parents will attain a significantly higher mean score on the Unconditional Love subscale of the PPAS posttest than will the control group parents.

2. The experimental group parents will attain a significantly lower mean total score on the Parenting Stress Index (PSI) posttest than will the control group parents.

(a) The experimental group parents will attain a significantly lower mean score on the Parent Domain of the PSI posttest than will the control group parents.

(b) The experimental group parents will attain a significantly lower mean score on the Child Domain of the PSI posttest than will the 
control group parents.

3. The experimental group parents will attain a significantly lower mean total score on the Measurement of Empathy in Adult-Child Interaction (MEACI) posttest than will the control group parents.

(a) The experimental group parents will attain a significantly lower mean score on the Communication subscale of the MEACI posttest than will the control group parents.

(b) The experimental group parents will attain a significantly lower mean score on the Allowing the Child Self-Direction subscale of the $\mathrm{MEACl}$ posttest than will the control group parents.

(c) The experimental group parents will attain a significantly lower mean score on the Involvement subscle of the MEACI posttest than will the control group parents.

4. The experimental group children will attain a significantly lower total mean t-score on the Parent Form of the Child Behavior Checklist (CBCL) posttest than will the control group children.

(a) The experimental group children will attain a significantly lower mean t-score on Externalizing Behavior Problems on the $\mathrm{CBCL}$ posttest than will the control group children.

(b) The experimental group children will attain a significantly lower mean t-score on Internalizing Behavior Problems on the CBCL posttest than will the control group children.

5. The experimental group children will attain a significantly lower 
mean total sten-score on the Child Anxiety Scale (CAS) posttest than will the control group children.

6. The experimental group children will attain a significantly higher mean total score on the Joseph Preschool and Primary Self-Concept Screening Test (JPPSST) posttest than will the control group children.

7. The experimental group children will attain a significantly lower mean total score on the Draw A Person: Screening Procedure for Emotional Disturbance (DAP:SPED) posttest than will the control group children.

\section{Limitations}

The results of this study may be limited due to the specific population of non-offending parents selected, the necessity of forming local groups, and the small number of subjects $(\underline{\mathrm{N}}=26)$ included in the study. Due to the confidential nature of this population, direct access to the subjects was difficult. The reliance on obtaining subjects by an agency to mail letters or word- of-mouth through professionals was not found to be as effective as personal contact by the investigator. Consequently, the data process took place over a 9-month period. The investigator conducted three groups of 10 -week training sessions. Random assignment was somewhat compromised due to the broad region from which the subjects were drawn. Non-offending parents were assigned to treatment groups by location of their residence and by the number needed to form an appropriate group. Some subjects were assigned to the control group because the group had commenced. 
Instruments

\section{Porter Parental Acceptance Scale}

The Porter Parental Acceptance Scale (PPAS) was developed by Porter (1954); it is a self-report inventory designed to measure parental acceptance as revealed in behavior and feelings toward, about, or with their child. Variables measured by the instrument are (a) respect for the child's feelings and right to express them; (b) appreciation of the child's unique make-up; (c) recognition of the child's need for autonomy and independence; and (d) unconditional love.

The instrument consists of 40 items, each with five multiple choice responses ranging from low to high acceptance. Two dimensions of acceptance are incorporated into the scale. The first reveals how the parent feels in a specific situation. The second reveals the parent's manifested behavior in a specific situation. The test may be scored to yield four subscale scores and one total score. Higher scores on the total score in each of the subscales indicates higher levels of positive behavior.

Porter (1954) reported a split-half reliability correlation of .766, raised by the Spearman Brown Prophecy formula to 865 . Later research reported a splithalf reliability coefficient of .666 , raised by the Spearman Brown formula to a total test reliability of .800 . Both of the reported coefficients are significant beyond the .01 level (Burchinal et al., 1957).

Porter (1954) investigated the validity of the instrument by using five expert judges to rank the responses on a continuum of 1 (low acceptance) to 5 (high acceptance). On all items, there was agreement among at least three of 
the five judges. The greatest degree of disagreement was by a distance of only 2 scale points, which occurred in less than $20 \%$ of the responses, suggesting that Porter's operational definition of parental acceptance is valid as measured by this scale.

Internal consistency of the scale was investigated by Burchinal et al. (1957), using item analysis. All items discriminated between high-and-low scoring fathers, with the exception of one item, which failed to show significance. Analysis of mothers' responses yielded similar results. In fact, 35 items in the mothers' responses and 33 in the fathers' responses were significant at the .001 level of probability, clearly demonstrating that the items discriminated consistently between high and low scorers. The instrument was thus deemed to be internally consistent.

\section{Parenting Stress index}

The Parenting Stress Index (PSI) was developed by Abidin (1983). This self-report inventory is a 101-item index designed to measure the level of stress in the parent-child system. The items are separated into two domains, the parent domain and the child domain. The parental characteristics measured by the PSI include the parent's sense of competence, parental attachment, restriction imposed by the parental role, the parent's feelings of social isolation, parental depression, relationship with spouse, and parental health. The child characteristics measured include the child's acceptability to the parent, the child's level of demandingness, the child's moodiness, the child's degree of distractibility, the child's adaptability, and the child's reinforcement of the parent. 
Higher scores indicate higher levels of stress and perceived negative behavior in the total score and in each of the subscales.

Zakreski (1983) used the test-retest method to determine a coefficient of reliability. This study produced coefficients of .778 for the child domain, .69 for the parent domain, and .88 for the total index. Alpha reliability coefficients were calculated on each total score and on each of the domains to determine internal consistency. The coefficient reported for the child domain was .89 and the coefficient for the parent domain was .93 , with a total reliability coefficient of .95 . These findings indicate a high degree of internal consistency for the PSI (Hauenstein, Scarr, \& Abidin, 1986).

\section{Measurement of Empathy in Adult-Child Interaction}

The Measurement of Empathy in Adult-Child Interaction (MECAI) is a rating form adapted by Bratton (1993/1994) from a scale developed by Stover et al. (1971) to operationally define empathy as related to parent-child interactions. This direct observational scale measures three specific parental behaviors: (a) communication of acceptance; (b) allowing the child self-direction; and (c) involvement. These three behaviors are identified as major aspects of empathy in adult-child interactions and, when combined, provide a total empathy score. Lower scores indicate higher levels of positive behavior in the subscales and total scores.

The Communication of Acceptance subscale measures the parent's verbal expression of acceptance-rejection of the child's feelings and behavior during spontaneous play sessions. The dimension of acceptance is viewed as a 
necessary condition for optimal development in the child's self-worth and the major element in the communication of empathy (Stover et al., 1971).

The Allowing the Child Self-Direction subscale measures the verbal expression of acceptance and the behavioral willingness on the part of the parent to follow the child's lead rather than attempt to control the child's behavior (Stover et al., 1971).

The Involvement subscale measures the parent's attention to and participation in the child's activity. Stover et al. (1971) found that parents who exhibited high levels of communication of acceptance and allowed the child selfdirection also demonstrated high levels of involvement.

The $\mathrm{MEACl}$ is a 5-point bipolar scale used to rate the three dimensions of parental behavior every 3 minutes for six consecutive coding intervals. The scale ranges from a high rating of 1 to a low rating of 4 . Each point on the scale is followed by typical responses obtained from codings of the direct observations of parent-child interactions. Considering the three subscales together as components of empathic behavior, the highest levels of empathy are evident when the parent is commenting frequently on the child's expression of feeling or behavior in a genuinely accepting manner; is clearly demonstrating that the child is fully permitted to engage in self-directed activity, and is attentive to the child's behavior. The lowest level of empathic communication is one in which the parent is verbally critical and rejecting of the feelings or behaviors of the child; cajoles, demands, and continually redirects the child's activity; and is self-involved, preoccupied, or shut off from the child. 
Reliability coefficients were established for each of the three subscales. After four training sessions for collaborative rating on a half hour play session, followed by discussions, six pairs of coders independently rated 7 to 10 parentchild play sessions of $\mathbf{2 0}$ minutes each. The average reliability correlation coefficient for the Communication of Acceptance subscale was .92. The Allowing the Child Self-Direction subscale had a median correlation coefficient of .89 , and the Parental Involvement subscale had an average coefficient of .89 (Stover et al., 1971).

Construct validity for each subscale and the total empathy score was demonstrated in a study with a group of 51 mothers who participated in filial therapy training (B. G. Guerney \& Stover, 1971). The filial therapy training method was utilized to demonstrate the validity of the scales because this method involved training parents in emphatic skills closely related to the behaviors the scales are intended to measure. The parents' levels of empathic interactions with their children were measured three times: (a) a pretraining play session; (b) the first posttraining play session; and (c) the third posttraining play session. Highly significant increases, at the .0005 level, between the pretraining and first posttraining play session were obtained on each subscale and for the total empathy score. A significant increase, at the .01 level, between the first and third posttraining play sessions demonstrated that the scales are extremely sensitive measures of empathic behaviors. Concurrent validity established by demonstrating a .85 correlation at the .005 level between the $\mathrm{MEACl}$ and a previously developed empathy measure for adult-child interaction (B. G. 
Guerney, Stover, \& DeMerrit, 1968).

Child Behavior Checklist-Parent Report Form

The Child Behavior Checklist-Parent Report Form (CBCL) was developed by Achenbach and Edelbrock $(1981,1983)$. In the current study, the 1991 profile (Achenbach, 1991) is used. The CBCL is a 113-item scale used with children from 2 to 16 years of age. The form is designed to be filled out by the parent and takes approximately 20 minutes to complete. The behavior problem scale consists of 113 items that have been factor analyzed into nine subscales (Achenbach, 1991): Withdrawn, Somatic Complaints, Anxious/Depressed, Social Problems, Thought Problems, Attention Problems, Delinquent Behaviors, Aggressive Behaviors, and Sex Problems. A second-order factor analysis of the behavior problem scale yielded two primary factors labeled Internalizing and Externalizing. A total behavior problem scale score may be computed. The scores for each subscale and factor can be computed, resulting in t-scores and percentiles.

Internal consistency is built in because the syndrome scales are derived from principal components of the correlation among items. For girls ages 4 to 11 , Cronbach's alpha is .90 for Internalizing behavior problems and .93 for Externalizing behavior problems. For boys ages 4 to 11 , Cronbach's alpha is .89 for Internalizing and .93 for Externalizing behavior problems. Cronbach's alpha represents the mean of the correlations between all possible sets of half the items comprising a scale. Inter-interviewer reliability of item scores was established at .959 for the problem items by comparing scores arrived at by 
three interviewers with 241 matched triads of children.

Test-retest reliability was established at .89 for Internalizing behavior problems and at .93 for Externalizing behavior problems. Long-term stability ( 2 years) of scaled scores was established at .70 and .86 for Internalizing and Externalizing behavior problems, respectively. Children who were receiving mental health services obtained long-term stability coefficients that were generally lower, with significant decreases in problem scores, indicating that the CBCL is sensitive to the effects of interventions with children.

Content validity is supported by the ability of the CBCL items to discriminate significantly between demographically matched referred and nonreferred children. Construct validity is supported by significant association with analogous scales on the Conners Parent Questionnaire (1973) and the Quay-Peterson Revised Behavior Problem Checklist (1983). Criterion-related validity is supported by the ability of the CBCL's quantitative scale scores to discriminate significantly between demographically matched referred and nonreferred children.

\section{Child Anxiety Scale}

The Child Anxiety Scale (CAS) was developed by Gillis (1980) to measure anxiety in young children ages 5 years 0 months to 12 years 11 months. The self-report instrument was designed to be brief, easy to administer, and simple to score. The measurement consists of 20 items related to anxiety and can be repeated to monitor anxiety level over time. The answer sheet is child-friendly, with both pictures and bright colors used to direct and maintain attention. 
Norm tables are available both for age and grade levels. Raw scores may be converted into one of the two types of standard scores, stens or percentiles. High scores are significant and reflect the presence of anxiety. Low scores are equally significant, pointing to the possible denial of anxiety.

The CAS was developed to provide a time-efficient measurement of anxiety in young children utilizing factor analysis of the Early School Personality Questionnaire (ESPQ). Created by Coan and Cattell (1966), the ESPQ was designed to provide comprehensive coverage of personality characteristics in young children. Factor analysis of the 13 ESPQ primary scales revealed a second-order factor which agreed well with a general anxiety pattern that was repeatedly found with older age groups (Gillis \& Cattell, 1979). Examination of a total of 320 items with regard to factor loadings on the second-order ESPQ anxiety factor resulted in selection of the 20 best items for inclusion in the CAS (Gillis, 1980).

Psychometrically, the CAS was found to have a test-retest reliability of .82 for grade $1, .85$ for grade 2 , and .92 for grade 3 using a total of 127 children (Gillis, 1980). The internal consistency analysis of the CAS has been examined in a sample of 343 children in which a Kuder-Richardson 20 coefficient of .73 was found. Item-factor validity was established by the correlation between individual items and the pure anxiety factor identified within the ESPQ (Gillis, 1980). Joseph Preschool and Primary Self-Concept Screening Test 
(JPPSST) was originally developed by Joseph (1979) for preschool children and later adapted for upper grade levels. The instrument is normed for ages 3 years 6 months through 9 years 11 months. Additionally the JPPSST may also be useful in identifying high-risk subjects as old as 13 years of age. The JPPSST is designed to measure the self-concept of a child by using pictures to stimulate responses from the child. First, the child identifies the pictures as pictures of himself or herself (from two sets of gender-specific pictures.). By using the child's descriptions of the activities and feelings surrounding the pictures of the self, the scorer is able to rate the child's self-esteem on a global index scale of 0 to 30 .

A test-retest sample to check the reliability of the JPPSST was $\underline{r}=.87$. A split-half test was given to determine internal consistency. The Kuder-Richardson 20 formula was used; it estimated the internal consistency in a range from .59 to.81, with a medium correlation of .73 . An item analysis was also performed, with item discrimination coefficients ranging from .30 to .70 as a function of the particular item and the age level of the sample. All items on the scale obtained correlation coefficients that significantly contribute to the overall test score performance.

Construct validity was addressed by correlating the global self-concept score, derived from two self-concept rating scales completed by teachers. The correlation coefficient between the scores of the two tests equaled .51, which was significant at the .01 level of confidence.

Draw A Person: Screening Procedure for Emotional Disturbance

The Draw A Person: Screening Procedure for Emotional Disturbance 
(DAP:SPED) was developed by Naglieri et al. (1991) to provide a screening measure to aid in the identification of children and adolescents who may have emotional disorders. The instrument was designed to incorporate what was written in the literature about children's human figure drawings as reflective of personality characteristics or emotional adjustment into a measurable instrument. Affect of the self, the ideal self, and perceptions of significant others can be elicited in a person's drawing of the human figure, in addition to personality traits, attitudes, concerns, and interpersonal skills (Kaufman \& Wohl, 1992).The DAP:SPED uses a human figure drawing scoring system comprised of 55 items considered to be indicators of emotional conflict. These items are scored as a screening for further evaluation of emotional disturbance. The instrument is normed for ages 6 through 17 (5-year-olds were included in the standardization sample, but the sample size was too small to constitute separate norms.). The DAP:SPED asks the child to draw a picture of a man, a woman, and himself or herself. The drawings are then scored using templates and itemanalysis. A $\underline{t}$ score is calculated from a raw score (Naglieri et al., 1992).

A test-retest sample to check the reliability of the DAP:SPED was taken, producing a reliability coefficient of .67 . Internal consistency was determined using Cronbach's alpha, which represents the mean of the correlations between all possible sets of half the items comprising the scale. For girls ages 6 to 8 , Cronbach's alpha is .7393 , and for ages 9 to 12 it is .7283 . For boys ages 6 to 8 , Cronbach's alpha is .7714 , and for ages 9 to 12 it is .7841 . Interrater reliability of the scoring system was established at $\underline{I}=.844$ and $\underline{I}=.830$, respectively (Naglieri 
et al., 1992).

Support for the validity of the DAP:SPED's screening ability was shown by the results of 49 adolescents in a psychiatric residential treatment facility compared to a nonclinical population of 218 individuals. A significant chi-square of 14.47 at the .0001 significance level was obtained (Naglieri et al., 1992).

Selection of Subjects

Advertisements stating the beginning of "parent-child relationship enhancement classes for non-offending parents of children who have experienced sexual abuse" were run in three area newspapers. Fliers were posted at the two local college campuses and various community agencies serving families throughout the county. Fliers were also mailed to public and private school professionals, medical professionals, and profit and nonprofit counseling centers. Agencies that exclusively serve the targeted population were contacted and asked to give the fliers personally to clients who fit the criteria. Parents who responded by the advertised deadline were contacted by the investigator and given more details about the parent training and the selection process. The classes were offered free of charge.

Parents were selected to participate in the study based on the following criteria: (a) must be a significant caregiver of a child between 4 and 10 years of age who has experienced sexual abuse; (b) must be a non-offender; (c) the child must be identified by an investigating agency as having been sexually abused; (d) must be able to speak, read, and write the English language; (e) must not be involved in classes that exclusively address parenting issues; (f) must be able to 
attend the 10 weeks of filial therapy training; $(g)$ must be able to attend a pretraining session to complete pretest instruments and be videotaped playing with their child; (h) must be able to attend a posttraining session to complete posttest instruments and be videotaped playing with their child; (f) must agree to participate in weekly 30-minute home play sessions with their child; and (g) must be willing to sign the consent-to-participate form.

The investigator met with each parent participant meeting the specified criteria to explain the purpose and the requirements of the filial therapy training, to provide information about how confidentiality would be maintained, and to answer any questions the participants had before they signed the consent form. The parents were informed that they and their children would be scheduled to participate in either the first series (experimental group) or second series (control group) of filial training classes. The experimental group immediately participated in 10 weeks of filial therapy training. The control group was offered filial therapy training at the end of 10 weeks.

This project was reviewed and approved by the University of North Texas Institutional Review Board for the protection of human subjects. All parents who met the criteria specified above ( $\underline{N}=31)$ were scheduled to bring their "child of focus" to a pretraining session to complete all pretest requirements. Under the convenience sampling method, group assignment was made matching subjects by communities. Participants were not matched on any other demographic variable prior to group assignment. The investigator randomly assigned parents to the experimental group $(\underline{n}=15)$ and the control group $(\underline{n}=16)$. Over the course 
of the 10 week treatment period, 1 subject from the experimental group and 4 subjects from the control group dropped out of the investigation. Thus 26 subjects completed the present study, 14 in the experimental group and 12 in the control group.

The experimental group was comprised of 11 mothers, 2 fathers, and 1 grandmother. There were 9 mothers and 3 fathers in the control group. The parents in the experimental group ranged in age from 25 to 56 years of age, with a mean age of 35.4 . The age range for the control group parents was 24 to 49 years of age, with a mean age of 36.4. The parents in the experimental group were approximately $93 \%$ Caucasian, and $7 \%$ Hispanic. In the control group, parents were $92 \%$ Caucasian and $8 \%$ Hispanic. Of the experimental group parents, $7 \%$ did not complete high school, $7 \%$ earned a GED, $79 \%$ completed high school, and $7 \%$ completed college. The control group parents' level of education was $67 \%$ completed high-school and $33 \%$ completed college.

The marital status in the experimental group parents included $57 \%$ married, $14 \%$ separated, and $28 \%$ divorced. In the control group parents, marital status was $75 \%$ married, $8.3 \%$ divorced, $8.3 \%$ separated, and $8.3 \%$ other. The experimental group had two pairs of parents, and the control group had three pairs of parents. One pair of experimental group parents had the same child as their "child of focus." The socioeconomic status in both group ranged from less than $\$ 15,000$ to over $\$ 40,000$. Specifically, the experimental group parents reported gross household family incomes from less than $\$ 15,000$ to $\$ 40,000$, with a mean of $\$ 32,000$. The control group parents reported $\$ 15,000$ to $\$ 40,000$, 
with a mean of $\$ 29,000$.

There were 10 girls and 3 boys in the experimental group and 5 girls and 4 boys in the control group. The children in both groups ranged in ages from 4 to 10 years. The experimental group included $8 \% 4$-year-olds, $23 \% 6$-yearolds, 31\% 8-year-olds, $15 \% 9$-year-olds, and $23 \% 10$-year-olds. The control group included $22 \%$ 4-year-olds, $22 \% 6$-year-olds, $34 \% 7$-year-olds, $22 \% 8$-yearolds.

Within the experimental group, 2 children lived with foster parents; 1 had play sessions with both of her foster parents; and 1 had play sessions with her biological parent during visitation. The experimental group children experienced the onset of sexual abuse at 18 months to 9.5 years of age, with a mean age of 5.4. In the control group children, the onset of sexual abuse was from 5 weeks to 8 years of age, with a mean age of 4.8 . The experimental group children were $85 \%$ intrafamilial, $7.5 \%$ extrafamilial abused, and $7.5 \%$ unknown. The control group children were $78 \%$ intrafamilial and $22 \%$ extrafamilial abused. Considering ethical issues and comprehensive treatment needs within this population, both the experimental and the control group children were allowed to continue with other forms of treatment. Individual therapy was attended by $46 \%$ of the experimental group children and $33 \%$ of the control group children. Group therapy was attended by $54 \%$ of the experimental group children and $78 \%$ of the control group children. Thirty-one percent of the experimental group children and $22 \%$ of the control group children had no treatment.

Demographically, the experimental and control groups were similar in 
many areas. The greatest variance between the groups was that the control group had a $26 \%$ higher rate of parents completing college; 9 -and 10 -year-olds were not represented in the control group; and $24 \%$ more control group children attended group therapy.

\section{Collection of Data}

Pretraining sessions were scheduled during the week prior to the first series of filial therapy training classes for the purpose of collecting data. Sessions for the three groups were held in a metroplex area Texas Department of Protective and Regulatory Services facility, a church, and a clinic at a university. Parents and their children were scheduled individually for the pretraining testing. During the pretraining sessions, parents completed the Porter Parental Acceptance Scale, the Parenting Stress Index, and the Child Behavior Checklist-Parent Report Form. Directions to complete the assessments were given verbally, and parents were instructed to respond to all items as it applied to their child of focus or to them personally. The children were administered the Child Anxiety Scale, the Joseph Preschool and Primary SelfConcept Screening Test, and the Draw a Person: Screening Procedure for Emotional Disturbance. The parent and child were then videotaped together in a room that contained specially-selected toys. They were shown the room and told that "this is a room where you may play with the toys in lots of ways that you would like to." They were also told that they would have 20 minutes together but that, at the end of 15 minutes they would be given a 5-minute warning that the session would be ending. The videotaping equipment did not work properly 
during the videotaping of one control group parent; therefore, the 12 control group parents were reduced to 11 on the MECAI. The researcher supervised the data collection. Masters-level research assistants were trained by the researcher and assisted in the data collection. The researcher or research assistant was present to answer any questions.

Confidentiality of the information provided on questionnaires and videotapes was insured by using code numbers, with only the investigator having a list of the participants' names. All confidential material was kept in a locked file. Names of both parents and children will not be disclosed in any publication or discussion of this material. The research assistants were made aware that the confidentiality of participants was to be maintained.

During the 2 weeks following the 10 weekly filial therapy training sessions, the posttest battery of instruments was administered to parents and children in both the experimental and control groups. The posttraining sessions followed the same procedures outlined in the pretraining sessions. The control group parents were given the opportunity to participate in filial therapy training at a time after they completed the posttesting requirements.

Treatment: Ten-Week Filial Therapy Training Model

The 20 experimental group parents were divided into 4 small groups to participate in the Landreth (1991) 10-week filial therapy model (Appendix C). Parents were assigned to one of the groups according to (a) location of meeting place to their residence and (b) random assignment. Group sizes ranged from 2 to 10 persons. Each group met weekly for a 2-hour training session for 10 
consecutive weeks. Missed sessions were made up with the group leader by individual arrangement. Child care was provided.

The Landreth (1991) 10-week filial therapy model utilizes both didactic and dynamic components. It was designed to enhance the parent-child relationship by helping parents learn how to create an accepting environment in which their children feel safe enough to express and explore thoughts and feelings. In the filial training sessions, parents learned new skills through demonstration and role play. At home, these skills were practiced while conducting required weekly 30 -minute special play sessions with their children. Parents were encouraged to report their experiences to the group. The parents were supplied with a special toy kit (described in the filial therapy handouts in Appendix C). In addition, each participant was video-taped once during the 10week training. Parents having access to a video camera, videotaped themselves at home. If video equipment was not available to the parent, the investigator arranged to video tape the participant. This tape was reviewed during a group training session. The participants received constructive feedback, encouragement, and support from both the facilitator and the group members. The opportunity to observe other parents during their special play times added to the learning experience.

\section{Training Session One}

During Session One, parents were asked to introduce themselves, describe their families, and characterize their "child of focus." Goals and objectives of the training were explained. The facilitator described the skills of 
reflective listening and tracking behavior and illustrated these skills through role play, with one of the parents playing the role of the child. Parents were encouraged to practice empathic responses and tracking behavior in a similar role-play situation with each other. Parents were introduced to the facial expressions of children through still photos of young children expressing various emotions. The homework assignment for the first session was to identify emotions of anger, happiness, sadness, and surprise in their child of focus and make a reflective response (see handout in Appendix C). Responses were written for reporting to the group.

\section{Training Session Two}

Session Two began with a review of homework assignments. Empathic responding was be elaborated on, and the facilitator demonstrated empathic responding with a volunteer, followed by viewing of a videotape of the facilitator in a play session with a child. Parents were given the opportunity to role play with selected toys in pairs, taking turns being the parent and the child. Parents were given a list of toys (playdough, crayons, paper, blunt scissors, nursing bottle, baby doll, rubber knife, dart gun, doll family, toy soldiers, car, Lone Ranger-type mask, Tinkertoys, doctor kit, Band-Aids, play money, rope, transparent tape, bop bag, bowling pins, ball, and cardboard box to be used as doll house and container for toys). The facilitator demonstrated each toy and explained the toy's purpose in the special sessions. The homework assignment was to select a time and an uninterrupted place in the home suitable for the play sessions. 


\section{Training Session Three}

During Session Three, the parents were asked to report on arrangements for their sessions. The facilitator reiterated the importance of developing trust through consistency with children in order to enhance the parent-child relationship. Play therapy skills were taught through role playing with toys. A second videotape was shown of the facilitator with a child in a play session. Parents were given filial kits, as described in Session Two. The homework assignment was to help the child make a "Play Session -- Do Not Disturb" sign to hang on the door and to have the first of their weekly play sessions. Parents were be given a list of play time rules (see Appendix $\mathrm{C}$ ). One parent was asked to volunteer to be videotaped either at home or as arranged by the facilitator for demonstration purposes at the next group meeting.

\section{Training Session Four}

During Session Four, the parents were asked to report on their first play sessions. Areas of difficulty were be discussed, with suggestions offered by the facilitator. The homework assignment was be for parents to continue home play sessions and to notice one intense feeling in themselves.

\section{Training Sessions Five Through Nine}

Sessions Five through Nine followed the same general format as Session Four. Brief reporting by the parents of their play sessions was interspersed with suggestions and instruction from the therapist, along with group interaction on common problems and attention to parents' feelings. A parent videotape was viewed and discussed during each session. Homework assignments in which 
written responses to typical happenings in play sessions were critiqued. Training and role playing of play session principles and skills were continued each session.

Training Session Five

Limit-setting was be discussed, using the handout "Two Techniques of Discipline That Work." Parents were invited to discuss the feelings they experienced during the play session with their child that week. The "sandwich hug" was demonstrated, and parents were asked to practice sandwich hugs and to practice giving their child one choice during the week.

\section{Training Session Six}

The handout "When Setting Limits Doesn't Work" was discussed. Parents were asked to write notes to all of their children following the format outlined in the manual for Session Six (see Appendix C). The importance of focusing on one child during this training period was reiterated. Parents were asked to notice any patterns that seemed to be emerging in their child's play sessions.

\section{Training Session Seven}

The facilitator reviewed reflective listening, setting limits, and giving choices. Parents were given the opportunity to practice their skills in role play. Parents shared the progress they had made in play sessions. The parents were asked to notice the number of times they touched their child during the week. Training Session Eight

The amount of physical interaction between parents and children was discussed. Parents debriefed their play sessions. The facilitator focused on 
parents accepting themselves and their children, allowing themselves and their children to make mistakes and be imperfect.

\section{Training Session Nine}

After play session debriefing, the facilitator asked parents to write down questions to be discussed during the final training session. Follow-up meetings were discussed with group members. Parents were encouraged to consider any changes they had seen in themselves and their children.

\section{Training Session Ten}

Parents reported on their play sessions, and a parent session was viewed. The facilitator shared notes of parents' original descriptions of their children as points of reference for parents to evaluate progress. The last hour was spent with parents sharing their evaluation of the experience and how and if they and their children had changed. Parents were encouraged to continue play sessions with their child of focus and to use play sessions with other children in the family.

\section{Facilitator}

The filial therapy training groups were facilitated by the investigator of this study, who is a licensed professional counselor in the state of Texas and a doctoral student at the University of North Texas (UNT). She had completed an introduction to play therapy course, an advanced play therapy course, a filial therapy course, a doctoral-level practicum in play therapy, and a doctoral internship in play therapy. She is a clinical supervisor at the Child and Family Resource Clinic at UNT. 
Statistical Analyses

Following the collection of the pretest and posttest data, the three selfreport instruments from the parents and the two self-report instruments and two drawings from the children were blind-scored by a research assistant and double-checked by a second research assistant. The pre-and posttraining videotapes of parent-child play were not rated until completion of the study to insure that the raters did not know whether they were rating a pretraining or posttraining session. Four doctoral students with advanced course work and training in play therapy and filial therapy blind-scored the videotapes over a 2week period. Interrater reliability for the four raters was established during a 2hour training session. Training included discussion and collaborative rating sessions following the procedures outlined by Stover et al. (1971). Interrater reliability was also checked midpoint of the scoring process and again at the end of the scoring, as suggested in the Manual for Coders (Muehl, 1961). Kendall's coefficient of concordance $W$ was used to calculate interrater reliability (see Table 1). Kendall's $\underline{W}$ is a nonparametric test of the hypotheses that several related samples are from the same population. Useful in testing for interrater or intertest reliability, $\underline{W}$ tests for agreement among judges' or raters' rankings of several variables (Norusis, 1988). 
Table 1

Interrater Reliability Coefficients of Concordance for Coding of the Measurement of Empathy in Adult-Child Interactions Scales

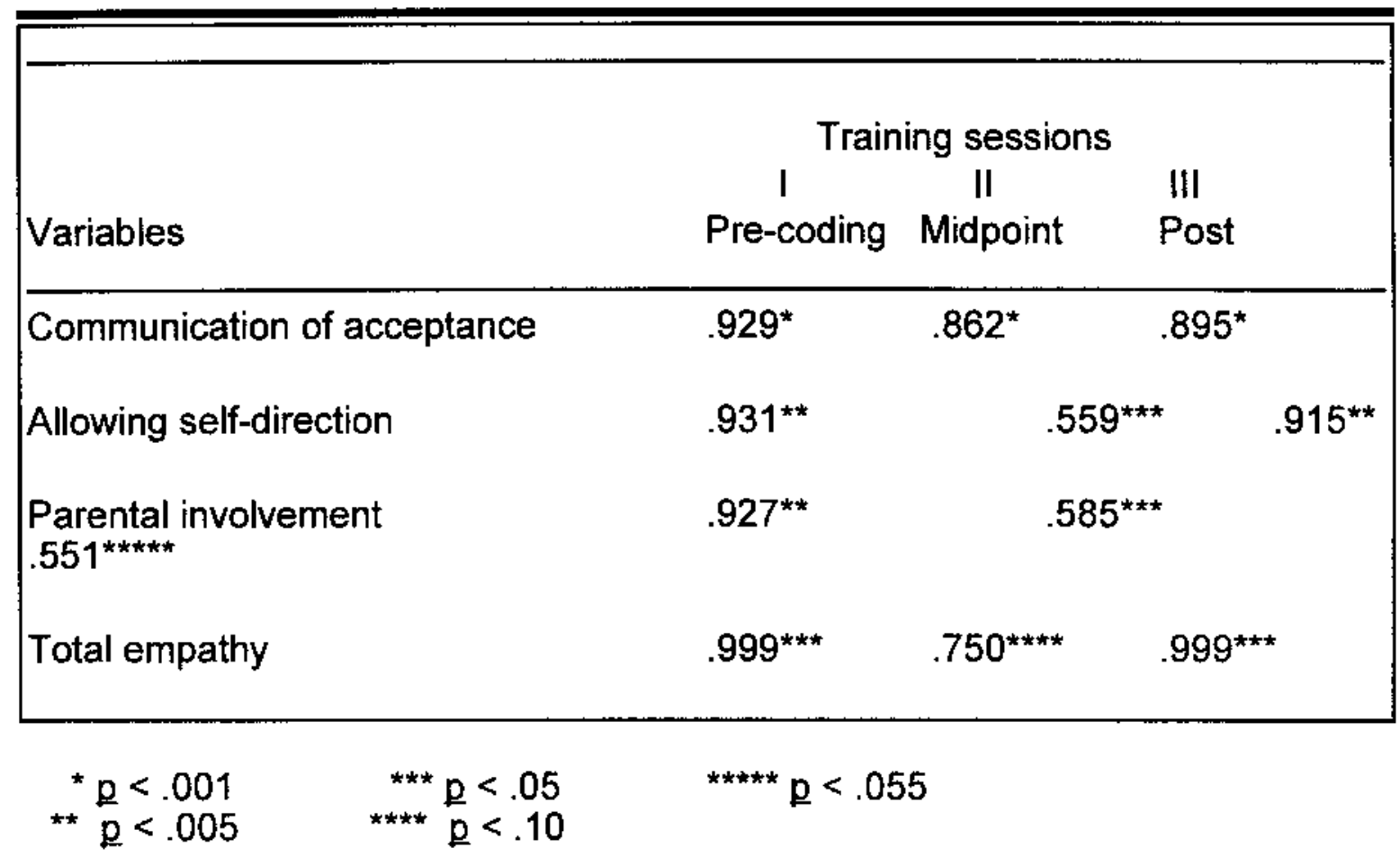

For the purpose of statistical analysis, data from all the filial therapy training groups were pooled to form the experimental group. The resulting data were keyed into the computer and analyzed by the researcher using SPSS (1993).

An analysis of covariance (ANCOVA) was computed to test the significance of the difference between the experimental group and the control group on the adjusted posttest means for each hypothesis. In each case, the posttest specified in each of the hypotheses was used as the dependent variable and the pretest as the covariate. ANCOVA was used to adjust the group means on the posttest on the basis of the pretest, thus statistically equating the control 
and experimental groups. Significance of difference between means was tested using .05 as the level of significance. On the basis of the ANCOVA, the hypotheses were either retained or rejected. 


\section{CHAPTER III}

\section{RESULTS AND DISCUSSION}

This chapter presents the results of the data analysis for each hypothesis tested in this study. Included also is a discussion of the results, observations, implications, and recommendations for further research.

\section{Results}

The results of this study are presented in the order in which the hypotheses were tested. Analyses of covariance were performed on all hypotheses, and a level of significance of .05 was established as the criterion for either retaining or rejecting the hypotheses.

\section{Hypothesis 1}

The experimental group parents will attain a significantly higher mean total score on the Porter Parental Acceptance Scale (PPAS) posttest than will the control group parents.

Table 2 presents the pre-and posttest means and standard deviations for the experimental and control groups. Table 3 presents the analysis of covariance data, showing the significance of difference between the experimental and control groups' posttest mean scores. 
Table 2

Mean Total Scores for the Porter Parental Acceptance Scale (PPAS)

\begin{tabular}{lrrrr}
\hline & \multicolumn{2}{c}{ Experimental $(n=14)$} & \multicolumn{2}{c}{ Control $(n=12)$} \\
& Pretest & Posttest & Pretest & Posttest \\
\hline Mean & 141.714 & 157.500 & 139.000 & 144.750 \\
SD & 19.840 & 14.075 & 19.098 & 14.716 \\
Total cases $=26$ & & & & \\
\hline
\end{tabular}

Table 3

Analysis of Covariance Data for the Mean Total Scores for the PPAS

\begin{tabular}{lrrrrr}
\hline $\begin{array}{l}\text { Source of } \\
\text { variation }\end{array}$ & $\begin{array}{l}\text { Sum of } \\
\text { squares }\end{array}$ & \multicolumn{1}{c}{ df } & $\begin{array}{l}\text { Mean } \\
\text { square }\end{array}$ & \multicolumn{1}{c}{$\begin{array}{c}\mathrm{F} \\
\text { ratio }\end{array}$} & \multicolumn{1}{c}{$\begin{array}{l}\text { Sign. } \\
\text { of } F\end{array}$} \\
\hline Main effects & 871.607 & 1 & 871.607 & 5.822 & .024 \\
Covariates & 1514.267 & 1 & 1514.267 & 10.114 & .004 \\
Error & 6008.154 & 25 & 240.326 & & \\
Total cases $=26$ & & & & & \\
\hline
\end{tabular}

Table 3 shows that the $\underline{E}$ ratio for the main effects was significant at the .024 level, indicating a significant increase in the experimental group parents' mean total scores for the PPAS. On the basis of this data, hypothesis 1 was retained.

Hypothesis 1.a

The experimental group parents will attain a significantly higher mean score on the Respect for the Child's Feelings and Right to Express Them 
subscale of the PPAS posttest than will the control group parents.

Table 4 presents the pre-and posttest means and standard deviations for the experimental and control groups. Table 5 presents the analysis of covariance data, showing the significance of difference between the experimental and control groups' posttest mean scores.

Table 4

Mean Scores for the PPAS Subscale: Respect for the Child's Feelings and Right to Express Them

\begin{tabular}{|c|c|c|c|c|}
\hline & \multicolumn{2}{|c|}{ Experimental $(n=14)$} & \multicolumn{2}{|c|}{ Control $(n=12)$} \\
\hline & Pretest & Posttest & Pretest & Posttest \\
\hline Mean & 34.714 & 41.143 & 35.750 & 38.083 \\
\hline$\underline{S D}$ & 6.707 & 5.641 & 6.240 & 6.748 \\
\hline Total cases $=26$ & & & & \\
\hline
\end{tabular}

Table 5

Analysis of Covariance Data for the Mean Scores on the PPAS Subscale: Respect for the Child's Feelings and Right to Express Them

\begin{tabular}{lrrrrr}
\hline \hline $\begin{array}{l}\text { Source of } \\
\text { variation }\end{array}$ & $\begin{array}{l}\text { Sum of } \\
\text { squares }\end{array}$ & df & $\begin{array}{l}\text { Mean } \\
\text { square }\end{array}$ & $\begin{array}{c}\text { F } \\
\text { ratio }\end{array}$ & $\begin{array}{c}\text { Sign. } \\
\text { of F }\end{array}$ \\
Main effects & 79.028 & 1 & 79.028 & 2.512 & .127 \\
Covariates & 190.940 & 1 & 190.940 & 6.068 & .022 \\
Error & 975.115 & 25 & 39.005 & & \\
Total cases $=26$ & & & & & \\
\hline
\end{tabular}


Table 5 shows that the $E$ ratio for the main effects was .127 , indicating no significant increase in the experimental group parents' mean total scores for the PPAS subscale: Respect for the Child's Feelings and Right to Express Them. On the basis of this data, hypothesis 1.a was not retained.

\section{Hypothesis 1.b}

The experimental group parents will attain a significantly higher mean score on the Appreciation of the Child's Unique Makeup subscale of the PPAS posttest than will the control group parents.

Table 6 presents the pre-and posttest means and standard deviations for the experimental and control groups. Table 7 presents the analysis of covariance data, showing the significance of difference between the experimental and control groups' posttest mean scores.

Table 6

Mean Scores for the PPAS Subscale: Appreciation of the Child's Unique Makeup

\begin{tabular}{lcccc}
\hline & \multicolumn{2}{c}{ Experimental $(n=14)$} & \multicolumn{2}{c}{ Control $(n=12)$} \\
& Pretest & Posttest & Pretest & Posttest \\
\hline Mean & 34.929 & 37.017 & 36.250 & 35.917 \\
SD & 4.599 & 3.872 & 4.535 & 4.078 \\
Total cases $=26$ & & & & \\
\hline
\end{tabular}


Table 7

Analysis of Covariance Data for the Mean Scores on the PPAS Subscale: Appreciation of the Child's Unique Makeup

\begin{tabular}{lrrrrr}
\hline $\begin{array}{c}\text { Source of } \\
\text { variation }\end{array}$ & $\begin{array}{c}\text { Sum of } \\
\text { squares }\end{array}$ & df & $\begin{array}{l}\text { Mean } \\
\text { square }\end{array}$ & $\begin{array}{c}E \\
\text { ratio }\end{array}$ & $\begin{array}{l}\text { Sign. } \\
\text { of } F\end{array}$ \\
Main effects & 12.682 & 1 & 12.682 & .814 & .376 \\
Covariates & 19.683 & 1 & 19.683 & 1.264 & .272 \\
Error & 386.462 & 25 & 15.458 & & \\
Total cases $=26$ & & & & & \\
\hline
\end{tabular}

Table 7 shows that the $E$ ratio for the main effects was .376 , indicating no significant increase in the experimental group parents' mean total scores for the PPAS subscale: Appreciation of the Child's Unique Makeup. On the basis of this data, hypothesis 1.b was not retained.

Hypothesis 1.c

The experimental group parents will attain a significantly higher mean score on the Recognition of the Child's Needs for Autonomy and Independence subscale of the PPAS posttest than will the control group parents.

Table 8 presents the pre-and posttest means and standard deviations for the experimental and control groups. Table 9 presents the analysis of covariance data, showing the significance of difference between the experimental and control groups' posttest mean scores. 
Table 8

Mean Scores for the PPAS Subscale: Recognition of the Child's Need for Autonomy and Independence

\begin{tabular}{lcccc}
\hline \hline & \multicolumn{2}{c}{ Experimental $(n=14)$} & \multicolumn{2}{c}{ Control $(n=12)$} \\
& Pretest & Posttest & Pretest & Posttest \\
\hline Mean & 40.429 & 42.000 & 38.000 & 40.917 \\
SD & 4.603 & 3.162 & 6.075 & 4.621 \\
Total cases $=26$ & & & & \\
\hline
\end{tabular}

Table 9

Analysis of Covariance Data for the Mean Scores on the PPAS Subscale: Recognition of the Child's Need for Autonomy and Independence

\begin{tabular}{lrrrrr}
\hline $\begin{array}{l}\text { Source of } \\
\text { variation }\end{array}$ & $\begin{array}{c}\text { Sum of } \\
\text { squares }\end{array}$ & \multicolumn{1}{c}{ df } & \multicolumn{1}{c}{$\begin{array}{l}\text { Mean } \\
\text { square }\end{array}$} & $\begin{array}{c}\text { E } \\
\text { ratio }\end{array}$ & $\begin{array}{l}\text { Sign. } \\
\text { of } F\end{array}$ \\
Main effects & .497 & 1 & .497 & .039 & .845 \\
Covariates & 73.634 & 1 & 73.634 & 5.814 & .024 \\
Error & 372.500 & 25 & 14.900 & & \\
Total cases $=26$ & & & & & \\
\hline
\end{tabular}

Table 9 shows that the $F$ ratio for the main effects was .845 , indicating no significant increase in the experimental group parents' mean total scores for the PPAS subscale: Recognition of the Child's Need for Autonomy and Independence. On the basis of this data, hypothesis 1.c was not retained. 
Hypothesis 1.d

The experimental group parents will attain a significantly higher mean score on the Unconditional Love subscale of the PPAS posttest than will the control group parents.

Table 10 presents the pre-and posttest means and standard deviations for the experimental and control groups. Table 11 presents the analysis of covariance data, showing the significance of difference between the experimental and control groups' posttest mean scores.

Table 10

Mean Scores for the PPAS Subscale: Unconditional Love

\begin{tabular}{lccrr}
\hline \hline & \multicolumn{2}{c}{ Experimental $(n=14)$} & \multicolumn{2}{c}{ Control $(n=12)$} \\
& Pretest & Posttest & Pretest & Posttest \\
\hline Mean & 31.643 & 37.286 & 29.000 & 29.833 \\
SL & 10.195 & 8.213 & 9.244 & 9.321 \\
Total cases $=26$ & & & & \\
\hline
\end{tabular}

Table 11

Analysis of Covariance Data for the Mean Scores on the PPAS Subscale: Unconditional Love

\begin{tabular}{|c|c|c|c|c|c|}
\hline $\begin{array}{l}\text { Source of } \\
\text { Variation }\end{array}$ & $\begin{array}{l}\text { Sum of } \\
\text { squares }\end{array}$ & $\mathrm{df}$ & $\begin{array}{l}\text { Mean } \\
\text { square }\end{array}$ & ratio & $\begin{array}{l}\text { Sign. } \\
\text { of } F\end{array}$ \\
\hline Main effects & 237.041 & 1 & 237.041 & 4.373 & .048 \\
\hline Covariates & 585.697 & 1 & 585.697 & 10.804 & .003 \\
\hline Error & 2191.385 & 25 & 87.655 & & \\
\hline \multicolumn{6}{|c|}{ Total cases $=26$} \\
\hline
\end{tabular}


Table 11 shows that the $E$ ratio for the main effects was .048 , indicating a significant increase in the experimental group parents' mean total scores for the PPAS subscale: Unconditional Love. On the basis of this data, hypothesis 1.d was retained.

Hypothesis 2

The experimental group parents will attain a significantly lower mean total score on the Parenting Stress Index (PSI) posttest than will the control group parents.

Table 12 presents the pre-and posttest means and standard deviations for the experimental and control groups. Table 13 presents the analysis of covariance data, showing the significance of difference between the experimental and control groups' posttest mean scores.

Table 12

Mean Scores for the Parenting Stress Index (PSI)

\begin{tabular}{lrrrr}
\hline & \multicolumn{2}{c}{ Experimental $(n=14)$} & \multicolumn{2}{c}{ Control $(n=12)$} \\
& Pretest & Posttest & Pretest & Posttest \\
\hline Mean & 244.643 & 221.071 & 247.083 & 257.083 \\
SD & 46.091 & 49.613 & 50.846 & 47.064 \\
Total cases $=26$ & & & & \\
\hline
\end{tabular}


Table 13

Analysis of Covariance Data for the Mean Scores for the PSI

\begin{tabular}{|c|c|c|c|c|c|}
\hline $\begin{array}{c}\text { Source of } \\
\text { variation }\end{array}$ & $\begin{array}{l}\text { Sum of } \\
\text { squares }\end{array}$ & $d f$ & $\begin{array}{l}\text { Mean } \\
\text { square }\end{array}$ & $\underset{\text { ratio }}{\mathrm{F}}$ & $\begin{array}{l}\text { Sign. } \\
\text { of } F\end{array}$ \\
\hline Main effects & 7622.894 & 1 & 7622.894 & 5.720 & .025 \\
\hline Covariates & 25712.834 & 1 & 25712.834 & 19.294 & .000 \\
\hline Error & 64743.538 & 25 & 2589.742 & & \\
\hline Total cases $=26$ & & & & & \\
\hline
\end{tabular}

Table 13 shows that the $E$ ratio for the main effects was .025 , indicating a significant decrease in the experimental group parents' mean total scores for the PSI. On the basis of this data, hypothesis 2 was retained.

Hypothesis 2.a

The experimental group parents will attain a significantly lower mean score on the Parent Domain of the PSI posttest than will the control group parents.

Table 14 presents the pre-and posttest means and standard deviations for the experimental and control groups. Table 15 presents the analysis of covariance data, showing the significance of difference between the experimental and control groups' posttest mean scores. 
Table 14

Mean Scores for the PSI Subscale: Parent Domain

\begin{tabular}{lrrrrr}
\hline \hline & \multicolumn{2}{c}{ Experimental $(n=14)$} & & \multicolumn{2}{c}{ Control $(n=12)$} \\
& Pretest & Posttest & & Pretest & Posttest \\
\hline Mean & 130.643 & 120.643 & 132.083 & 135.000 \\
SD & 29.801 & 31.624 & 32.456 & 33.683 \\
Total cases $=26$ & & & & \\
\hline
\end{tabular}

Table 15

Analysis of Covariance Data for the Mean Scores for the PSI Subscale: Parent

Domain

\begin{tabular}{lrrrrr}
\hline $\begin{array}{l}\text { Source of } \\
\text { variation }\end{array}$ & $\begin{array}{c}\text { Sum of } \\
\text { squares }\end{array}$ & $\mathrm{df}$ & \multicolumn{1}{c}{$\begin{array}{l}\text { Mean } \\
\text { square }\end{array}$} & $\begin{array}{c}\mathrm{F} \\
\text { ratio }\end{array}$ & $\begin{array}{l}\text { Sign. } \\
\text { of } F\end{array}$ \\
Main effects & 1120.116 & 1 & 1120.116 & 2.636 & .118 \\
Covariates & 15708.367 & 1 & 15708.367 & 36.969 & .000 \\
Error & 26813.115 & 25 & 1072.525 & & \\
Total cases $=26$ & & & & & \\
\hline
\end{tabular}

Table 15 shows that the $E$ ratio for the main effects was 118 , indicating no significant decrease in the experimental group parents' mean total scores for the PSI subscale: Parent Domain. On the basis of this data, hypothesis 2.a was not retained.

Hypothesis 2.b

The experimental group parents will attain a significantly lower mean 
score on the Child Domain of the PSI posttest than will the control group parents.

Table 16 presents the pre-and posttest means and standard deviations for the experimental and control groups. Table 17 presents the analysis of covariance data, showing the significance of difference between the experimental and control groups' posttest mean scores.

Table 16

Mean Scores for the PSI Subscale: Child Domain

\begin{tabular}{lrrrr}
\hline \hline & \multicolumn{2}{c}{ Experimental $(n=14)$} & \multicolumn{2}{c}{ Control $(n=12)$} \\
& Pretest & Posttest & Pretest & Posttest \\
\hline Mean & 113.429 & 100.429 & 115.000 & 122.083 \\
SD & 22.356 & 21.625 & 24.439 & 17.906 \\
Total cases $=26$ & & & & \\
\hline
\end{tabular}

Table 17

Analysis of Covariance Data for the Mean Scores for the PSI Subscale: Child Domain

\begin{tabular}{lcrcrc}
\hline $\begin{array}{l}\text { Source of } \\
\text { variation }\end{array}$ & $\begin{array}{c}\text { Sum of } \\
\text { squares }\end{array}$ & $\mathrm{df}$ & $\begin{array}{c}\text { Mean } \\
\text { square }\end{array}$ & $\begin{array}{c}\mathrm{F} \\
\text { ratio }\end{array}$ & $\begin{array}{c}\text { Sign. } \\
\text { of } F\end{array}$ \\
Main effects & 2812.697 & 1 & 2812.697 & 10.106 & .004 \\
Covariates & 3204.868 & 1 & 3204.868 & 11.515 & .002 \\
Error & 12636.346 & 25 & 505.454 & & \\
Total cases $=26$ & & & & & \\
\hline
\end{tabular}

Table 17 shows that the $\underline{E}$ ratio for the main effects was .004 , indicating a significant decrease in the experimental group parents' mean total scores for the 
PSI subscale: Child Domain. On the basis of this data, hypothesis 2 .b was retained.

Hypothesis 3

The experimental group parents will attain a significantly lower mean total score on the Measurement of Empathy in Adult-Child Interaction Rating Form (MEACl) posttest than will the control group parents.

Table 18 presents the pre-and posttest means and standard deviations for the experimental and control groups. Table 19 presents the analysis of covariance data, showing the significance of difference between the experimental and control groups' posttest mean scores.

Table 18

Mean Total Scores for the Measurement of Empathy in Adult-Child Interaction Rating Form (MEACl)

\begin{tabular}{lcccc}
\hline \hline & \multicolumn{2}{c}{ Experimental $(n=14)$} & \multicolumn{2}{c}{ Control $(n=11)$} \\
& Pretest & Posttest & Pretest & Posttest \\
\hline \multirow{2}{*}{ Mean } & 57.875 & 30.786 & 57.273 & 54.977 \\
SD & 9.207 & 11.550 & 10.789 & 8.469 \\
Total cases $=25$ & & & & \\
\hline
\end{tabular}

Note. A decrease in the mean score indicates an increase in empathic behavior. 
Table 19

Analysis of Covariance Data for the Mean Total Scores on the MEACl

\begin{tabular}{lrrrrr}
\hline $\begin{array}{l}\text { Source of } \\
\text { variation }\end{array}$ & $\begin{array}{l}\text { Sum of } \\
\text { squares }\end{array}$ & df & $\begin{array}{l}\text { Mean } \\
\text { square }\end{array}$ & \multicolumn{1}{c}{$\begin{array}{c}\text { ratio } \\
\text { ration }\end{array}$} & $\begin{array}{l}\text { Sign. } \\
\text { of } F\end{array}$ \\
Main effects & 3668.226 & 1 & 3668.266 & 37.701 & .000 \\
Covariates & 311.108 & 1 & 311.108 & 3.197 & .088 \\
Error & 6056.690 & 24 & 252.362 & & \\
Total cases $=25$ & & & & & \\
\hline
\end{tabular}

Table 19 shows that the $E$ ratio for the main effects was $<.001$, indicating a significant increase in the experimental group parents' empathic interactions with their children during observed play sessions. On the basis of this data, hypothesis 3 was retained.

Hypothesis 3.a

The experimental group parents will attain a significantly lower mean score on the Communication of Acceptance subscale of the MEACI posttest than will the control group parents.

Table 20 presents the pre-and post-test means and standard deviations for the experimental and control groups. Table 21 presents the analysis of covariance data, showing the significance of difference between the experimental and control groups' posttest mean scores. 
Table 20

Mean Total Scores for the MEACI Subscale: Communication of Acceptance

\begin{tabular}{|c|c|c|c|c|}
\hline & \multicolumn{2}{|c|}{ Experimental $(n=14)$} & \multicolumn{2}{|c|}{ Control $(n=11)$} \\
\hline & Pretest & Posttest & Pretest & Posttest \\
\hline Mean & 19.804 & 11.214 & 18.909 & 19.341 \\
\hline$\underline{\mathrm{SD}}$ & 3.560 & 3.673 & 2.892 & 2.642 \\
\hline Total cases $=25$ & & & & \\
\hline
\end{tabular}

Note. A decrease in the mean score indicates an increase in communication of acceptance.

Table 21

Analysis of Covariance Data for the Mean Total Scores on the MEACI Subscale:

Communication of Acceptance

\begin{tabular}{lrrrrr}
\hline \hline $\begin{array}{l}\text { Source of } \\
\text { variation }\end{array}$ & $\begin{array}{l}\text { Sum of } \\
\text { squares }\end{array}$ & df & $\begin{array}{l}\text { Mean } \\
\text { square }\end{array}$ & $\begin{array}{c}\mathrm{F} \\
\text { ratio }\end{array}$ & $\begin{array}{c}\text { Sign. } \\
\text { of } F\end{array}$ \\
\hline Main effects & 427.910 & 1 & 427.910 & 42.990 & .000 \\
Covariates & 26.161 & 1 & 26.161 & 2.628 & .119 \\
Error & 651.960 & 24 & 27.165 & & \\
Total cases $=25$ & & & & & \\
\hline
\end{tabular}

Table 21 shows that the $E$ ratio for the main effects was $<.001$, indicating a significant increase in the experimental group parents' communication of acceptance of their children's feelings and behaviors during observed play sessions. On the basis of this data, hypothesis 3.a was retained. 
Hypothesis 3.6

The experimental group parents will attain a significantly lower mean score on the Allowing the Child Self-Direction subscale of the MEACI posttest than will the control group parents.

Table 22 presents the pre-and posttest means and standard deviations for the experimental and control groups. Table 23 presents the analysis of covariance data, showing the significance of difference between the experimental and control groups' posttest mean scores.

Table 22

Mean Total Scores for the MEACI Subscale: Allowing the Child Self-Direction

\begin{tabular}{|c|c|c|c|c|}
\hline & \multicolumn{2}{|c|}{ Experimental $(n=14)$} & \multicolumn{2}{|c|}{ Control $(n=11)$} \\
\hline & Pretest & Posttest & Pretest & Posttest \\
\hline Mean & 21.679 & 9.750 & 21.582 & 21.000 \\
\hline$\underline{\mathrm{SD}}$ & 5.158 & 5.173 & 4.417 & 4.068 \\
\hline Total cases $=25$ & & & & \\
\hline
\end{tabular}

Note. A decrease in the mean score indicates an increase in allowing the child self-direction. 
Table 23

Analysis of Covariance Data for the Mean Total Scores on the MEACI Subscale: Allowing the Child Self-Direction

\begin{tabular}{lrrrrr}
\hline $\begin{array}{l}\text { Source of } \\
\text { variation }\end{array}$ & $\begin{array}{c}\text { Sum of } \\
\text { squares }\end{array}$ & df & \multicolumn{1}{c}{$\begin{array}{l}\text { Mean } \\
\text { square }\end{array}$} & $\begin{array}{c}\text { E } \\
\text { ratio }\end{array}$ & $\begin{array}{l}\text { Sign. } \\
\text { of } F\end{array}$ \\
\hline Main effects & 779.544 & 1 & 779.544 & 34.587 & .000 \\
Covariates & 17.529 & 1 & 17.529 & .778 & .387 \\
Error & 1293.000 & 24 & 53.875 & & \\
Total cases $=25$ & & & & & \\
\hline
\end{tabular}

Table 23 shows that the $E$ ratio for the main effects was $<.001$, indicating a significant increase in the experimental group parents' acceptance and behavioral willingness to follow their children's lead rather than attempt to control their children's behavior during observed play sessions. On the basis of this data, hypothesis $3 . b$ was retained.

Hypothesis 3.c

The experimental group parents will attain a significantly lower mean score on the Involvement subscale of the MEACl posttest than will the control group parents.

Table 24 presents the pre-and posttest means and standard deviations for the experimental and control groups. Table 25 presents the analysis of covariance data, showing the significance of difference between the experimental and control groups' posttest mean scores. 
Table 24

Mean Total Scores for the MEACI Subscale: Involvement

\begin{tabular}{|c|c|c|c|c|}
\hline & \multicolumn{2}{|c|}{ Experimental $(n=14)$} & \multicolumn{2}{|c|}{ Control $(n=11)$} \\
\hline & Pretest & Posttest & Pretest & Posttest \\
\hline Mean & 16.393 & 9.821 & 16.682 & 14.591 \\
\hline$\underline{S D}$ & 4.306 & 3.297 & 5.288 & 4.134 \\
\hline Total cases $=25$ & & & & \\
\hline
\end{tabular}

Note. A decrease in the mean score indicates an increase in involvement.

Table 25

Analysis of Covariance Data for the Mean Iotal Scores on the MEACI Subscale: Involvement

\begin{tabular}{|c|c|c|c|c|c|}
\hline $\begin{array}{l}\text { Source of } \\
\text { variation }\end{array}$ & $\begin{array}{l}\text { Sum of } \\
\text { squares }\end{array}$ & df & $\begin{array}{l}\text { Mean } \\
\text { square }\end{array}$ & $\underset{\text { ratio }}{\mathrm{F}}$ & $\begin{array}{l}\text { Sign. } \\
\text { of } F\end{array}$ \\
\hline Main effects & 133.930 & 1 & 133.930 & 12.061 & .002 \\
\hline Covariates & 67.911 & 1 & 67.911 & 6.116 & .022 \\
\hline Error & 452.340 & 24 & 18.848 & & \\
\hline \multicolumn{6}{|c|}{ Total cases $=25$} \\
\hline
\end{tabular}

Table 25 shows that the $E$ ratio for the main effects was .002 , indicating a significant increase in the experimental group parents' attention to and participation in their children's play during observed play sessions. On the basis of this data, hypothesis 3.c was retained. 


\section{Hypothesis 4}

The experimental group children will attain a significantly lower total mean t-score on the Parent Form of the Child Behavior Checklist (CBC) posttest than will the control group children.

Table 26 presents the pre-and posttest means and standard deviations for the experimental and control groups. Table 27 presents the analysis of covariance data, showing the significance of difference between the experimental and control groups' posttest mean t-scores.

Table 26

Total Mean t-scores for Total Behavior Problems on the Parent Form of the Child Behavior Checklist (CBC)

\begin{tabular}{llrlrl}
\hline \hline & \multicolumn{2}{c}{ Experimental $(n=14)$} & \multicolumn{2}{c}{ Control $(n=12)$} \\
& Pretest & Posttest & & Pretest & Posttest \\
\hline \multirow{2}{*}{ Mean } & 64.357 & 58.429 & 68.750 & 66.083 \\
SD & 13.754 & 14.340 & 9.781 & 10.255 \\
Total cases $=26$ & & & & \\
\hline
\end{tabular}


Table 27

Analysis of Covariance Data for the Mean t-scores for Total Behavior Problems on the Parent Form of the CBC

\begin{tabular}{lrrrrr}
\hline $\begin{array}{l}\text { Source of } \\
\text { variation }\end{array}$ & $\begin{array}{l}\text { Sum of } \\
\text { squares }\end{array}$ & df & \multicolumn{1}{c}{$\begin{array}{l}\text { Mean } \\
\text { square }\end{array}$} & \multicolumn{1}{c}{$\begin{array}{r}\text { ratio } \\
\text { ration. }\end{array}$} & $\begin{array}{l}\text { Sign. } \\
\text { of } F\end{array}$ \\
Main effects & 89.822 & 1 & 89.822 & 1.848 & .187 \\
Covariates & 2712.275 & 1 & 2712.275 & 55.795 & .000 \\
Error & 4208.962 & 25 & 168.358 & & \\
Total cases $=26$ & & & & & \\
\hline
\end{tabular}

Table 27 shows that the $E$ ratio for the main effects was .187 , indicating no significant decrease in the experimental group children's' Total Behavior Problems as indicated on the Parent Form of the CBC. On the basis of this data, hypothesis 4 was not retained.

Hypothesis 4.a

The experimental group children will attain a significantly lower mean tscore on Externalizing Behavior Problems on the Parent Report Form of the CBC posttest than will the control group children.

Table 28 presents the pre-and posttest means and standard deviations for the experimental and control groups. Table 29 presents the analysis of covariance data, showing the significance of difference between the experimental and control groups' posttest mean t-scores. 
Table 28

Mean t-scores for Externalizing Behavior Problems on the Parent Report Form of the $\mathrm{CBC}$

\begin{tabular}{lcccc}
\hline & \multicolumn{2}{c}{ Experimental $(n=14)$} & \multicolumn{2}{c}{ Control $(n=12)$} \\
& Pretest & Posttest & Pretest & Posttest \\
\hline \multirow{2}{*}{ Mean } & 62.286 & 58.500 & 65.417 & 62.750 \\
SD & 10.716 & 11.601 & 9.510 & 9.873 \\
Total cases $=26$ & & & & \\
\hline
\end{tabular}

Table 29

Analysis of Covariance Data for the Mean t-scores on Externalizing Behavior

Problems on the Parent Report Form of the CBC

\begin{tabular}{lrrrrr}
\hline \multicolumn{1}{c}{$\begin{array}{l}\text { Source of } \\
\text { variation }\end{array}$} & $\begin{array}{c}\text { Sum of } \\
\text { squares }\end{array}$ & $\mathrm{df}$ & \multicolumn{1}{c}{$\begin{array}{l}\text { Mean } \\
\text { square }\end{array}$} & $\begin{array}{c}\mathrm{F} \\
\text { ratio }\end{array}$ & $\begin{array}{l}\text { Sign. } \\
\text { of } F\end{array}$ \\
Main effects & 18.397 & 1 & 18.397 & .358 & .556 \\
Covariates & 1638.964 & 1 & 1638.964 & 31.871 & .000 \\
Error & 2938.462 & 25 & 117.538 & & \\
Total cases $=26$ & & & & & \\
\hline
\end{tabular}

Table 29 shows that the $\underline{F}$ ratio for the main effects was .556 , indicating no significant decrease in the experimental group children's' Externalizing Behavior Problems as indicated on the Parent Report Form of the CBC. On the basis of this data, hypothesis 4 .a was not retained. 
Hypothesis 4.b

The experimental group children will attain a significantly lower mean t-score on Internalizing Behavior Problems as indicated on the Parent Report Form of the CBC posttest than will the control group children.

Table 30 presents the pre-and posttest means and standard deviations for the experimental and control groups. Table 31 presents the analysis of covariance data, showing the significance of difference between the experimental and control groups' posttest mean t-scores.

Table 30

Mean t-scores for Internalizing Behavior Problems on the Parent Report Form of the CBC

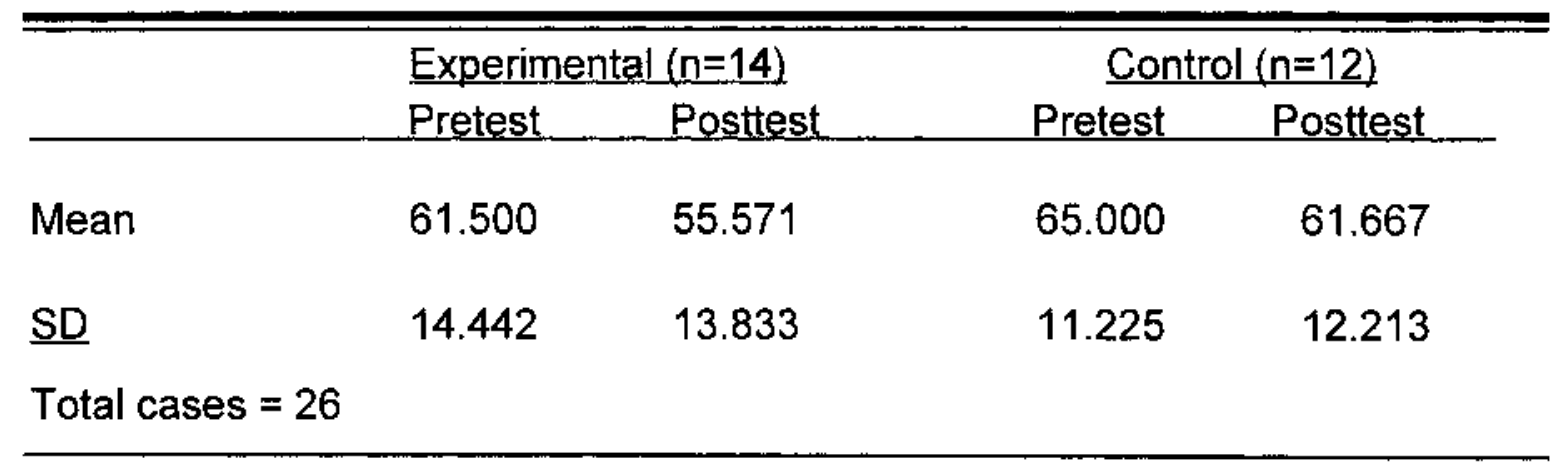


Table 31

Analysis of Covariance Data for the Mean t-scores for Internalizing Behavior

Problems on the Parent Form of the $\mathrm{CBC}$

\begin{tabular}{|c|c|c|c|c|c|}
\hline $\begin{array}{l}\text { Source of } \\
\text { variation }\end{array}$ & $\begin{array}{l}\text { Sum of } \\
\text { squares }\end{array}$ & df & $\begin{array}{l}\text { Mean } \\
\text { square }\end{array}$ & $\underset{\text { ratio }}{E}$ & $\begin{array}{l}\text { Sign. } \\
\text { of } F\end{array}$ \\
\hline Main effects & 61.544 & 1 & 61.544 & 1.221 & .281 \\
\hline Covariates & 2969.163 & 1 & 2969.163 & 58.926 & .000 \\
\hline Error & 4368.154 & 25 & 174.726 & & \\
\hline Total cases $=26$ & & & & & \\
\hline
\end{tabular}

Table 31 shows that the $E$ ratio for the main effects was .281 , indicating no significant decrease in the experimental group children' Internalizing Behavior Problems as indicated on the Parent Form of the CBC. On the basis of this data, hypothesis 4.b was not retained.

\section{Hypothesis 5}

The experimental group children will attain a significantly lower mean total sten score on the Child Anxiety Scale (CAS) posttest than will the control group children.

Table 32 presents the pre-and posttest means and standard deviations for the experimental and control groups. Table 33 presents the analysis of covariance data, showing the significance of difference between the experimental and control groups' posttest mean sten scores. 
Table 32

Mean Total Sten Scores for the Child Anxiety Scale (CAS)

\begin{tabular}{lllll}
\hline & \multicolumn{2}{c}{$\begin{array}{c}\text { Experimental }(\mathrm{n}=12) \\
\text { Pretest }\end{array}$} & Posttest & \multicolumn{2}{c}{ Control $(\mathrm{n}=7)$} \\
& & & & \\
Mean & 6.250 & 6.167 & 5.857 & 6.571 \\
SD & 2.221 & 3.070 & 2.035 & 2.149 \\
Total cases $=19$ & & & & \\
\hline
\end{tabular}

Table 33

Analysis of Covariance Data for the Mean Total Sten Scores on the CAS

\begin{tabular}{lrrrrr}
\hline $\begin{array}{l}\text { Source of } \\
\text { variation }\end{array}$ & $\begin{array}{l}\text { Sum of } \\
\text { squares }\end{array}$ & df & $\begin{array}{l}\text { Mean } \\
\text { square }\end{array}$ & $\begin{array}{c}\text { E } \\
\text { ratio }\end{array}$ & $\begin{array}{l}\text { Sign. } \\
\text { of F }\end{array}$ \\
Main effects & 2.167 & 1 & 2.167 & .404 & .534 \\
Covariates & 45.616 & 1 & 45.616 & 8.510 & .010 \\
Error & 132.105 & 18 & 7.339 & & \\
Total cases $=19$ & & & & & \\
\hline
\end{tabular}

Table 33 shows that the $\underline{E}$ ratio for the main effects was .534 , indicating no significant decrease in the experimental group children's mean total sten scores for the CAS. On the basis of this data, hypothesis 5 was not retained. Hypothesis 6

The experimental group children will attain a significantly higher mean total score on the Joseph Pre-School and Primary Self-Concept Screening Test (JPPCST) posttest than will the control group children. 
Table 34 presents the pre-and posttest means and standard deviations for the experimental and control groups. Table 35 presents the analysis of covariance data, showing the significance of difference between the experimental and control groups' posttest mean scores.

Table 34

Mean Total Scores for the Joseph Pre-School and Primary Self-Concept Screening Test (JPPCST)

\begin{tabular}{lrrrr}
\hline \hline & \multicolumn{2}{c}{ Experimental $(n=13)$} & & Control $(n=9)$ \\
& Pretest & Posttest & Pretest & Posttest \\
\hline Mean & 20.231 & 21.769 & 24.444 & 23.556 \\
SD & 5.761 & 6.809 & 4.391 & 4.475 \\
Total cases $=22$ & & & & \\
\hline
\end{tabular}

Table 35

Analysis of Covariance Data for the Mean Total Scores on the JPPCST

\begin{tabular}{lrrrrr}
\hline $\begin{array}{l}\text { Source of } \\
\text { variation }\end{array}$ & $\begin{array}{c}\text { Sum of } \\
\text { squares }\end{array}$ & df & $\begin{array}{l}\text { Mean } \\
\text { square }\end{array}$ & $\begin{array}{c}\mathrm{F} \\
\text { ratio }\end{array}$ & $\begin{array}{l}\text { Sign. } \\
\text { of } F\end{array}$ \\
Main effects & .693 & 1 & .693 & .023 & .881 \\
Covariates & 147.491 & 1 & 147.491 & 4.925 & .039 \\
Error & 733.500 & 21 & 34.929 & & \\
Total cases $=22$ & & & & & \\
\hline
\end{tabular}

Table 35 shows that the $E$ ratio for the main effects was .881 , indicating no significant increase in the experimental group children's mean total scores for 
the JPPCST. On the basis of this data, hypothesis 6 was not retained.

Hypothesis 7

The experimental group children will attain a significantly lower mean total t-score on the Draw A Person: Screening Procedure for Emotional Disturbance (DAP:SPED) posttest than will the control group children.

Table 36 presents the pre-and posttest means and standard deviations for the experimental and control groups. Table 37 presents the analysis of covariance data, showing the significance of difference between the experimental and control groups' posttest mean t-scores.

Table 36

Mean Total t-scores for the Draw A Person: Screening Procedure for Emotional Disturbance (DAP:SPED)

\begin{tabular}{|c|c|c|c|c|}
\hline & \multicolumn{2}{|c|}{ Experimental $(n=12)$} & \multicolumn{2}{|c|}{ Control $(n=7)$} \\
\hline & Pretest & Posttest & Pretest & Posttest \\
\hline Mean & 56.917 & 52.333 & 61.857 & 55.143 \\
\hline$S D$ & 11.774 & 10.085 & 13.446 & 10.931 \\
\hline Total cases $=19$ & & & & \\
\hline
\end{tabular}


Table 37

Analysis of Covariance Data for the Mean Total t-scores on the DAP:SPED

\begin{tabular}{lrrrrr}
\hline \hline $\begin{array}{l}\text { Source of } \\
\text { variation }\end{array}$ & $\begin{array}{c}\text { Sum of } \\
\text { squares }\end{array}$ & \multicolumn{1}{c}{ df } & $\begin{array}{l}\text { Mean } \\
\text { square }\end{array}$ & $\begin{array}{c}\mathrm{F} \\
\text { ratio }\end{array}$ & $\begin{array}{l}\text { Sign. } \\
\text { of } \mathrm{F}\end{array}$ \\
\hline Main effects & 4.030 & 1 & 4.030 & .044 & .837 \\
Covariates & 360.140 & 1 & 360.140 & 3.906 & .066 \\
Error & 1870.421 & 18 & 103.912 & & \\
Total cases $=19$ & & & & & \\
\hline
\end{tabular}

Table 37 shows that the $E$ ratio for the main effects was .837 , indicating no significant increase in the experimental group children's mean total t-scores for the DAP:SPED. On the basis of this data, hypothesis 7 was not retained.

Discussion

The results of this study, along with parents' comments and the facilitator's observations, provide information regarding filial therapy training as an intervention with non-offending parents of children who have experienced sexual abuse and also provide information for future research studies with this or a similar population. Of the 18 separate parts listed as hypotheses, 8 were retained, and 10 were rejected. However, all measures showed positive trends, although not at the .05 level of significance. An interpretation of all scores is provided in the following section.

\section{Parental Acceptance}

As can be seen in Tables 2 through 11, the parents in the experimental 
group demonstrated significant increases in their perceived acceptance of their children in one of the four subscales and the total score as measured by the Porter Parental Acceptance Scale (PPAS). The parents reported growth in unconditional love for their children as well as an overall growth in acceptance for their children. In the 1st week of training, the parents reported struggling with what had happened to their children and how the abuse would affect their children. In the 10th week of training, the parents reported that it was easier to let the children be who they were, accept the circumstances as they were and not have to change them or try to make the situation better. One parent commented:

I see my child and the problems she was having differently, not in the same magnitude. To me, the problems seem more normal and everyday childlike. I feel more in control because I have the tools to respond to everyday interactions that seemed monumental before.

Positive gains were shown in the remaining three subscales Respect for the Child's Feelings and the Right to Express Them, Appreciation of the Child's Unique Makeup, and Recognition of the Child's Need for Autonomy and Independence. However, those gains were not significant at the .05 level. As the parents continue the play session, more growth would be expected in these areas.

Although the parents expressed a desire for the children to be able to feel free to talk to them and express feelings, what appeared to be more important to the parents was for their children to talk about the abuse, with the parents focusing on the content. This factor may have inhibited the parents' ability to 
respect their children' feeling and their right to express them. The parents had difficulty allowing feelings to spontaneously emerge. Perhaps they were apprehensive concerning the consequences if emotions were unleashed and fearful that their children would become out of control. Additionally, the parents expressed their own strong feelings about the abuse, particularly significant guilt and anger, making it difficult to experience their children's true emotions. Their own consequences of strong emotion may have also added to their fears. One parent exclaimed the week after an intense session with her child's hitting the Bobo:

I was surprised by the intensity of her actions in hitting the Bobo. At first it was scary. I was curious who Bobo was. Even though she was not able to put words to her actions, I could tell that this was real important to her. Afterwards she was in a calmer mood. I was glad I resisted my temptation to have her tell me how she was feeling and who she was mad at. I am not sure I did a good job of reflecting her feelings, but I did not interfere with them.

At the beginning of training, the parents expressed strong feelings of responsibility for their children' happiness after the children had experienced abuse. The filial therapy training had an obvious positive effect, as stated one parent at the end of 10 weeks:

The training has made me a better listener. I don't feel as guilty about what I can do and can't do. Reflective listening gives me time to really feel what my child is feeling and better understand where she is coming from. 
In the area of autonomy, this group of parents whose children had experienced trauma would naturally be more sheltering and view their role as a protecting parent, prompting them to move more slowly in letting the children be independent. This group of parents very much wanted to become closer to their children and thus may have had difficulty seeing independence as a positive indicator. Several parents discussed their conflicts over the value of autonomy versus wanting to get closer so that the abuse would not happen again. One parent commented at the end of the 10 weeks of training, "I like that it has seemed to make my daughter and I closer. I look at her in a different way than when I started the therapy."

Boundaries are not always healthy in a family in which incest has occurred. One mother described how confusing it was for her to allow her daughter to be in the lead during special play times. Compensating for role reversals between her and her daughter that were imposed by the abuser, she was instructed by professionals to stay in charge. She had become weary of the many power struggles she was experiencing in her attempt to reclaim the mother role. At the end of the 10 weeks of training she exclaimed, "The concept of giving choices is the best thing I learned; I use it all the time. It has removed the power struggle and made us both feel more in control."

The results on the PPAS suggest that a 10 week filial therapy training model is effective in increasing overall parental acceptance among nonoffending parents of children who have experienced sexual abuse. Although the results with parents of sexually abused children may not have gained 
significance in all areas of the PPAS, they support earlier studies in filial therapy (Bratton, 1992/1993; Chau, 1996; Demantatis, 1981; Glass, 1986; GlazerWaldman, 1991; L. Guerney \& Gavigan, 1981; Harris, 1995; Kale, 1997; Lebovitz, 1982; Lobaugh, 1991/1992; Sensue, 1981; Sywulak) that determined filial therapy to be effective with parents in increasing their acceptance of their children.

\section{Parental Stress}

As indicated by the results shown in Tables 12 through 17, the experimental group parents showed significant decreases in their mean total tscores and child domain stress scores as measured by the Parenting Stress Index. Although there was not a significant decrease in stress as measured by the parent domain, the mean scores demonstrated positive trends. The control group parents' reported an increase in stress as measured by the three areas of the Parenting Stress Index.

The experimental group parents expressed significant reservations about their role as a parent and the situation in which they found themselves. They reported feeling stressed and described their world as being turned upside down. Although this group of parents reported feeling personally stressed, their focus was more on how this intervention would help them help their child. Several parents in the groups had recently found out about the abuse and were still intensely involved emotionally and with social services. Several of the abusers were the children's fathers who were now out of the home, leaving the mother (the filial parent) to maintain the home on her own. Mortgages were now made 
on one income; one family was court-ordered to move in with a relative, creating new family dynamics. During the training time, another family moved from their home to an apartment. The court system was an active and often disruptive part of their new lives. One child was admitted to an outpatient program at a hospital. These ongoing stresses and more may have contributed to the lack of significant results on the parent domain of the PSI. However, it is noteworthy that there was a general positive decrease in scores on the parent domain subscale of the PSI. At the end of 10 weeks, the parents of the experimental group appeared to be more accepting of their children and feeling less stressed about their children as evidenced by their significant child domain scores. One parent who, although she recorded significantly high Parenting Stress Index scores, found personal benefit from filial therapy. She reflected on the training:

I think this 10 weeks has been real helpful. While I have been trying to raise my self-esteem, I have been helping my child to be the same she was, a real happy little girl. The play sessions have helped her to do that. I also have benefited by learning to play with my child. That is something I needed.

Another mother commented:

Filial therapy training has helped me to reduce stress by teaching me to not own so much of my child's problems and behaviors. It teaches me clear ways of using choice giving and self-responsibility. It allows me to give up control that I don't want anyway.

The results of the Parenting Stress Index suggest that a 10-week therapy 
training group is an effective treatment for decreasing overall parental stress and stress related to certain characteristics demonstrated in the child. The findings in the present study are similar to those of other studies (Bratton,1992/1993; Chau, 1996; Kale, 1997; Lobaugh, 1991/1992; Tew, 1997; Yuen, 1997) on the effectiveness of filial therapy relating to parental stress. Comparing the parents of children who have been sexually abused and the parents in these other studies, results show that the parents in the present study were unique in that they did not reduce stress on the PSI in the parent domain.

\section{Empathy in Adult-Child interactions}

As can be seen in Tables 18 through 25 the experimental group parents demonstrated significant increases in empathic behavior during observed play sessions with their children as measured by the three subscales of the Measurement of Adult-Child Interaction. The experimental parent group's posttest mean total score $(\mathrm{g}<001)$ decreased a dramatic 27 points, whereas the control group's mean score decreased only 2 points. For this scale, a decrease in the mean score indicates an increase in the desired behavior. The experimental parent group demonstrated increased skill in communicating acceptance, allowing the child self-direction, and being involved with the child during a special play session. These results are of particular interest because they are based on direct observation of specific parenting behaviors by trained professionals rather than self-report instruments.

It is important to note that, whereas the parents in the experimental group demonstrated improved skill in communicating acceptance of their children, 
scores for the control group parents showed a decline in their ability to communicate acceptance. These results, along with the significant scores on the total acceptance of the PPAS, confirm that the experimental group parents not only became more accepting of their children but aiso learned how to communicate this acceptance. The facilitators' observations and the parents' comments also support these results. At the conclusion of the 10 weeks of filial therapy training, one parent, who had difficulty accepting her child's reactive behaviors following the abuse, reflected:

I feel better about myself knowing that I know how to talk to my child. I can respond better than before this training without screaming at my little girl. My daughter has changed more since ... all of this happened. She is now like a new little girl. She does not feel afraid of hugging her daddy, both grandfathers, brothers, uncles, and everybody.

These results in the area of communicating acceptance are of particular importance to the mental health of children who have been sexually abused. According to Stover et al. (1971), the parent's verbal expression of acceptance of the child was the major element in the communication of empathy. This element has been regarded as a measure of success in learning a therapeutic role, yet it rarely occurs in spontaneous interactions between parent and child. The authors of the $\mathrm{MEACl}$ observation instrument also stated that the verbal acceptance of a child's feeling may be an important variable in explaining exceptionally positive or healthy adult-child relationships. For children who have been sexually abused, the development of healthy relationships is important, along with the 
acknowledgment of their feelings. Many of these children have been

manipulated by abusers, then left abandoned and confused as the system

intervened. They have often experienced nonacceptance through interrogations and disregard for their feelings. On the 10th week, one parent talked about the results of communicating acceptance of her daughters feelings:

I liked being able to learn how to help my child realize that I'm here for her when she needs me. Since starting our play sessions, she has opened up a little and was able to tell me something else that had happened that she was afraid to tell me before. It has helped me feel like there is more that I can do myself emotionally to help my daughter regain her self-control.

The significant positive changes indicated by this observational measure suggest that filial therapy parent training is an effective treatment for increasing empathy and involvement, allowing child self-direction, and communicating acceptance in parent-child interactions. The results of this study support earlier investigations in filial therapy that used direct observations to measure empathic behavior in parents as they interacted with their children in play sessions (Bratton, 1992/1993; Chau, 1996; Glover, 1996; B.G. Guerney \& Stover, 1971;

B. G. Guerney et al., 1968; Harris, 1995; Stover et al., 1971).

Problematic Behaviors of Children

Although the children of the parents in the experimental group evidenced fewer behavior problems as measured by the Parent Report of the Child Behavior Checklist, the results were not significant at the .05 level. The movement towards positive trends on the $\mathrm{CBC}$ points to the possibility that filial 
therapy with non-offending parents of children who have been sexually abused facilitates changes in their undesirable behaviors; yet, because the child had the benefit of the intervention for only 7 weeks, there may not have been enough time for change to be significant. A possible explanation could also be that the measuring instrument, the $\mathrm{CBC}$, although being normed on large populations $(\underline{N}=1200)$, is not sensitive to small studies $(\underline{N}=26)$. The findings of the present study were similar to Kale's (1997) study with parents of children experiencing learning difficulties in demonstrating positive trends in decreasing children's problematic behavior through the use of filial therapy training.

Examination of the mean t-scores in all three areas measured by the $\mathrm{CBC}$ showed that the pretest mean t-scores for both the experimental and the control group parents were in the clinical range indicating that they perceived their children's behaviors as problematic. At posttesting, the experimental group parents rated their children' behaviors in the normal range, whereas the control group parents' ratings of their children remained in the clinical or borderline clinical for all three areas measured. This positive trend for the experimental group may indicate that, although the children's behaviors were becoming less problematic, the parents, with their increased acceptance and decreased stress, may also have been viewing their children more developmentally accurately and less hypersensitively. One parent at posttesting commented:

I see the questions on these assessments as possibilities to be more like I would like to be as a parent. I am not as bothered by her behaviors. Before, I looked for any misbehavior as a sign of the abuse. Now, I see it 
as more childhood normal.

\section{Children's Anxiety}

Although there was a positive decrease in anxiety of the children whose parents participated in filial therapy training as measured by the Child Anxiety Scale, the results were not significant at the .05 level. The control group children's mean sten scores increased, indicating a trend toward an escalation of anxiety. These results may indicate that the 7 weeks during which the children were involved in the special play times was not enough time to demonstrate significant change. Upon closer examination, the mean sten scores in the preand posttest for both the experimental and control group children were in the average range. This may indicate the absence of anxiety for this group.

\section{Children's Self-Concept}

Although there was a positive increase in self-esteem of the children whose parents participated in filial therapy training as measured by the Joseph Pre-School and Primary Self-Concept Screening Test, the results were not significant at the .05 level. An examination of the self-concept scores revealed a markedly low self-concept for both the experimental and control groups. The 7 weeks during which the children experienced the special playtime with their parents may not be enough time to impact change in the perception-of-self for this group. However, Lobaugh (1991/1992) found that children of incarcerated fathers demonstrated an increase in self-esteem in the same amount of time. This may suggest that the intensity of trauma is an element to consider when examining children's self-esteem. The clinically low results found in this study 
may indicate the severity of sexual abuse on children's self-esteem. Posttest results may also indicate that a challenge is present when helping sexually abused children overcome low self-esteem in a short period of time. The individual test scores of the 26 children tested were examined to determine if there was any pattern. No overall patterns were evident. However, some test questions were noted as not appropriate for some of the individual cases. For example, questions relating to how high a child can jump and how fast a child can run were not appropriate for one child who was confined to a wheel chair. Also during posttesting, one child answered negatively to a question about being a winner or a loser after coming from losing a Little League baseball game. The answer may not have been an accurate assessment of how he felt about himself; it may have been simply the result of an event that had just occurred. Emotional Disturbance

Tables 36 and 37 show that, although there was a positive decrease in mean t-scores in emotional disturbance of the experimental group children as measured by the Draw A Person: Screening Procedure for Emotional Disturbance (DAP:SPED), there was also a positive decrease in the control group children. Difficulty was found in using this instrument. Age norms required the sample size to be decreased, which may have affected the significance of the results. Scores for the experimental group were in the normal range, indicating that further evaluation is not warranted, which leaves little chance for change to occur. Another consideration that this instrument may not have been useful in examining the enhancement of emotional adjustment in sexually 
abused children in the present study is the developmental aspects of the children's drawings. The DAP:SPED's standardization samples with 5-year-olds was not large enough to constitute a separate norm. To retain the largest sample size possible, the 5-year- olds in the filial therapy training study were included in the 6-year-old norms. This may have skewed the results.

\section{Observations}

Non-offending parents of children who have been sexually abused have a unique parenting role. They must sort through their feelings as they strive to facilitate healing in children with uncommon experiences. Parents who volunteered for this study were seeking novel means to support their children while pursuing innovative methods to maintain a stable environment. As a group, they initiated an interesting, rewarding, and challenging task for the facilitator.

Parents in the filial therapy training presented with a mixture of enthusiasm, skepticism, eagerness, and intensity. Attendance was sporadic, but, their motivation to help their children was never doubted. They took turns missing, always giving excuses, usually the products of life in chaos. Each session missed was made up so that they would all have the same knowledge and, it was hoped, be moving at the same level. What could not be duplicated was the group dynamics that offered so much richness. Because each parent was at a different stage of the journey with their child, they gained different perspectives as they told their stories. For some, the telling of the abuse was an ever-occurring need; others appeared to have a strong desire to move on. As the facilitator, I noticed a tendency to be drawn into the emotional content and 
found it an ongoing struggle to refocus and redirect.

Feeling compelled to meet the emotional needs of those in the group, I reminded myself also of the importance of the didactic aspect of the group. Balancing the two was a challenge as court dates came up, divorces were finalized, and a family car was repossessed initiated by the spouse in jail. Many of the parents were attending other groups to address the abuse, but they sometimes had difficulty not monopolizing the filial therapy group with unresolved needs. One parent commented, "I felt sometimes some people went a little over on their personal situations and others were cut-off at times and not able to expand as much. Others I felt needed to talk more and time did not always permit."

Because the children were an integral part of these parents' lives and many parents felt uncomfortable leaving them in the care of others, babysitting was important. Activities were provided, and the children seemed to enjoy getting together each week. Most of these families had busy schedules, and the addition of one more night was a sacrifice. Snacks were provided for both the parents and children and seemed to be genuinely appreciated and enjoyed by all.

For some, the logistics of videotaping the play session was an obstacle. Each parent was asked to bring in one videotape of a play session during the 10 weeks to view and to discuss with the group. Those who did not own a camcorder were recommended to check with friends to borrow one. Several of the parents needed the facilitator to arrange to videotape the play session, which may suggest a helplessness or degree of isolation that may be a component of 
the functioning level for parents in this population. Overall, the parents seemed determined not to let the experience of sexual abuse take over their lives.

From these experiences and observations, the following suggestions are offered for consideration in the formation and facilitating of filial therapy training groups with non-offending parents of sexually abused children:

1. The facilitator should allow for the emotional needs of the parents and the hectic schedules of the families (typical childhood activities coupled with ongoing social services); the pace of the training may need to be slowed down and perhaps intensified. Meeting twice a week at first and lengthening the duration of weeks, then spreading the lessons out as the parents become more proficient in skills should facilitate greater support and more in-depth learning.

2. An integrated approach with Child Protective Services could overlap and better define the didactic/dynamic content of filial therapy.

3. The facilitator should allow parents the opportunity to express their emotions while teaching them the value of putting these emotions aside appropriately as they attend to the tasks of the group. Additional time could be allotted, either before or after group meetings, to discuss more personal topics as an option for those who desired to attend.

4. The facilitator should recognize the importance of structuring the lessons so that each parent can learn the skills needed for growth.

5. The facilitator should pay close attention to the dynamics of the group while recognizing personal strengths and weaknesses in leading the group.

6. The groups should be kept small (5-6) to allow for trust, interpersonal 
dynamics, and more time to share.

7. The children could be used for live demonstrations and practice with the parents.

8. The facilitator could provide parents with the equipment to videotape their play sessions and/or give live feedback.

9. The children's babysitting could be combined with activities that promote their well-being.

\section{Implications}

The results of this study, along with the facilitator's observations and the parents' comments, indicate that filial therapy training is an effective method for use with non-offending parents of children who have experienced sexual abuse. The parents demonstrated their ability to learn therapeutic skills by extending empathy and acceptance to their children in special playtime. Overall, the parents reported an increase in acceptance of their children, both inside and outside the special play times. The parents also reported a decrease in stress and in turn adopted a new perspective of their role in their children's lives. Reporting that they felt empowered by parenting skills designed to enhance the children's self-direction and responsibility, the parents were enthusiastic as they related the benefits they experienced in positive interactions with their children.

These results suggest that the non-offending parents in this study were able to employ a more therapeutic role with their children during the special play sessions. In acquiring the basic skills of empathy and acceptance, skills fundamental to the therapeutic role, the non-offending parents gained the ability 
to be proactive in their children's mental health and well-being following a traumatic experience. Children benefit greatly when parents are actively involved in their lives.

\section{Recommendations}

Based on the results of this study, the following recommendations are offered:

1. Filial therapy training an be used as a viable intervention for the nonoffending parents of children who have experienced sexual abuse.

2. Follow-up research with the subjects from this study examining the effectiveness of filial therapy in 6 months from completion of training using the same instruments utilized in this study.

3. Families recovering from recent trauma need more time to implement the skills they have learned and gain desired support for unique issues. Further research might design an approach in which filial therapy training is coupled with additional intensive support groups to address unique needs. The design may benefit from condensing the first four training sessions into four sessions over two weeks, moving into the play session more quickly, and extending the training to include five additional sessions.

4. Further research could be done in which sexually abused children's art is objectively measured by the investigator before and after the filial therapy training. Such studies might include the development of a subjective art assessment instrument that is valid for the age group (3-10) commonly seen in filial therapy training. 
5. Further research might investigate the use of filial therapy training with a population, using a broader definition of trauma and comparing the results with this study.

6. Further research might examine the significance incorporating parallel programs for parent and child to increase the intensity of filial therapy training as an intervention. Such studies might involve the programs already in place at Child Protective Services and similar agencies and include redesigning the format such as adding more sessions or condensing the spacing of the sessions.

7. Further research might include a longitudinal study to determine the long-term effects of filial therapy training with non-offending parents of children who have experienced sexual abuse.

8. Further research might examine the effectiveness of filial therapy training when more than one significant adult works with a child who has experienced sexual abuse, such as an additional parent, a step-parent, foster parents, grandparents, or others.

9. Further research could be done comparing the effectiveness of filial therapy to other types of intervention commonly used with children who have experienced sexual abuse, such as individual and group therapy.

10. Further research might investigate the effectiveness of filial therapy with noncustodial parents of children who have experienced sexual abuse. Such a study might examine how filial therapy training might affect noncustodial parents working towards reunification. 
Conclusion

Filial therapy training is a practical and valid intervention for non-offending parents of children who have experienced sexual abuse. The training provides both support and educational possibilities. As society's awareness of the impact of childhood sexual abuse grows, the need for effective treatment increases. Social services are charged with ensuring that the child will be protected after abuse is reported. Parents, or the non-offending parent in cases in which the abuse is intrafamilial, are charged with picking up the pieces. They often are not prepared for this task, bearing the burden additionally of their own emotional content. Relationships are altered by the presence of sexual abuse, whether the abuse occurred intra-or extrafamilial. The child frequently suffers from low selfesteem, which is manifested through physical, emotional, and behavioral disturbances.

Filial therapy training provides parents with skills that will enhance their relationship with their children and assist them in adopting a therapeutic role. Healthy relationships are a benefit to both the parent and child as they heal from the traumatic experience of abuse. Filial therapy training guides and instructs parents in skills designed to listen to the child's inner world. Parents learn to communicate empathy and acceptance, creating an environment in which sexually abused children may thrive. As children feel more understood, they can begin to accept, trust, and depend on themselves. Parents are empowered by assisting their children to become more self-reliant. Filial therapy training extends significant opportunities for parents of children who have experienced sexual abuse to engage proactively in the future well-being of their children. 
APPENDIX A

LETTER OF AGREEMENT

FROM CHILD PROTECTIVE SERVICES 
EXECUTTVE DIRECTOR

BOARD MEMBERS

James R. Hine

Jon M. Bradiey

Chairman, Dallas

Penny Beaumont

Bryan

September 29, 1997

Maurine Dickey

Dallas

Richard S. Hoffman

Brownsville

Catherine Clark Mosbacher

Housion

Mary B. Costas, M.Ed.

Bill Sheetian

Doctoral Candidate

Dumas

Department of Counseling, Development and Higher Education

University of North Texas

Denton, Texas 76203-6857

Re: Research Proposal

Filial Therapy with Non-Offending Parents

of Sexually Abused Children

Dear Ms. Costas:

I have reviewed your written research proposal, and have discussed with you the plans for carrying out the proposal. I have accepted your proposal and have agreed to work with you and this study.

I understand that you plan to work with TDPRS clients who volunteer to participate in your study. No information will be given to you about a client by TDPRS until that client has expressed an interest in participating. The client will be introduced to your study through a letter of introduction prepared by you. At that point the client can choose to waive his or her right to confidentiality, and talk with you about the study. I understand that you are developing an "informed consent" form for the parent and child to sign indicating they understand and consent to participate in the study. The client could choose not to sign the "informed consent" and can decide to withdraw from the study at anytime.

Please contact me at 817/534-1002 if I can be of assistance.

Sincerely,

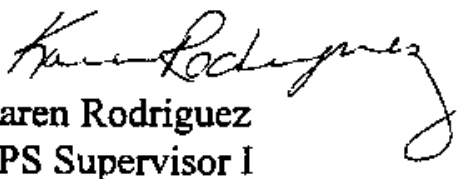

CPS Supervisor I 
APPENDIX B

\section{MARKETING SAMPLES}


EXECUTIVE DIRECTOR

James R. Hine

August 14, 1997

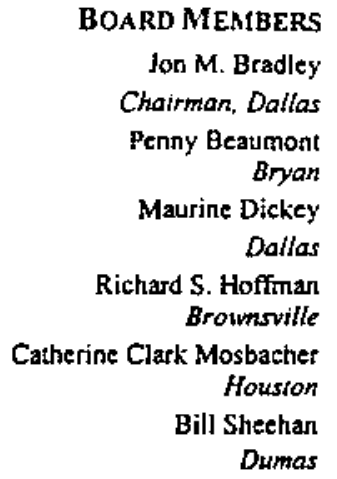

Jon M. Bradley

Chairman, Dallas

Bryan

Dallas

S. Hoffman

osbachet

Dumas

Dear Parents,

I am writing to let you, as parents who participated in or who were referred to the Child Protective Services Group Treatment Program, know about a special opportunity for you and your child. The attached flyer provides you with information regarding a unique parent training/support group that is going to be offered in Tarrant County, in connection with the University of North Texas. I would like you to consider being part of this group.

The group is being offered to help you as parents help your child. Mary Costas, a University of North Texas Ph.D. candidate, who specializes in child ' 'Td family counseling will be the group facilitator. I would highly recommend you consider $t . . . \quad$ - part of this unique opportunity. I know you want to better the relationship you have $u . . .$. , uur child and this group will help you to help them to grow and develop into better individuals and citizens.

As the flyer states, you may call me (534-1002, ext. 397) or Mary Costas (817/565-2066) to sign up for the group. You may also call us if you have any questions before making a final decision.

Please do not delay, as the group starts soon.

Sincerely,

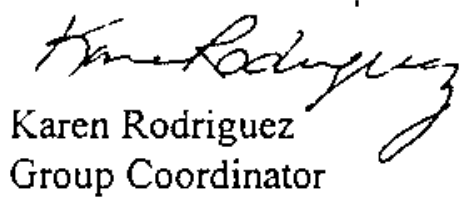




\section{University of North Texas}

College of Education

Child and Family Resource Clinic

January 15, 1998

Dear

I am enclosing information about exciting research being conducted in the Department of Counseling, Development, and Higher Education at the University of North Texas. The study is designed to assist parents of children who have experienced trauma (sexual and/or physical abuse, significant loss, medical trauma, etc.). I am asking you to read the enclosed information and identify clients who would benefit from the study. Please pass the information to them or with their permission, contact me with their name so I may contact them. All information will be treated with strict confidentiality. Groups are being formed now and are limited.

You will find the following for your use:

$$
\begin{aligned}
& \text { General Information on Filial Therapy (green) } \\
& \text { Description of the Study (purple) } \\
& \text { Client Flyer for Additional Copies (white) } \\
& \text { Multiple Copies of Flyer for Clients (lime green) }
\end{aligned}
$$

Groups were conducted this fall and the response at the conclusion was overwhelmingly positive. The parents described feeling more empowered and confident in their role as a parents, hei 'ing them to help their children heal from their unique experiences. These groups are a wonder:al opportunity for parents of children who have been traumatized to access additional resources and receive free services.

Please recommend this opportunity personally to appropriate clients as I have found that they are more inclined to inquire for more information when recommended by someone they know. Please do not hesitate to call me if you have any questions.

Thank you for your time. Your assistance will contribute greatly to the field of mental health.

Sincerely,

Mary B. Costas

Doctoral Candidate 


\author{
Mary Costas, M.Ed., LPC \\ University of North Teras-Doctoral Candidate \\ Child and Family Resource Clinic-Assistant Director of Counseling Services \\ 817-565-2066 (Work) \\ 817-236-7927 (Home)
}

\title{
FILIAL THERAPY
}

Filial Therapy: Developed by Bernard Guerney in the early 1960's in response to the growing demand for and unavailability of mental health services for children and their families (influenced by Axline's work with children in child-centered play therapy).

Definition: A therapeutic intervention that can heip children by teaching parents psychological principles and training them as therapeutic agents. Parents are trained to become a constructive force for change in their children's behaviors and attitudes by utilizing basic play therapy principles in weekly play sessions with their children. Utilizing a support group format in combination with didactic instruction, parents learn to convey acceptance, empathy, and encouragement to their children: as well as master the skills of effective limit setting.

\section{Rationale:}

- Allows helping professionals to effectively assist more individuals.

- Preventative treatment, as well as intervention.

- Assumes parents can learn the necessary therapeutic skills to be effective, focusing on conveying unconditional acceptance and empathy.

- Utilizes the naturally existing bond between parent and child, based on the assumption that the parent has more emotional significance to the child than does the therapist and the potential to continue to influence the child positively for a long time.

- Utilizes play, children's natural and spontaneous way of expressing and mastering their world.

- Utilizes an educational model in combination with a support group format, based on the assumption that most of the difficulties that parents experience with children arise from a lack of knowledge and/or skill and that parents need emotional support to begin to make changes as they acquire new knowledge/skills, just as their children do.

- Acknowledges the vital importance of the child-parent relationship. Enriching and strengthening parent's relationship with their children is the foundation for children's

$\therefore$ future happiness and success.

- Anxieties learned or influenced by parental attitudes can be more effectively worked through under similar conditions.

- Empowers parents to help their children; thereby avoiding the potential feelings of guilt and belplessness parents may develop when dependent upon a professional for problem resolution. 


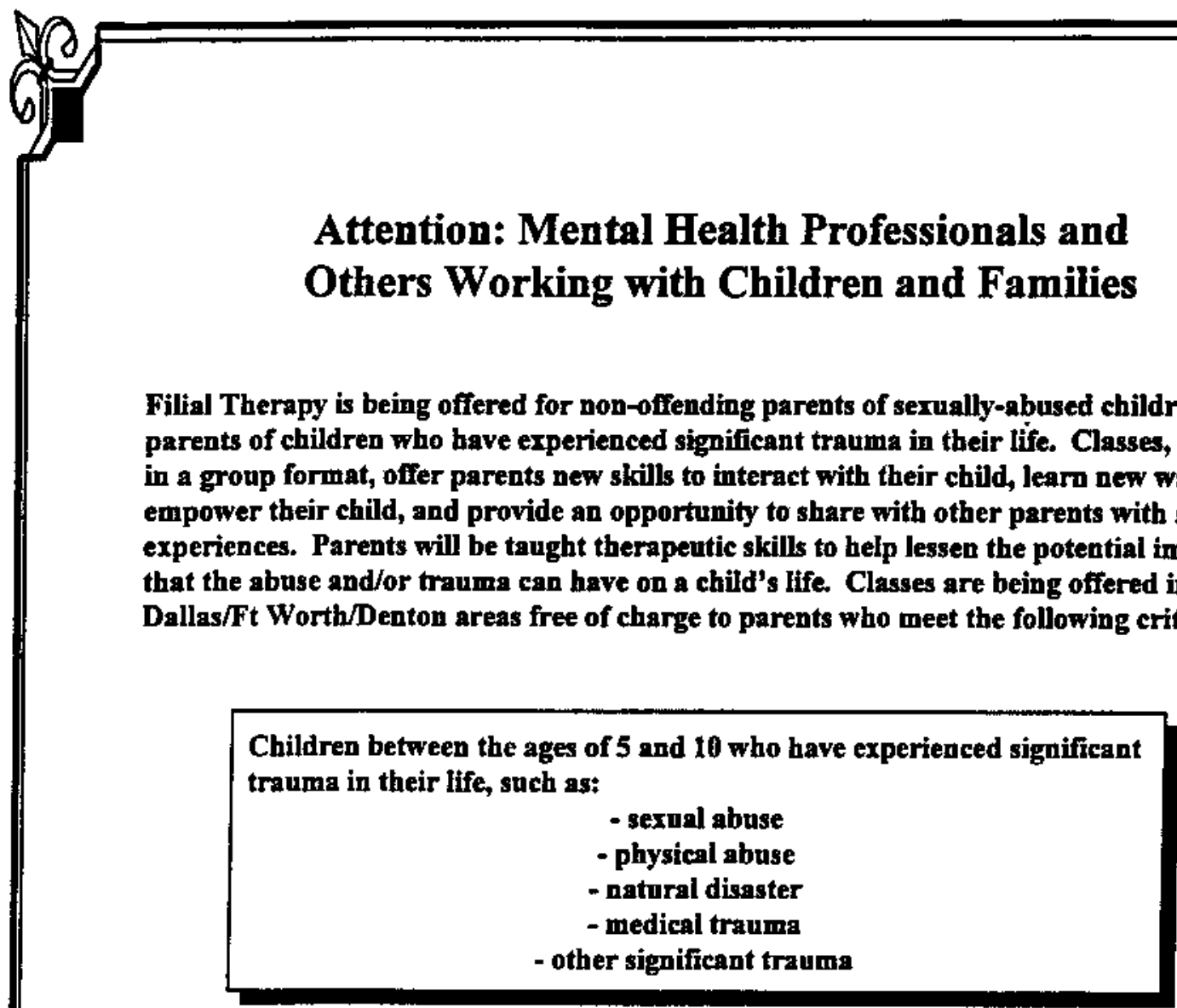

If you have clients who are interested please call the Child and Family Resource Clinic at (940) 565-2066 or Mary Costas at (817) 236-7927. 


\title{
ATTENTION PARENTS OF CHILDREN WHO HAVE EXPERIENCED SEXUAL ABUSE OR SIGNIFICANT TRAUMA
}

\author{
Recent research has shown that you, the parent, can make a significant \\ contribution to your child's healing, emotional adjustment, and development.
}

In today's world, being a parent is a challenge, especially when a child's experiences are unique and may require special attention. As a parent of a child who has experienced sexual abuse or significant trauma (such as physical abuse, natural disaster, medical trauma, loss of parent, etc.), you may face that challenge in many different areas of your child's life. Whether your child is showing outward signs of behavior difficulties or has adjusted with little difficulty, the experience becnmes a significant part of their life. Like most parents you probably feel at a loss in how to best help your child. WE CAN TEACH YOU HOW TO BELP YOUR CHILD with many behavioral problems such as lack of self-control, withdrawn, fear, bed wetting, anger outbursts, etc.

A unique parent training/support group that focuses on specific strategies for helping you help vour child is being offered. The training and support groups ( 5 parents per group) will be beld once a week for 10-weeks and will be open to parents of children ages 5 to 10. The first 20 participants will receive a special box of toys valued at $\$ 50.00$ for use with their child. The training is FREE and will be led by Mary Costas, a University of North Texas Ph.D. candidate, who specializes in child and family counseling. These classes will train parents how to be therapeutic with their children and can be useful as a preventative treatment as well as an intervention. Learn how to help your child learn selfdiscipline, gain self-control, build self-esteem, and increase attention span. As a parent, you will regain control and reduce stress.

If you are interested in receiving more information about these special parent training and support groups please call Mary Costas at (940) 565-2066 (work); (817) 236-7927 (home); or (817) 824-9360 (beeper). New groups will be forming in January and enrollment is limited. Parents will be accepted on a first come first served basis. 


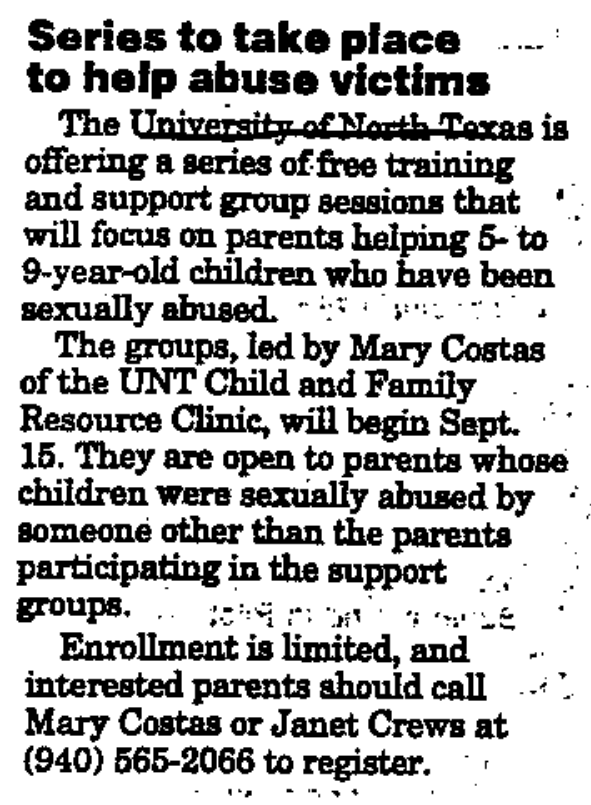

\section{Training groups offer support to parents of abused children}

A Luththue parent training/support group that focuses on specific strategies for helping parents help their child is being offered.

The training and support groups will be held once $\vec{a}$ week for 10 weeks and will be open to non-offending parents of sexually abused children ages 5 to 9 . The free groups will be led by Mary Costas, a clinical supervisor at the Child and Family Resource Clinic at the IIniversitv of North Texas. who specializes in child and family counseling.

Benefits of this training include a better relationship with your child, a greater understanding of your child and his or her uniqueness, a better sense of your abilities as a parent and an improvement in your child's self-esteem.

If you are interested in receiving more information about these special parent training and support groups please call Mary Costas or Janet Crews at Child and Family Resource Clinic at (940) 565-2066. Even though the groups do not begin until Sept. 11, please call ASAP as enrollment is limited. Parents will be accepted on a first-come, first-served basis. 


\section{APPENDIX C}

PARENTING CLASS INFORMATION AND CONSENT FORMS 


\section{PARENTING CLASS INFORMATION}

You are invited to participate in a study to determine the effectiveness of Filial Therapy training with parents of children who have been sexually abused. You will be asked to complete three questionnaires before and after the training. Your child will be interviewed to complete three questionnaires before and after training. You will also be asked to participate in a 20-minute videotaped play session with your child before and after training.

Filial Therapy is a family skills training program that focuses on enhancing the parent-child relationship. The training will consist of ten weekly sessions, lasting two hours per week. During the sessions, the group leader will be teaching you and other parents some techniques on how to interact with your child in ways that will enhance your child's self-esteem as well as strengthen your relationship with your child. You will be asked to share some insights, feelings, questions, and comments with the other participants in the group, during the sessions. You will also be asked to participate in seven weekly 30-minute play sessions at home with your child practicing the techniques being taught in the training sessions.

There is no personal risk or discomfort directly involved with this study. You will be asked to give some of your time, and to be willing to explore some new ideas and feelings related to the parenting of your child. There may be times during the play sessions when your child could express sadness, anger, or frustration. While these sessions cannot avoid these situations, neither will they increase the emotion. In fact, the training should help you deal with these situations more effectively. Your participation and your child's participation is completely voluntarily. You may withdraw at any time without penalty or prejudice.

The information you provide when you answer the questionnaire will be kept confidential. Your name and your child's name will not be disclosed in any publication or discussion of this material. Information obtained from the questionnaires will be recorded with a code number. Only the investigator, Mary Costas, will have a list of participants' names. At the conclusion of this study the list of participants names will be destroyed.

If you are not selected to receive the training during this first training period, your name will be placed on a waiting list and you will be contacted regarding a second section of training which will be offered after the completion of the first 10-week section.

If you agree to participate, please fill out and sign this consent form. For further information, please contact, Mary Costas, researcher, at (817) 565-2066, or Dr. Garry Landreth, Faculty Supervisor, at (817) 565-2916. 


\section{PARENTING CLASS \\ Informed Consent}

You are making a decision whether or not to participate in this study. You should sign only when you understand all the information presented on the front of this form and all your questions about the research have been answered to your satisfaction. Your signature indicates that you meet all the requirements for participation as explained by Mary Costas and have decided to participate, having read the information on the front of this form.

Signature of Participant Age Date

Name of Child of Focus Age

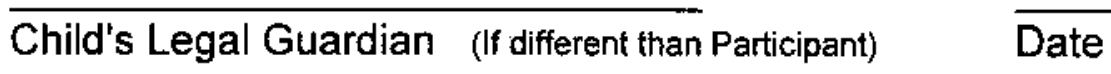

Signature of Witness

Date

Signature of Investigator

Date

This project has been reviewed and approved by the University of North Texas Institutional Review Board for the protection of human subjects (817)565-3940. 


\section{CHILD'S FORM \\ Informed Consent}

I understand that I am going to be part of a project with an adult who takes care of me (mom, dad, or another significant care giver). The adult will be taking some classes to learn how to play with me in some new ways. For seven weeks, I will have special play sessions with this adult in my home for 30 minutes once each week. I understand that I can stop taking part in this project at any time I choose. My "mark", or signature, means that I understand what has explained to me and that I am willing to be part of this project.

Signature of Child

Date

Name of Child

Age

Signature of Parent

Date

Signature of Investigator

$\overline{\text { Date }}$

This project has been reviewed and approved by the University of North Texas institutional Review Board for the Protection of human subjects (817)565-3940. 
APPENDIX D

DEMOGRAPHICS DATA FORM 
PARENTING CLASS INFORMATION

Adult's Name Child's Name

Relationship to Child Child's DOB Age __ Gender:_M_F

Adult's DOB Age _ Marital Status: __ Married _ Separated__ Divorced__ Widowed _. Other (explain)

Ethricity: (indicate a=adult; c=child) Caucasian _ African American _ Hispanic/Latin __ Asian _ Native American _ Bi-racial__ Other (explain)

Street Address

Phone \# $(1$ City Zip Code (HM) $\overline{(W K}$

Gross Household Annual Income:

_Less than 15,000

$-18,001-20,000$

$-24,001-26,000$

- $31,001-34,000$

$15,000-16,000$
$-20,001-22,000$
$-26,001-28,000$
$-34,001-39,000$

$-16,001-18,000$

$-22,001-24,000$

$28,001-31,000$

$-40,000+$

Adult's Educational Level:

_8th Grade or Below _ Some College

_High School

-GED

-Trade School

-College Graduate

-Master's Degree

-Ph.D. Degree

Have you attended parenting classes? _ Yes _ No; When? What?

What trauma has your child experienced? _ Sexual Abuse; _ Physical Abuse; _ Family

Violence;

_ Medical; _ Loss of significant care giver; _ Other: Explain

Age of child at onset of trauma ____ Length of trauma

Severity of trauma for your child, by your estimation $\overline{(\text { Circle one) }}$ Mild 12345678 Intense

If child was abused, was it reported? _._Yes_No To Whom?

Relationship of offender with offender? _ Yes _.. No Does your child have present contact

Is your child presently in counseling? _. Yes _ No Where?

Type and length of counseling

Are you presently in counseling? _ Yes _. No Where?

Type of counseling Are parenting issues addressed? _ Yes No 


\section{APPENDIXE \\ LETTER OF PERMISSION TO USE \\ THE PORTER PARENTAL ACCEPTANCE SCALE}




\section{BLAINE R PORTER \\ BRIGHAM YOUNG UNIVERSITY \\ 1675 PINE LANE \\ PROVO, UTAH 84604-2163 \\ Tel (801) 377-2411 Fax (801) 375-5115 \\ E-Mail brporter@cougar.netutah.net}

April 27, 1998

Mary Costas

7705 Woodside Hill

Fort Worth, TX 76179

Dear Ms. Costas

I am pleased to learn of your interest in using the Porter Parental Acceptance Scale in your research. I am pleased to grant you permission to use it. I will appreciate it if you will send me an abstract or summary of the results of your study when it is completed.

Best wishes for success in your research.

Sincerely yours,

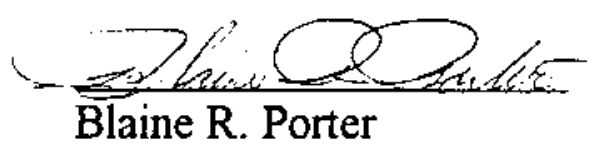

$\mathrm{BRP} / \mathrm{ms}$ 


\section{APPENDIX F}

PORTER PARENTAL ACCEPTANCE SCALE 
PORTER PARENTAL ACCEPTANCE SCALE

We are trying to learn more about parent-child relationships. Please assist us by filling out this questionnaire as frankly and as carefully as possible. Your answers will be absolutely confidential. You have been asked to focus on only one child during this training...please think only of that child as you answer these questions. Please answer all questions. If you cannot give an exact answer, answer the best you can.

INFORMATION ABOUT YOUR CHILD

Many parents say that their feelings of affection toward or for their child varies with the child's behavior and with circumstances. Please read each item carefully and place a check in the column which most nearly describes the degree of feeling of affection which you have for your child in that situation.

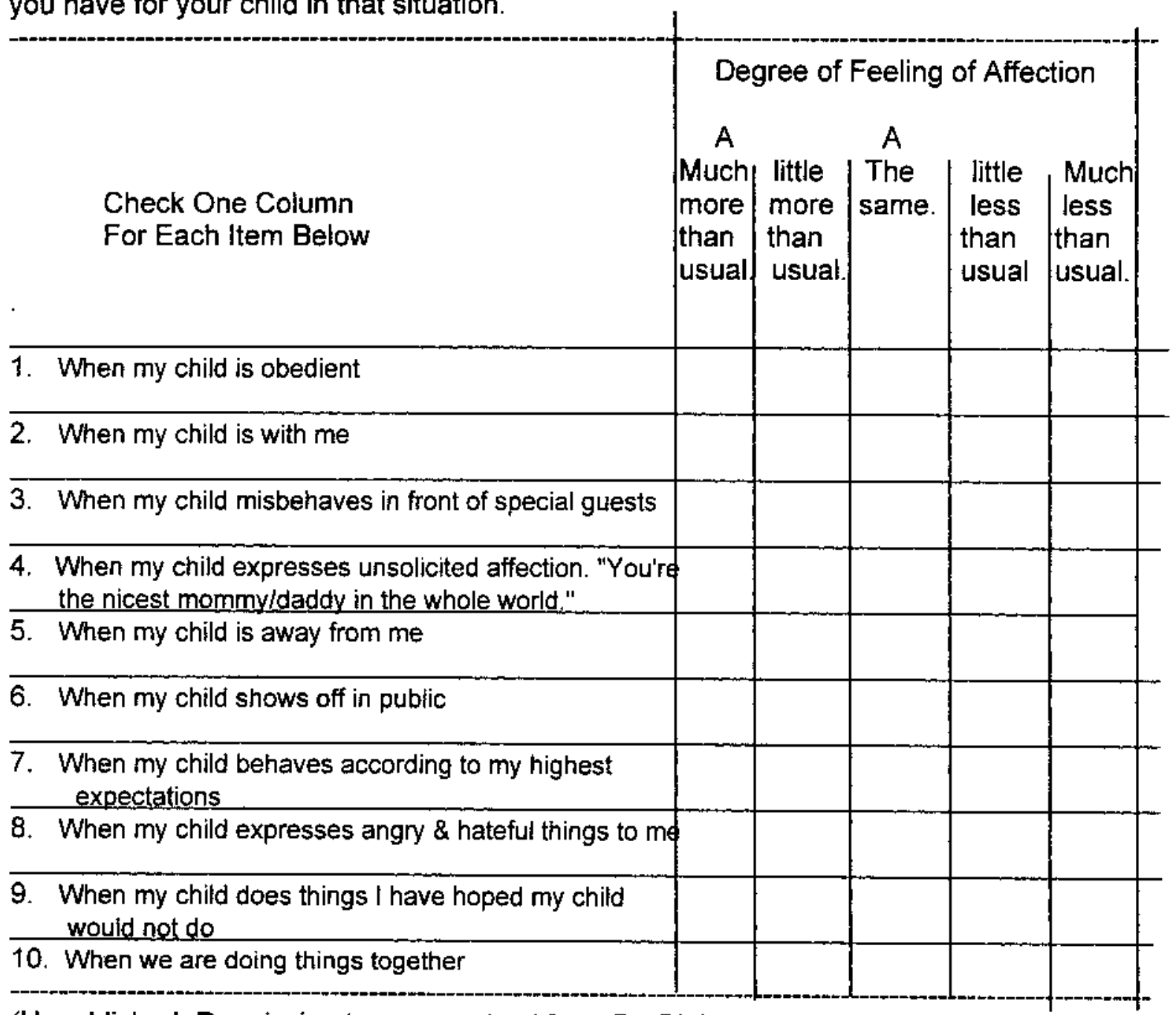

(Unpublished: Permission to use received from Dr. Blaine Porter, Brigham Young University.) 
Listed below are several statements describing things which children do and say.

Following each statement are five responses which suggest ways of feeling or courses of action.

Read each statement carefully and then place a circle around the number in front of the one response which most nearly describes the feeling you usually have or the course of action you most generally take when yourchild says or does these things.

It is possible that you may find a few statements which describe a type of behavior which you have not yet experienced with your child. In such cases, mark the response which most nearly describes how you think you would feel or what you think you would do.

Be sure that you answer every statement and mark only one response for each statement

11. When my child is shouting and dancing with excitement at a time when I want peace and quiet, I:
a. feel annoyed.
b. want to know more about what excites my child.
c. feel like punishing my child.
d. feel that I will be glad when my child is past this stage.
e. feel like telling my child to stop.

12. When my child misbehaves while others in the group are behaving well, I:
a. see to it that my child behaves as the others.
b. tell my child it is important to behave well when in a group.
c. let my child alone if the others are not disturbed by the behavior.
d. ask my child to suggest an alternate behavior.
e. help my child find an alternate behavior to enjoy while not disturbing the group.

13. When my child is unable to do a thing which I think is important for him/her, I:
a. want to help my child find success in other things.
b. feel disappointed in my child.
c. wish my child could do it.
d. realize that my child can not do everything.
e. want to know more about the things my child can do.

14. When my child seems to be more fond of someone else (teacher, friend, relative) than me, l:
a. realize that my child is growing up.
b. am pleased to see my child's interests widening to other people.
c. feel resentful.
d. feel that my child doesn't appreciate what I have done for him/her.
e. wish my child liked me more. 
15. When my child is faced with two or more choices and has to choose only one, I:

a. tell my child which choice to make and why.

b. think it through with my child.

c. point out the advantages and disadvantages of each, but let my child decide.

d. tell my child that I am sure he/she can make a wise choice and help my child foresee the consequences.

e. make the decision for my child.

16. When my child makes decisions without consulting me, I:

a. punish my child for not consulting me.

b. encourage my child to make many of his/her own decisions.

c. allow my child to make many of his/her own decisions.

d. suggest that we talk it over before he/she makes the decision.

e. tell my child he/she must consult me first before making a decision.

17. When my child kicks, hits, or knocks his/her things about, l:

a. feel like telling my child to stop.

b. feel like punishing him/her.

c. am pleased that my child feels free to express himself/herself.

d. feel that I will be glad when my child is past this stage.

e. feel annoyed.

18. When my child is not interested in some of the usual activities of his/her age group, I:

a. realize that each child is different.

b. wish my child were interested in the same activities.

c. feel disappointed in my child.

d. want to help my child find ways to make the most of his/her interests.

e. want to know more about the activities in which my child is interested.

19. When my child acts silly and giggly, I:

a. tell my child I know how he/she feels.

b. pay no attention to him/her.

c. tell my child he/she shouldn't act that way.

d. make my child quit.

e. tell my child it is all right to feel that way, but help him/her find other ways of expression.

20. When my child prefers to do things with his/her friends rather than with the family, 1 :

a. encourage my child to do things with his/her friends.

b. accept this as part of his/her growing up.

c. plan special activities so that my child will want to be with the family.

d. try to minimize his/her associations friends.

e. make my child stay with the family.

21. When my child disagrees with me about something which I think is important, l:

a. feel like punishing him/her.

b. am pleased that my child feels free to express his/her thoughts and feelings.

c. feel like persuading my child that my way is best.

d. realize my child has ideas of his/her own.

e. feel annoyed. 
22. When my child misbehaves while others in his/her group are behaving well, I:

a. realize that my child does not always behave as others in his/her group.

b. feel embarrassed.

c. want to help my child find the best ways to express his/her feelings.

d. wish my child would behave like the others.

e. want to know more about his/her feelings.

23. When my child is shouting and dancing with excitement at a time when I want peace and quiet, I:

a. give my child something quiet to do.

b. tell my child that I wish he/she would stop.

c. make my child be quiet.

d. let my child tell me about what is so exciting.

e. send my child somewhere else.

24. When my child seems to be more fond of someone else (teacher, friend, relative) than me, I:

a. try to minimize my child's association with that person.

b. let my child have such associations when I think he/she is ready for them.

c. do some special things for my child to remind him/her of how nice I am.

d. point out the weaknesses and faults of the other person(s).

e. encourage my child to create and maintain such associations.

25. When my child says angry and hateful things about me to my face, I:

a. feel annoyed.

b. feel that I will be glad when my child is past this stage.

c. am pleased that my child feels free to express himself/herself.

d. feel like punishing my child.

e. feel like telling my child not to talk that way to me.

26. When my child shows deep interest in something I don't think is important, I:

a. realize my child has interests of his/her own.

b. want to help my child find ways to make the most of this interest.

c. feel disappointed in my child.

d. want to know more about my child's interests.

e. wish my child were more interested in the things I think are important for him/her.

27. When my child is unable to do some things as well as others in his/her group, I:

a. tell my child he/she must try to do as well as the others.

b. encourage him/her to keep trying.

c. tell my child that no one can do everything well.

d. call attention to the things he/she does well.

e. help my child make the most of the activities which he/she can do well. 
28. When my child wants to do something which I am sure will lead to disappointment for him/her, 1:

a. occasionally let my child carry such an activity to its conclusion.

b. don't let my child do it.

c. advise my child not to do it.

d. help my child with it in order to ease the disappointment.

e. point out what is likely to happen.

29. When my child acts silly and giggly, I:

a. feel that I will be glad when he/she is past this stage.

b. am pleased that my child feels free to express himself/herself.

c. feel like punishing my child.

d. feel like telling him/her to stop.

e. feel annoyed.

30. When my child is faced with two or more choices and has to choose only one, I:

a. feel that I should tell my child which choice to make and why.

b. feel that I should point out the advantages and disadvantages of each.

c. hope that I have prepared him/her to choose wisely.

d. want to encourage my child to make his/her own choices.

e. want to make the decision for my child.

31. When my child is unable to do something which I think is important for him/her, I:

a. tell my child he/she must do better.

b. help my child make the most of the things which he/she can do.

c. ask my child to tell me more about the things which he/she can do.

d. tell my child that no one can do everything.

e. encourage him/her to keep trying.

32. When my child disagrees with me about something which I think is important, I:

a. tell my child he/she should not disagree with me.

b. make my child quit.

c. listen to my child's side of the issue and change my mind if that seems reasonable.

d. tell my child maybe we can do it his/her way another time.

e. explain that I am doing what is best for him/her.

33. When my child is unable to do some things as well as others in his/her group, l:

a. realize that my child can't do as well as others in everything.

b. wish that my child could do as well.

c. feel embarrassed.

d. want to help my child find success in the things he/she can do well.

e. want to know more about the things my child can do well. 
34. When my child makes decisions without consulting me, I:

a. hope that I have prepared my child adequately to make his/her

decisions.

b. wish that my child would consult me.

c. feel disturbed.

d. want to restrict his/her freedom.

e. am pleased to see that as my child grows, I am needed less.

35. When my child says angry and hateful things about me to my face, I:

a. tell my child it is all right to feel that way, but help him/her find other

ways to express himself/herself.

b. tell my child I know how he/she feels.

c. pay no attention to him/her.

d. tell my child he/she shouldn't say such things to me.

e. make my child quit.

36. When my child kicks, hits, and knocks his/her things about, I:

a. make my child quit.

b. tell my child it's alright to feel that way, but help him/her find other ways of expressing him/herself.

c. tell my child he/she shouldn't do such things.

d. tell my child I know how he/she feels.

e. pay no attention to him/her.

37. When my child prefers to do things with friends rather than with the family, I:

a. wish my child would spend more time with us.

b. feel resentful.

c. am pleased to see my child's interests widening to other people.

d. feel my child doesn't appreciate us.

e. realize that he/she is growing up.

38. When my child wants to do something which I am sure will lead to disappointment, I:

a. hope that I have prepared him/her to meet disappointment.

b. wish that my child did not have to experience unpleasant events.

c. want to keep my child from doing it.

d. realize that occasionally such an experience will be good for him/her.

e. want to postpone these experiences.

39. When my child is not interested in some of the usual activities of his/her age group, I:

a. help my child realize that it's important to be interested in the same things as others in the group.

b. call attention to the activities in which he/she is interested.

c. tell my child it is all right not to be interested in the same things as others in his/her group.

d. See to it that my child does the same things as others in his/her group.

e. help my child find ways of making the most of his/her interests. 
40. When my child shows a deep interest in something I don't think is important, I:
a. let my child go ahead this interest.
b. ask my child to tell me more about this interest.
c. help my child find ways to make the most of this interest.
d. do everything | can to discourage my child's interest in it.
e. try to interest him/her in more worthwhile things.

THANK YOU VERY MUCH FOR YOUR COOPERATION 
APPENDIX G

MEASURE OF EMPATHY IN ADULT-CHILD INTERACTION

RATING FORM 
Measurement of Empathy In Adult-Child Interaction Rating Form

Rater's Initials

Videotape

Code \#

Communication of Acceptance verbal expression of acceptance/rejection

1. Verbally Conveys Acceptance of Feelings: You're proud of ..., You really like..., That made you angry...

2. Vetbally Recognizes \& Accepts Behavior Only (tracking, giving credit). You got it that time. You're hitting the..., You really stabbed

3. Social or NQ Conversation: Mothers aren't very good at that. These are nice toys.

4. Slight to Moderate Verbal Criticism: No, not thas woy, You'll hove to be more careful. That's cheating. You'll ruin the paints.

5. Strongly Critical/Preaching/Rejecting: You see. I told you to do it the other woy, It's not nice to feelsay... How stupid! You're being nasty

Allowing the Child Self-Direction: behavioral willingness to follow the child's lead (rather than control child's behavior)

1. Follows Child's Lead (no verbal comment necessary): You'd like me to... I'm supposed ta.... Show me how you want me .... (whisper technique)

2. Allows Child Option for Lead-Taking butt askjvolunteers info; gives praise What shall we do? "Good", You can shoot this. You did that right

3. Parent Takes Lead (teaching how to do): Are you sure that's how... See if you can do..., Take your time and aim..., It might work better...

4. Directs or Instructs Child (initiates new activity) Put the doll away irst. Why con't you..., Let's pfay.... Don't put the ...

5. Persuades, Demands, Intempts, Interferes. Insists- No, take this one. That's enough.... I told you not to..., You've got to...

Involvemen: Parent's attention to and participation in the child's activity (May not always contribute in a positive way)

1. Fully Observant (more attention to child than objects being used): involved verbally and with "eyes" (\& physically when imvited by child)

2. High Level of Attention (attention to activity rather than child): when parent more involved in game than attending to child's reactions/behoviors

3. Marginal Attention: no joins activity, actult involved in own activity ro degree it interferes with attentiveness occasionally comments on child's activity

4. Partially Withoraw/Preoccupied: infrequently observes, but doesn't comment: fails to attend to child's needs. but responds when asked by child

5. Self-involved/Shut-off: child ignored for prolonged period, child must repeat or prompt to get a response.

DIRECTIONS FOR SCORING. A rating is made every 3 minute interval for 6 intervals (scoring is retrospective) (highest score $=1$; Lowest score $=5$ )

Communication of Accentance

Score Highest. Level

Score Lowest Level

\begin{tabular}{|l|l|l|l|l|l}
\hline & & & & & \\
\hline & & & & & \\
\hline
\end{tabular}

Score

Average Total

Comments:

Allowing Self-Direction:

Score Lowest Level

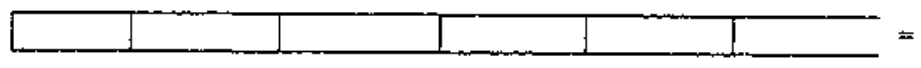
$=$

Total

Comments:

Involvement:

Score Lowest Level

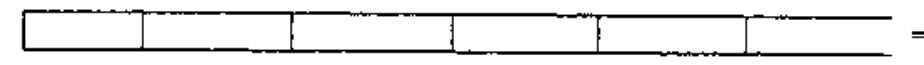

Comments:

Empathy Score $=$ Grand Total $=$

(This form was developed by Bratton (1993) adapted from Stover, B. Guemey, and O'Connetl. 1971) 


\section{APPENDIX H}

FILIAL THERAPY TRAINING SESSION OUTLINE AND HANDOUTS 


\section{FILIAL SESSION \#1}

(Garry L. Landreth, 1983)

I. Introduce self, welcome group, give name tags and booklets to all members.

II. Overview of Filial Training:

Play is the child's language.

Based on actions, not words.

Way of preventing problems since adults become aware of child's needs.

"In ten weeks, you are going to be different, and your relationship with your child will be different."

Techniques from play therapy will: Return control to you.

Provide closer, happier times with your child.

III. Group Introductions:

Give key to your child's inner world.

Describe entire family - help pick child of focus.

Tell concerns about this child (take notes).

Make generalizing comments to other parents..

Anyone "else felt angry with their child this week?"

IV. Provide Basic Agenda:

One-half hour play sessions.

Everyone will be video-taped here at least once for replay.

(Bring your own tape to keep.)

We will see demonstrations before starting.

Patience is important in learning a new language.

V. Show video tape of "Children's Emotions."

VI. Reflective listening: A way of following, rather than leading.

Don't ask questions.

Reflect behaviors, patterns and feelings.

Responses say:

I am here; I hear you.

I understand.

I care.
Not:

I always agree.

I must make you happy.

I will solve your problems.

Keep focus on the positive.

RULE OF THUMB: You can't give away what you do not possess.

As significant care givers we may be coming to the sessions deeply aware of our failures. Yet we can't effectively enter this process by being impatient and unaccepting toward ourselves while trying to extend patience and acceptance to a child.

\section{Homework:}

(1) Notice some physical characteristic about your child you haven't seen before.

(2) Practice reflective listening this week (hand out 4 faces sheet). 


\section{NOTES: Filial Session \#1}

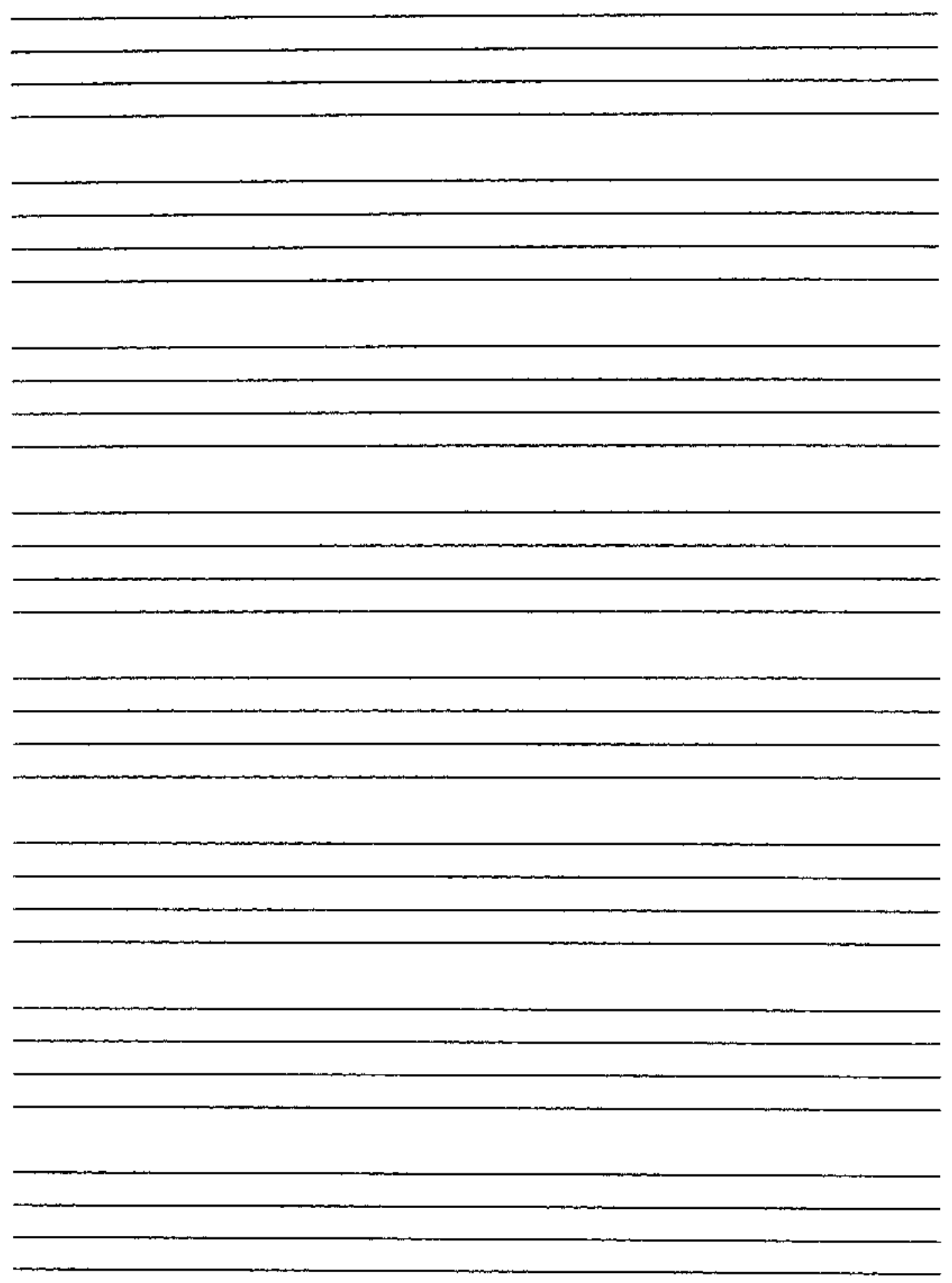


Session \#1 Handout

THE FOUR BASIC FEELINGS

(Garry L. Landreth, 1983)

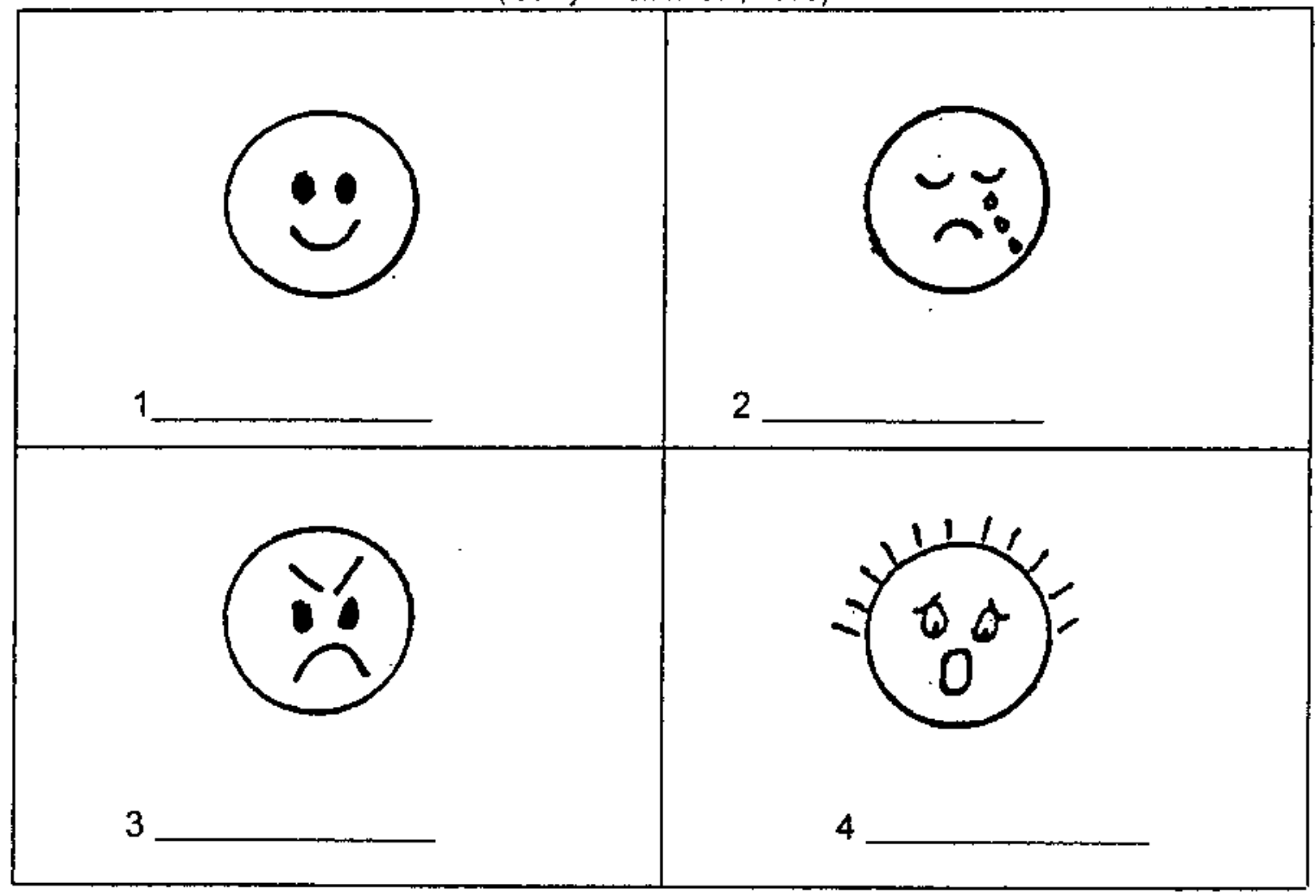

Reflective responses this week.

1.

2.

3.

4. 


\section{FILIAL SESSION \#2}

(Garry L. Landreth, 1983)

I. Review homework:

(1) Physical Characteristic

(2) 4 Faces Sheet

II. Handout: "Filial Therapy Group"

Go over entire sheet, especially list of toys. (Demonstration Box.)

The "how to" of play sessions.

III. Show video tape of session or do live demonstration.

IV. Have participants pair off and role play to practice reflective responding.

RULE OF THUMB: When a child is drowning, don't try to teach the child to swim.

If a child is feeling upset, that is not the moment to impart a rule or value.

Homework:

(1) "Facilitating Reflective Communication" handout.

(2) Pick spot and time for sessions -- report back next week. 


\section{FILIAL THERAPY GROUP}

\section{Session \#2 Handout A}

(Garry L. Landreth, 1983)

Basic Principles of the Play Sessions

(1) The child should be completely free to determine how the child will use the time. The child leads and the parent follows without making suggestions or asking questions.

(2) The adult's major task is to empathize with the child, to understand the intent of the child's actions, and the child's thoughts and feelings.

(3) The parent's next task is to communicate this understanding to the child by appropriate comments, particularly, whenever possible, by verbalizing the feelings that the child is actively experiencing

(4) The parent is to be clear and firm about the few "limits" that are placed on the child. Limits set are on time, not breaking specified toys, and not physically hurting the adult.

\section{Goals of the Play Sessions}

(1) To help the child change perceptions of the adult's feelings, attitudes, and behavior.

(2) To allow the child - through the medium of play - to communicate thought, needs,

and feelings to the adult.

(3) To help the child develop more positive feelings of self-respect, self-worth, confidence.

\section{REMINDER}

These play sessions and the techniques you use are relatively meaningless if they are applied mechanically and not as an attempt to be genuinely empathic and to truly understand your child.

\section{Toys for the Play Sessions}

Creative: $\quad$ Play Doh, crayons $(8$ colors), paper, blunt scissors,

Nurturing: nursing bottle (plastic), doll, small blanket, tea set for two, doctor kit, Aggressive: rubber knife, dart gun, toy soldiers (10-15), punching bag, 5' rope, toy snake

Dramatic: family of small dolls, doll house furniture, Lone Ranger type mask,

Other: hand puppet, plastic animals ( 2 domestic, 2 wild) small plastic car, Tinkertoys, ball (soft sponge type), bowling pins \& ball

\section{Place for the Play Sessions}

Whatever room you feel offers the fewest distractions to the child and the greatest freedom from worry about breaking things or making a mess. Set aside a regular time in advance. This time is to be undisturbed -- no phone calls or interruptions by other children. You may wish to explain to your child that you are having these sessions because you are interested in learning how to play with the child in a different, "special" way than you usually do.

\section{Process}

Let the child use the bathroom prior to the play sessions. Tell the child, "we will have thirty minutes of special play time and you may choose to play with the toys in many of the ways you would like." Let the child lead from this point. Play actively with the child if the child requests your participation. Set limits only behaviors that make you feel uncomfortable. Track the child's behavior and feelings verbally. Do not identify toys by their normal names; call them "it", "that", etc. Give the child a five minute advance notice before terminating the session. Do not exceed the time limit by more than two or three minutes. 
Session \#2 Handout B

\section{FACILITATING REFLECTIVE COMMUNICATION}

(Garry L. Landreth, 1983)

What response would you make to the following situations if you were practicing reflecting the child's feeling:

1. Joe: (With wrinkled brow, red face, and tears in his eyes) "We lost.

That team didn't play fair!"

Adult:

2. Jill: (Enters with C-test paper in hand) "I tried so hard, but it didn't do any good."

Adult:

3. Janet: (Rummaging through her drawer wildly, looking for a particular sweater she wanted to wear to the party she had been looking forward to for a long time) "I can never find anything I want." (Begins to cry)

Adult:

4. John: (Undressing Barbie doll) "Wow!" Look at her butt!"

Adult:

5. Carol: (Looking through the doonway to a dark room) "What's in there? Will you come with me?"

Adult:

6. Charlie: (Showing you his torn, smudged painting from school) "Look! Isn't it neat! My teacher said I was a good artist!"

Adult: 


\section{FILIAL SESSION \#3}

(Garry L. Landreth, 1983)

I. Review homework:

(1) "Facilitating Reflective Communication" Handout

(2) Time and Place for Play Sessions

NAME

TIME

PLACE

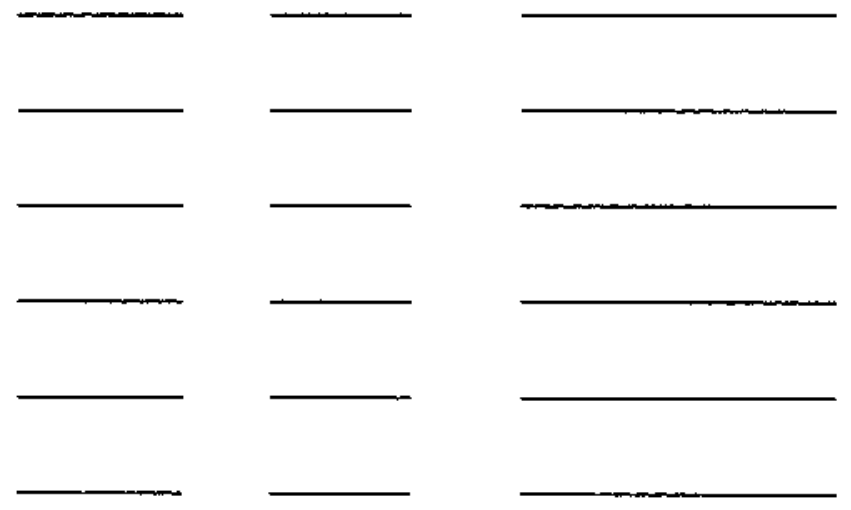

(3) Toys

II. Handout in Class: "Basic Rules for Filial Therapy". Use to review rules for play sessions.

Basic Limits: Child's name

Reflect feeling ... "I know you'd like to shoot the gun at me...

Set limit ... but, I'm not for shooting.

Alternative...You can choose to shoot at that (point at something acceptable)."

III. Demonstration

IV. Arrange for a parent to do video-taping during the week.

First Volunteer:

RULE OF THUMB: Be a thermostat, not a thermometer.

Reflecting feelings creates an environment that is comfortable and accepting, as opposed to merely reacting to feelings.

Homework:

(1) Begin play sessions at home this week. 


\section{BASIC RULES FOR FILIAL THERAPY}

Session \#3 Handout A

(Garry L. Landreth, 1983)

\section{Don't}

1. Don't criticize any behavior.

2. Don't praise the child.

3. Don't ask leading questions.

4. Don't allow interruptions of the session.

5. Don't give information or teach.

6. Don't preach

7. Don't initiate new behavior (These first 7 are taken from Guerney, 1972)

8. Don't be passive, quiet.

\section{Do}

1. Do set the stage.

2. Do let the child lead.

3. Do track behavior.

4. Do reflect the child's feelings.

5. Do set limits.

6. Do salute the child's power and effort.

7. Do join in the play as a follower.

8. Do be verbally active.

Check your responses to your children. Your responses should convey:

1. "You are not alone: I am here with you."

2. "I understand how you feel and I hear/see you."

3. "I care."

Your responses should not convey:

1. "I will solve your problems for you."

2. "I am responsible for making you happy."

3. "Because I understand you, that means I automatically agree w/you." 
Session \#3 Handout B

\section{THE EIGHT BASIC PRINCIPLES (of Non-Directive Play Therapy)}

(Virginia M. Axline, 1969)

1. The therapist must develop a warm, friendly relationship with the child, in which good rapport is established as soon as possible.

2. The therapist accepts the child exactly as the child is.

3. The therapist establishes a feeling of permissiveness in the relationship so that the child feels free to express feelings completely.

4. The therapist is alert to recognize the feelings the child is expressing and reflects those feelings back to the child in such a manner that the child gains insight into behavior.

5. The therapist maintains a deep respect for the child's ability to solve problems if given an opportunity to do so. The responsibility to make choices and to institute change is the child's.

6. The therapist does not attempt to direct the child's actions or conversation in any manner. The child leads the way; the therapist follows.

7. The therapist does not attempt to hurry the therapy along. It is a gradual process and is recognized as such by the therapist.

8. The therapist establishes only those limitations that are necessary to anchor the therapy to the world of reality and to make the child aware of the child's responsibility in the relationship.

[Axline, V. M. (1969). Play Therapy. New York: Ballantine Books. \{pp. 72-73\}] 


\section{FILIAL SESSION \#4}

(Garry L. Landreth, 1983)

I. Debriefing. How did the play sessions go?

(Be aware of the time -- keep group process moving!)

II. As reporting is occurring, use their examples to illustrate rules of filial therapy. Also, focus on how they were able to reflect on their child's feelings.

III. Handout: "Two Techniques of Discipline that Work".

Go over importance of using this as first step in discipline process.

IV. Arrange for next parent to video tape.

Second Volunteer:

V. Show video tape from first volunteer.

RULE OF THUMB: Good things come in small packages.

We enter our child's world in little ways, not big ones.

We can't expect to be part of only the big events in our child's life.

Homework:

(1) Notice one intense feeling in yourself this week. 


\section{TWO TECHNIQUES OF DISCIPLINE THAT WORK}

Session \#4 Handout

(Garry L. Landreth, 1983)

1. Firm limit-setting

A. Three steps:

(1) Recognize the feeling -- "I know you'd really like to ... ", or "I can tell you're really feeling ...", etc.

(2) Set the limit -- "... but you may not ", or ". . . but the cabinet door is not for kicking.", or ". . but the answer is no."

Provide an alternative -- "You can if you'd like.", or

B. After three-step process, DON'T discuss: "I can tell you'd lie to discuss this some more, but l've already answered that question."

C. If you're not prepared to answer the question (want to talk it over with someone; want to get more information; want to think about it).

"l can't answer that question now . . . (because .. .)." "l'Il let you know (specific time)."

(2) Nagging begins: "If you must have an answer now, the answer will have to be NO."

D. If the child asks the same question again: Calmly -- "I've already answered that question." Variations:

(1) "Do you remember the answer I gave you a few minutes ago when you asked that same question?" (Child answers, "No, I don't remember.") "Go sit down in a quiet place and think and I know you'll remember."

(2) "I've answered that question once (twice), that's enough."

(3) If you think the child doesn't understand: "I've already answered that question. You must have some question about the answer."

E. If you're undecided and open to persuasion: "I don't know . . Let's sit down and discuss it."

2. Oreo Cookie Theory: Give the child a choice, providing acceptable choices commensurate with the child's ability to choose. 


\section{FILIAL SESSION \#5}

(Garry L. Landreth, 1983)

I. Debriefing, combined with report on one intense feeling they had. Focus on importance of awareness of themselves in the play sessions.

II. Handout: "When Setting Limits Doesn't Work"

III. Arrange next taping session.

Taping Session:

IV. Review video of play session.

RULE OF THUMB: The most important thing may not be what you do, but what you do after what you have done.

It's not whether we make mistakes, but how we handle our mistakes that counts.

\section{Homework:}
(1) Sandwich hugs - explain.
(2) Continue play sessions.
(3) Practice giving one choice. 
Session \#5 Handout

\section{WHEN "SETTING THE LIMIT" DOESN'T WORK ...}

(Garry L. Landreth, 1983)

You have been careful several times to 1) reflect the child's feelings, 2) set clear, fair limits, and 3) give the child an alternate way to express feelings. Now the child continues to deliberately disobey. What do you do?

1. Look for natural causes for rebellion: Fatigue, sickness, hunger, extreme stress, abuse/neglect, etc. Take care of physical needs and crises before expecting cooperation.

2. Remain in control, respecting yourself and the child: You are not a failure if your child rebels, and your child is not bad. All kids need to "practice" rebelling.

3. Set reasonable consequences for disobedience: Let the child choose to obey or disobey, but set a reasonable consequence for disobedience. Example: "If you choose to watch TV instead of going to bed, then you choose to give up TV all day tomorrow."

4. Never tolerate violence: Physically restrain the child who becomes violent, without becoming aggressive yourself. Reflect the child's anger and loneliness. Provide compassionate control and alternatives.

5. If the child refuses to choose, you choose for the child: The child's refusal to choose is also a choice. Set the consequences. Example: "If you choose not to (choice A . . or B), then you have chosen for me to pick the one that is most convenient for me."

6. ENFORCE THE CONSEQUENCES: "Don't draw your gun unless you intend to shoot." If you crumble under your child's anger or tears, you have abdicated your role as adult and lost your power. GET TOUGH: TRY AGAIN.

7. Recognize signs of depression: The chronically angry or rebellious child is in emotional trouble and may need professional help. Share your concerns with the child. Example: "John, l've noticed that you seem to be angry and unhappy most of the time. I love you, and I'm worried about you. We're going to get help so we can all be happier." 


\section{FILIAL SESSION \#6}

(Garry L. Landreth, 1983)

I. Debriefing on play sessions and giving one choice.

II. Handout: "Common Problems in Filial Therapy"

III. Arrange next taping session.

Taping Session:

RULE OF THUMB: Grant in fantasy what you can't grant in reality.

It's okay for the "baby brother" doll to be thrown out a window in play time.

\section{Homework:}

(1) Write a note to your child of focus (as well as other children in the family) for three weeks, pointing out a positive character quality you appreciate.

"I was just thinking about you and I think you are

That is such an important quality, we're going to put this note up."

(2) Continue play sessions -- notice patterns of play that are showing up. 
Session \#6 Handout COMMON PROBLEMS IN FILIAL THERAPY

(Garry L. Landreth, 1983)

1. Q: My child notices that I talk differently in the play sessions, and wants me to talk "normally". What should I do?

A:

2. Q: My child asks many questions during the play sessions and resents my not answering them. What should I do?

A:

3. Q: I'm bored. What's the value of this?

A:

4. Q: My child doesn't respond to my comments. How do I know I'm on target?

A:

5. Q: When is it okay for me to ask questions, and when is it not okay?

A:

6. Q: My child hates the play sessions. Should I discontinue them?

A:

7. Q: My child wants the play time to be longer. Should I extend the session?

A: 


\section{FILIAL SESSION \#7}

(Garry L. Landreth, 1983)

I. Debriefing on play sessions with focus on patterns.

II. Review reflective listening, setting limits, giving choices, etc.

III. Show video tape of session.

N. Arrange next taping session.

Taping Session:

RULE OF THUMB: Praise the effort, not the product.

\section{Homework:}

(1) Notice the number of times during the week you touch your child.

(2) Continue play sessions. 


\section{FILIAL SESSION \#8}

(Garry L. Landreth, 1983)

I. Debriefing on play sessions and number of times they physically touched their child.

II. Show video tape of session.

III. Arrange next taping session.

Taping Session:

RULE OF THUMB: If you draw your gun, shoot.

Idle threats harm your relationship with your child.

Homework:

(1) Continue play sessions.

(2) Write down any unanswered questions and bring next time. 


\section{FILIAL SESSION \#9}

(Garry L. Landreth, 1983)

I. Debriefing on play sessions. Give time for questions on various topics.

II. Show video tape of session.

III. Arrange last taping session.

Taping Session:

IV. Mention filial follow-up meetings.

RULE OF THUMB: Don't answer questions that haven't been asked.

Look behind the question for the deeper question.

\section{Homework:}

(1) Continue play sessions. 


\section{FILIAL SESSION \#10}

(Garry L. Landreth, 1983)

I. Briefly debrief.

II. Show last video taped session.

III. Handout: "Rules of Thumb and Other Things to Remember"

IV. Closing Procedures:

Focus on looking at differences in child and adult -- then and now. Encourage feedback within group on positive changes made.

(Praise them, they may be scared about leaving the safety of the group!)

V. Emphasize continued meetings.

VI. Encourage them to continue play sessions.

"If you stop now, the message is that you were playing with your child because you had to, not because you wanted to."

RULE OF THUMB: If you can't say it in 10 words or less, don't say it.

\section{Recommended Reading:}

1. How to Really Love Your Child, Campbell.

2. Between Parent and Child, Ginott.

3. Liberated Parents, Liberated Children, Faber \& Mazlish.

4. How to Talk So Kids Will Listen, \& Listen So Kids Will Talk, Faber \& Mazlish. 


\section{REFERENCES}

Abidin, R. (1983). Parenting Stress Index. Charlottesville, VA: Pediatric Psychology Press.

Achenbach, T. (1991). Child Behavior Checklist Computer Scored Profile, Parent and Teacher Forms. Burlington: University of Vermont:

Achenbach, T., \& Edelbrock, C.(1981). Behavioral problems and competencies reported by parents of normal and disturbed children aged four through sixteen. Monographs of the Society for Research in Child Development. $46(1$, Serial No. 18$)$.

Achenbach, T., \& Edelbrock, C. (1983). Manual for the child behavior checklist and revised child behavior profile. Burlington, VT: University Associates in Psychiatry.

Andronico, M., \& Blake, I. (1971). The application of filial therapy to young children with stuttering problems. Journal of Speech and Hearing Disorders, 36 (3), 377-381.

Andronico, M., \& Guerney, B. (1967). The potential application of filial therapy to the school situation. Journal of School Psychology. 6 (1), 2-7.

Ausbel, D. P., Balthazar, E. E., Rosenthal, I., Blackman, L. S., Schpoont, S. H., \& Welkowitz, J.(1954). Perceived parent attitudes as determinants of children's ego structure. Child Development, 25. 173-183.

Axline, V. M. (1969). Play therapy. New York: Ballentine Books. 
Axline, V. M. (1971). Dibs: In search of self. New York: Ballentine Books.

Bagley, C., \& King, K. (1989). Child sexual abuse: The search for healing. London: Tavistock/Routledge.

Baruch, D. (1949). New ways to discipline. New York: McGraw-Hill

Baumrind, D. (1967). Child care practices anteceding three patterns of preschool behavior. Genetic Psychology Monographs, 75, 43-88.

Bavin-Hoffman, R. C. (1994). Filial therapy: A qualitative study of the parental perceptions of the process. Unpublished doctoral dissertation, Texas Woman's University, Denton.

Beitchman, J. H., Zucker, K. J., Hood, J. E., daCosta, G. A., \& Akman, D. (1991). A review of the short-term effects of child sexual abuse. Child Abuse and Neglect. 15, 537-556.

Bettelheim, B. (1987, March). The importance of play. The Atlantic Monthly, $35-46$.

Boll, L. (1972). Effects of filial therapy on maternal perceptions of their mentally retarded children's social behavior (Doctoral dissertation, The University of Oklahoma). Dissertation Abstracts International, 33, 6661A.

Bratton, S. C. (1994). Filial therapy with single parents.(Doctoral dissertation, University of North Texas, 1993). Dissertation Abstracts International. 54 (08), A2890.

Browne, A., \& Finkelhor, D. (1986). Impact of child sexual abuse: A review of the research. Psychological Bulletin, 99(1), 66-77.

Burchinal, L., Hawkes, G., \& Gardner, B. (1957). The relationship between 
parental acceptance and adjustment of children. Child Development, 28, 67-77.

Chau, I. (1996). Filial therapy with Chinese parents. Unpublished doctoral dissertation, University of North Texas, Denton.

Coan, R. W. \& Cattell, R. B. (1966). Manual for the early school personality questionaire. Champaign, IL. Institute for Personality and Ability Testing.

Cooper, J. E., Holman, J., \& Braithwaite, V. A. (1983). Self-esteem and family cohesion: The child's perspective and adjustment. Journal of Marriage and the Family, 153-159.

Coopersmith, S. (1967). The antecedents of self-esteem. San Francisco: W. H. Freeman.

Cox, W. H. (1970). Intrafamily comparison of loving-reject child-rearing practices. Chid Development, $91,437-448$.

Davies, M. G. (1995). Parental distress and ability to cope following discosure of extra-familial sexual abuse. Child Abuse \& Neglect. 19, 399-408.

Dematatis, C. (1981). A comparison of the traditional filial therapy program to an integrated filial - IPR program (Doctoral dissertation, Michigan State University). Dissertation Abstracts International, 42, 4187B.

DeYoung, M. (1994). Women as mothers and wives in paternally incestuous families: Coping with role-conflict. Child Abuse and Neglect. 18. 73 83.

Dubowitz, H., Black, D., Harrington, D., \& Verschoore, A. A. (1993). A follow-up study of behavior problems associated with child sexual abuse. Child Abuse \& Neglect, 17, 743-754. 
Duncan, K. (1985). The impairment of the relationship between mother and daughter in intrafamilial sexual abuse. Unpublished master thesis, University of Texas, Arlington.

Eisman, E. (1981). Sex-role characteristics of the parent, parental acceptance of the child and child self-concept (Doctoral dissertation, California School of Professional Psychology). Dissertation Abstracts international, 42. 2026B.

Ellinwood, C. (1989). The young child in person-centered family therapy. Person-Centered Review. 4 (3), 256-262.

Esparza, D. (1993). Maternal support and stress response in sexually abused girls ages 6-12. Issues in Mental Health Nursing, 14, 85-107.

Everson, M. D., Hunter, W. M., Runyon, D. K., Edelsohn, G. A., \& Coulter, M. L. (1989). Maternal support following disclosure of incest. American Journal of Orthopsychiatry, 59(2), 197-207.

Everstine, D. S., \& Everstine, L. S. (1989). Sexual trauma in children and adolescents: Dynamics and treatment. New York: Brunner/Mazel.

Faber, A., \& Mazlish, E. (1980). How to talk so kids will listen and listen so kids will talk. New York: Avon Books.

Finkelhor, D. (1984). Child sexual abuse. New York: The Free Press.

Finkelhor, D. (1986). A sourcebook on child sexual abuse. London: Sage Publications.

Finkelhor, D., \& Browne, A. (1985). The traumatic impact of child sexual abuse: A conceptualization. American Journal of Orthopsychiatry, 55, 530-541. 
Freud, S. (1959). Analysis of a phobia in a five-year-old boy. Collected papers: Case histories. New York: Basic Books.

Friedrich, W. N., Urquiza, A. J., \& Beilke R. L. (1986). Behavior problems in sexually abused young children. Journal of Pediatric Psychology, 11, 47-57.

Fuchs, N. (1957). Play therapy at home. Merrill-Palmer Quarterly, $3.89-95$.

Furniss, T. (1983). Family process in the treatment of intrafamilial child sexual abuse. Journal of Family Therapy, $5,263-278$.

Giarretto, H. (1989). Community-based treatment of the incest family. Psychiatric Clinics of North America, 12, 351-361.

Gil, G. (1991). The healing power of play. New York: Guilford Press.

Gillis, J. S. (1980). Child anxiety scale. Champaign, IL: Institute for Personality and Ability Testing.

Gillis, J.S., \& Cattell, R.B. (1979). Comparison of second-order personality structure at 6-8 years with later patterns. Multivariate Experimental Clinical Research, 4, 93-99.

Ginott, H. G. (1965). Between parent and child. New York: Macmillan. Company.

Ginsberg, B. G. (1976). Parents as therapeutic agents: The usefulness of filial therapy in a community mental health center. The Psychoanalytic Study of the Child. 12, 250-262.

Giveans, D. (1988). The positive effects of child development classes on incarcerated fathers. Nurturing Today, 10(1), 16-17.

Glass, N. M. (1987). Parents as therapeutic agents: A study of the effect of 
filial therapy (Doctoral dissertation, University of North Texas, 1986). Dissertation Abstracts International, 47 (7), A2457.

Glazer-Waldman, H. R. (1991). Filial therapy: CPR training for families with chronically ill children. Unpublished master's thesis, University of North Texas, Denton.

Glazer-Waldman, H. R., Zimmerman, J. E., Landreth, G. L., \& Norton, D. (1992). Filial therapy: An intervention for parents of children with chronic illness. International Journal of Play Therapy. 1, 31-42.

Glover, G. J. (1996). Filial therapy with Native Americans on the Flathead Reservation. Unpublished doctoral dissertation, University of North Texas, Denton.

Green, A. H. (1993). Child sexual abuse: Immediate and long-term effects and intervention. Journal of American Academy of Child Adolescence, 32(5), 890-902.

Guerney, B., Coufal, J., \& Vogelsong, E. (1976). Filial therapy used as a treatment method for disturbed children. Evaluation, 3 , 34-35.

Guerney, B., \& Flumen, A. (1970). Teachers as psychotherapeutic agents fot wihdrawn children. Journal of School Psychology. 8 (2), 107-113.

Guerney, B. G., Jr. (1964). Filial therapy: Description and rationale. Journal of Consulting Psychology. 28 (4), 304-310.

Guerney, B.G., Jr. (1976). Filial therapy as a treatment method for disturbed children. Evaluation, 3, 34-35.

Guerney, B. G., Jr., Guerney, L. F., \& Andronico, M. P. (1966). Filial 
therapy. Yale Scientific Magazine, 40, 6-14.

Guerney, B. G., Jr., \& Stover, L. (1971). Filial therapy: Final report on MH 18254-01. Unpublished manuscript, The Pennsylvania State University.

Guerney, B. G., Jr., Stover, L., \& DeMerritt, S. (1968). A measurement of empathy for parent-child interaction. Journal of Genetic Psychology, 112, 49-55.

Guerney, L. (1975). Brief follow-up study on filial therapy. Paper presentes at the Eastern Psycholgical Association, New York City.

Guerney, L., \& Gavigan, M. (1981). Parental acceptance and foster parents. Journal of Clinical Child Psychology 27-32.

Guerney, L. F. (1979). Play therapy with learning disabled children. Journal of Clinical Child Psychology, 242-244.

Haenes, J. R., Jr. (1996). Treatment of the non-offending mother in child sexual abuse cases: An exploratory study. (Masters thesis, University of Texas at Arlington, 1996). Masters Abstract International, (08), 2502.

Harris, Z. L. (1995). Filial therapy with incarcerated mothers. Unpublished doctoral dissertation, University of North Texas, Denton.

Hauenstein, E., Scarr, S., \& Abidin, R. (1986). Measurement of parental stress across cultures: Validation of the Parenting Stress Index with American and Bermudian parents. Unpublished manuscript, University of Virginia.

Hildebrand J., \& Forbes, C. (1987). Group work with mothers whose children have been sexually abused. British Journal Of Social Work, 17, 285304.

Hollin, C. R., \& Howells, K. (Eds.). (1991). Clinical approaches to sex 
offenders and their victims. New York: Wiley.

Hooper, C. A. (1992). Mothers surviving child sexual abuse. London: Tavistock/Routledge.

Hopper, J. (1997). Child abuse: Statistics, research, and resources [Online]. Available: http//www.jimhopper.com/abstats

Hornsby, L., \& Applebaum, A. (1978). Parents as primary therapists: Filial therapy. In L. Arnold (Ed.), Helping parents help their children (pp. 126-134). New York: Brunner/Mazel.

Howard, C. A. (1993). Factors influencing a mother's response to her child's disclosure of incest. Professional Psychology: Research and Practice. 24 , 176-181.

Hurley, J. (1967). Readings in the psychology of parent child relations. New York: Wiley.

Hyde, C., Bentovim, A., \& Monck, E. (1995). Some clinical and methodological implications of a treatment outcome study of sexually abused children. Child Abuse \& Neglect, 19(11), 1387-1399.

Jacobs, L. (1949). Methods used in the education of mothers: A contribution to the handling and treatment of developmental difficulties in children under five years of age. The Psychoanalytic Study of the Child. 3-4. $408-422$.

James, B. (1989). Treating traumatized children. Lexington,MA: Lexington. Joseph, J. (1979). Joseph pre-school and primary self-concept screening test: Instruction manual. Chicago: Stoelting. 
Kagan, J., \& Moss, H. (1962). Birth to maturity. New York: Wiley.

Kale, A. (1997). Filial therapy with parents of children experiencing learning disabilities. Unpublished doctoral dissertation, University of North Texas, Denton.

Kaufman, B., \& Wohl, A. (1992). Casualties of childhood: A developmental perspective on sexual abuse using projective drawings. New York:

Brunner/Mazel.

Kezur, B. (1980). Mother-child communication patterns based on therapeutic principles (Doctoral dissertation, The Humanistic Psychology Institute). Dissertation Abstracts International, 41, 4671B.

Kinnear, K. L. (1996). Childhood sexual abuse: A reference handbook. Santa Barbara, CA: Contemporary World Issues.

Lahti, S. L. (1993). An ethnographic study of the filial therapy process (Doctoral dissertation, University of North Texas, 1992). Dissertation Abstracts International, 53 (08), A2691.

Landreth, G. L. (1983). Outline and handouts for the 10-week filial therapy training model. Unpublished manuscript, University of North Texas, Denton.

Landreth, G. L. (1991). Play therapy: The art of the relationship. Muncie, IN: Accelerated Development.

Lebovitz, C. K. (1983). Filial therapy: Outcome and process (Doctoral dissertation, Texas Tech University, 1982). Dissertation Abstracts International. $\underline{43}(12), \mathrm{B} 4152$.

Ligezinska, M., Firestone, P., Manion, I. G., Mclntyre, J., Ensom, R., \& Wells, G. (1996). Children's emotional and behavioral reactions following the 
disclosure of extrafamilial sexual abuse: Initial effects. Child Abuse \& Neglect. $\underline{20}(2), 111-125$.

Lobaugh, F. A. (1992). Filial therapy with incarcerated parents (Doctoral dissertation, University of North Texas, 1991). Dissertation Abstracts International, 53 (04), B2046.

Lovett, B. B. (1993). Child sexual abuse: A multivariate analysis of the mother-daughter relationship and its effect on the victims' behavior and competency (Doctoral dissertation, Tulane University, 1993). Dissertation Abstracts International 54 (05), A1952.

Lovett, B. B. (1995). Child sexual abuse: The female victim's relationship with her non-offending mother. Child Abuse \& Neglect, 19, 729-738.

MacDonald, K., Lambie, 1., \& Simmonds, L. (1995). Counselling for sexual abuse: A therapist's guide to working with adults, children, and families. Oxford, UK: Oxford University Press

Madonna, P., van Scoyk, S., \& Jones, D. P. H. (1991). Family interaction within incest and nonincest families. American Journal of Psychiatry, 14, 46-49.

Manion, I. G., McIntyre, J., Firestone, P., Ligezinska, M., Ensom, R., \& Wells, G. (1996). Secondary traumatization in parents following the disclosure of extrafamilial child abuse: Initial effects. Child Abuse \& Neglect, 20(11), 10951096.

Medennus, G. (1965). Delinquents' perception of their parents. Journal of Consulting Psychology, 29, 592-593.

Moustakas, C. E. (1959). Psychotherapy with children. New York: Harper. 
Muehl, D. (1961). A manuel for coders. Ann Arbor: University of Michigan.

Naglieri, J. A., Mc Neish, T. J., \& Bardos, A. N. (1991). Draw a person:

Screening for emotional disturbance. Austin, TX: PRO-ED.

National Center on Child Abuse and Neglect. (1981). Study findings:

National study of incidence and severity of child abuse and neglect. Washington, DC: DHEW.

Newberger, C. M., Gremy, I. M., Waternaux, C. M., \& Newberger, E. H. (1993). Mothers of sexually abused children: Trauma and repair in longitudinal perspective. American Journal of Orthopsychiatry, 63(1), 92-102.

Norusis, M. J. (1988). SPSS/PC+ Studentware. Chicago: SPSS.

Oxman, L. K. (1972). The effectiveness of filial therapy: A controlled study (Doctoral dissertation, Rutgers University, The State University of New Jersey, 1972). Dissertation Abstracts International, 32 (11), B6656.

Packer, P. D. (1990). The initial process of filial therapy: A case study of a four year-old child and her parents (Doctoral dissertation, The Pennsylvania State University, 1990). Dissertation Abstracts International, 51 (06), A1903.

Payton, I. E. (1980). Filial therapy as a potential primary preventive process with children between the ages of four and ten (Doctoral dissertation, University of Northern Colorado). Dissertation Abstracts International, 41 (07), A2942.

Perkins, H. (1974). Human development and learning. Belmont, CA: Wadsworth.

Peters, S. (1988). Child sexual abuse and later psychological problems. In G. Wyatt, \& G. Powell (Eds.), Lasting effects of child sexual abuse (101-117). 
Newbury Park, CA: Sage Publications.

Porter, B. (1954). Measurement of parental acceptance of children. Journal of Home Economics, 46 (3), 176-182.

Regehr, C. (1990). Parental responses to extrafamilial child sexual assult. Child Abuse \& Neglect. 14, 113-120.

Rogers, C. (1951). Client-centered therapy. Cambridge: The Riverside Press.

Rohner, E. C. (1980). Perceived parental acceptance-rejection and children's reported personality and behavioral dispositions: An intracultural test. Behavioral Science Research, 15, 81-88.

Rohner, E. C., Chaille, C., \& Rohner, R. P. (1980). Perceived parental acceptance-rejection and the development of children's locus of control. The Journal of Psychology, 104, 83-86.

Rohner, R. P. (1980). Worldwide tests of parental acceptance-rejection theory: An overview. Behavior Science Research, 15, 23-39.

Sensue, M. E. (1981). Filial therapy follow-up study: Effects on parental acceptance and child adjustment (Doctoral dissertation, The Pennsylvania State University, 1981). Dissertation Abstracts International, 42 (01), A148.

Sgroi, S. M. (1982). Handbook of clinical interventions in child sexual abuse. Lexington, MA: Lexington.

Sgroi, S. M. (1988). Vulnerable populations: Evaluation and treatment of sexually abused children and adult survivors (Vol. 1). Lexington, MA: Lexington.

Sgroi, S. M., \& Dana, N. T. (1982). Individual and group treatment of 
mothers of incest victims. In S. M. Sgroi (Ed.), Handbook of clinical intervention in child sexual abuse (pp 191-214). Lexington, MA: Lexington.

SPSS for Windows (Release 6.0) \{Computer Software\}. (1993). Chicago, IL: SPSS Inc.

Strand, V.C. (1991). Victim of sexual abuse: Case of Rosa, age 6. In N. B. Webb (Ed.), Play therapy with children in crisis: A casebook for practitioners. (PP. 69-91). New York: Guilford Press.

Stover, L., \& Guerney, B. (1967). The efficacy of training procedures for mothers in filial therapy. Psychotherapy: Theory, research, and practice, 4 (3), $110-115$.

Stover, L., Guerney, B., \& O'Connell, M. (1971). Measurements of acceptance, allowing self-direction, involvement, and empathy in adult-child interaction. Journal of Psychology, 77, 261-269.

Sywulak, A. E. (1978). The effect of filial therapy on parental acceptance and child adjustment (Doctoral dissertation, Pennsylvania State University, 1977). Dissertation Abstracts International, 38 (12), B6180.

Tew, K. (1997). The efficacy of filial therapy with families with chronically ill children. Unpublished doctoral dissertation, University of North Texas, Denton.

Tufts' New England Medical Center, Division of Child Psychiatry (1984). Sexually exploited children: Service and research project. Final report for the Office of Juvenile Justice and Delinquency Prevention. Washington, DC: U.S. Department of Justice.

Vargo, B., Stavrakaki, C., Ellis, J., \& Williams, E. (1988). Child sexual 
abuse: Its impact and treatment. Canadian Journal of Psychiatry. 33, 468-473.

Walker, L. E. A. (Ed.). (1988). Handbook of sexual abuse of children: Assessment and treatment issues. New York: Springer.

Wall, L. (1979). Parents as play therapists: A comparison of three interventions into children's play (Doctoral dissertation, University of Northern Colorado). Dissertation Abstracts International, 40, 5597B.

Wolfe, D., Edwards, B., Manion, I., \& Koverola, C. (1989). Early intervention for parents at risk of child abuse and neglect: A preliminary investigation. Journal of Consulting and Clinical Psychology, 56, 40-47.

Yuen, T. (1997). Filial therapy with immigrant chinese parents in Canada. Unpublished doctoral dissertation, University of North Texas, Denton.

Zakreski, J. (1983). Prematurity and the single parent: Effects of cumulative stress on child development. Unpublished doctoral disertation, University of Virginia, Institute of Clinical Psychology. 